مجلة الاقتصاد المنزلي - مجلد · r - العدد (ع) • r • r م

$$
\begin{aligned}
& \text { المؤتمر الدولى السابع- العربى الحادى والعشرون }
\end{aligned}
$$

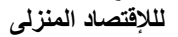

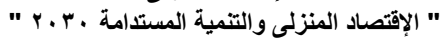

$$
\begin{aligned}
& 0
\end{aligned}
$$

http://homeEcon.menofia.edu.eg

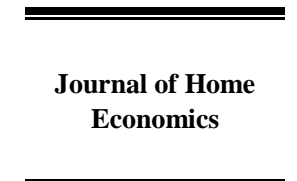

ISSN 1110-2578

\title{
إدارة الوقت والجها وعلاقتها بمواجهة الضغوط الحياتية لدى أمهات المعاقين سمعيًا
}

ربيع محمود علي نوفل' ،منى محمد زكى صقر " ، مروى مختار أبو عطية”

تمثلت أهداف هذه الدراسة في تحديد طبيعة العلاقة بين كل من إدارة

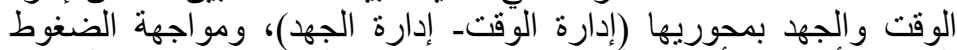

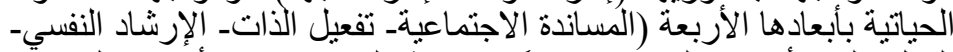

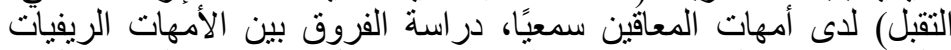

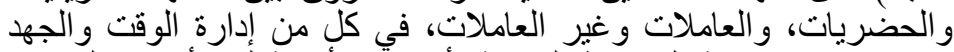

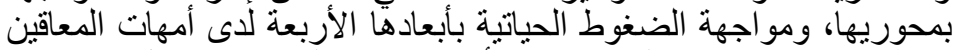

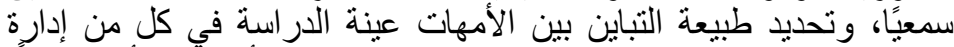

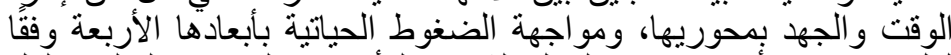
لكل من عدد الأبناء، وفئات الدخل الثهري للأسرة، و والمستوي التعليمي لكل

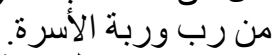

و اتبعت الدراسة الحالية المنهج الوصفي التحليلي، حيث نم إعداد وتقنين

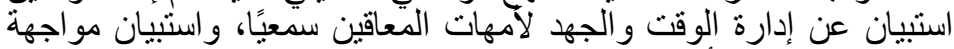

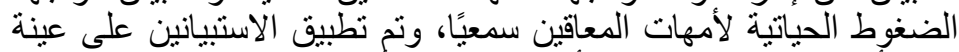

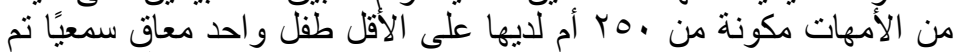

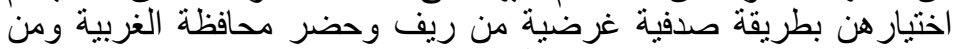
مستويات اجتماعية و اقتصادية مختلفة.

' أستاذ بقسم إدارة المنزل والمؤسسات - كلية الاقتصاد المنزلي - جامعة المنوفية

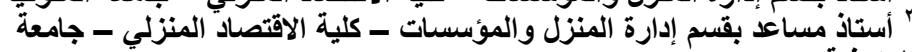

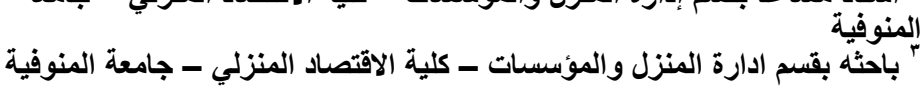




$$
\text { مجلة الاقتصاد المنزلي - مجلد · r - العدد (؟) • ب • م م }
$$

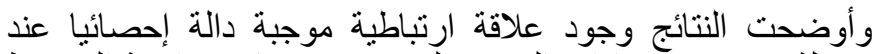

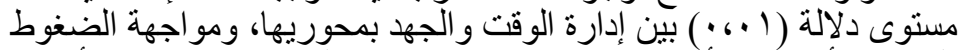

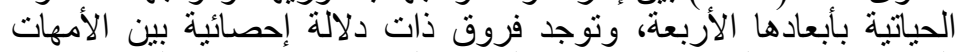

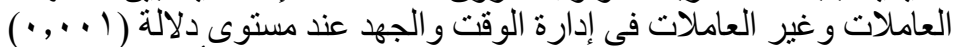

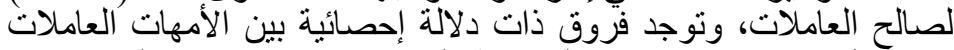

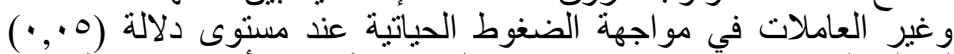

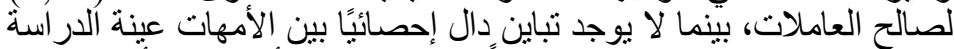

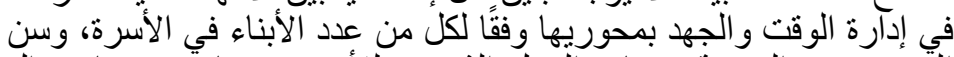

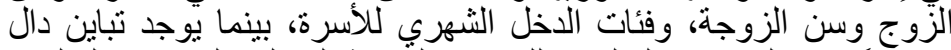

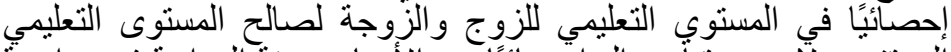

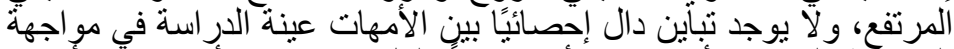

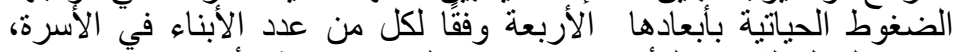

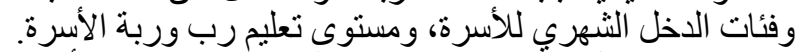

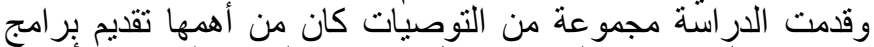

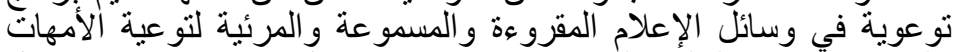

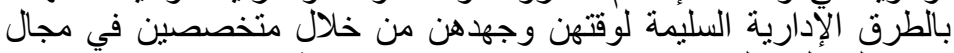

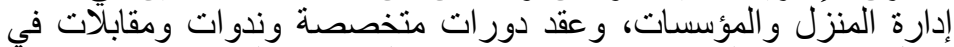

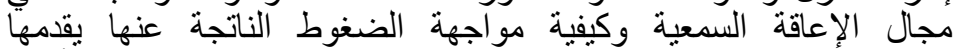

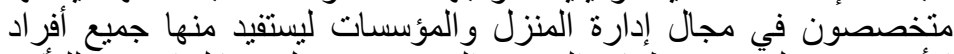

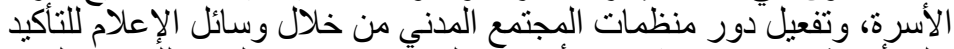

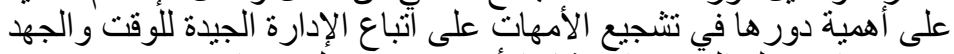

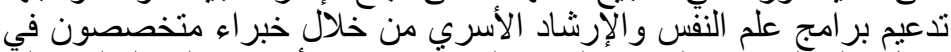

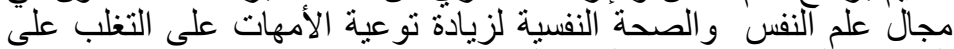
الضغوط الحياتية بطريقة علمية سليمة.

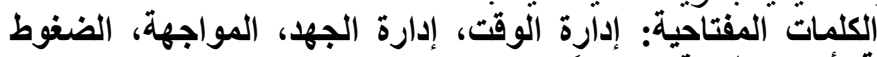

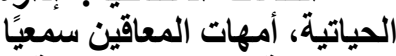

إدارة" الوقت وأمهات والجهاتوعلاقينتيا بمواجهة الضغوط الحياتية لاى أمهات

ألمعاقين سمعيًا

مقدمة ومشكلة البحث

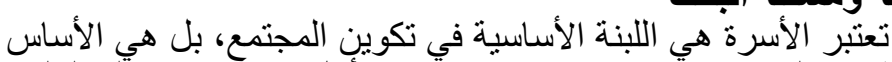

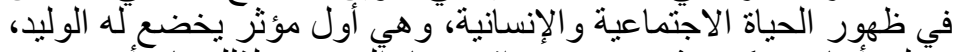

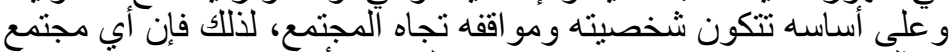

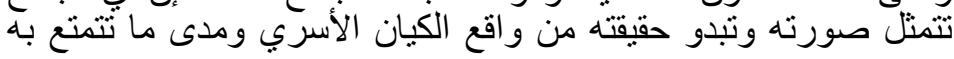




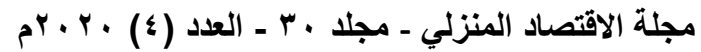

الأسرة من قوة وتماسك، وما تقوم عليه علاقاتهم من استقرار وتكيف وما

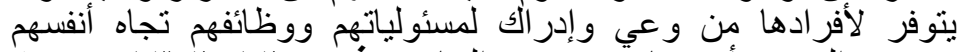

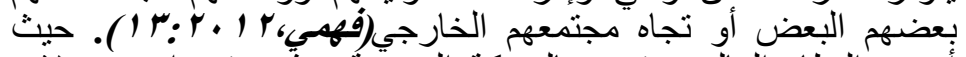

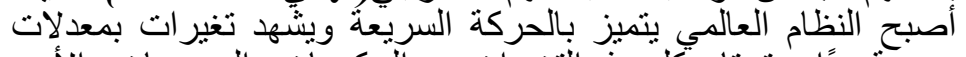

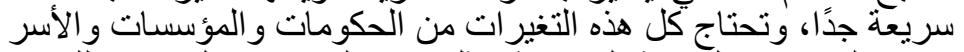

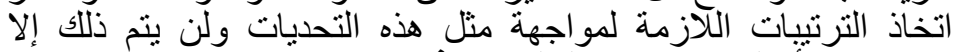

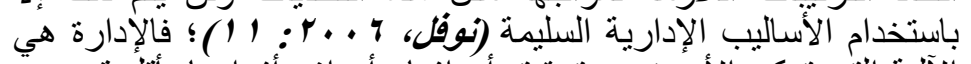

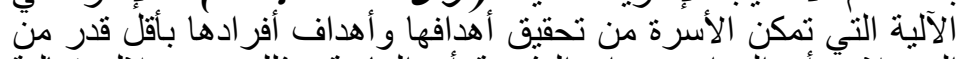

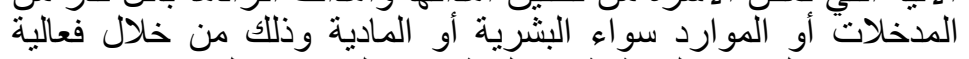

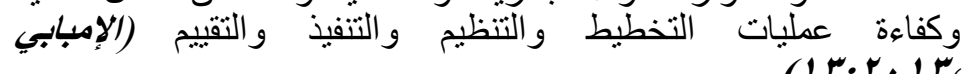
كما أن الإدارة تمس حياة كل إنسان وتؤثر في ممارساته حيث تجعل

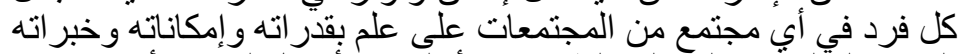

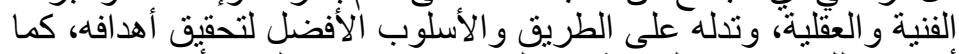

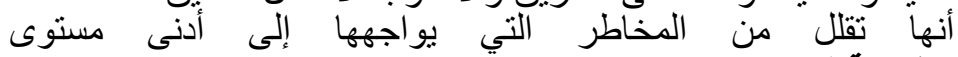

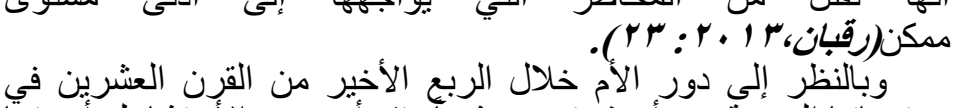

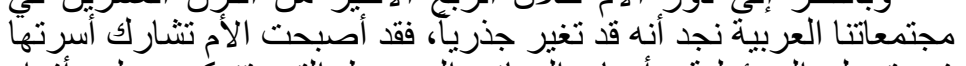

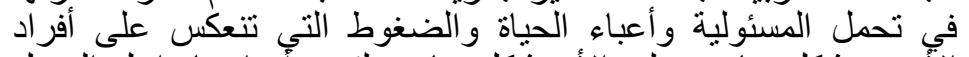

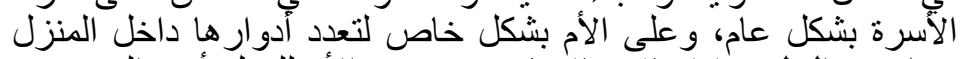

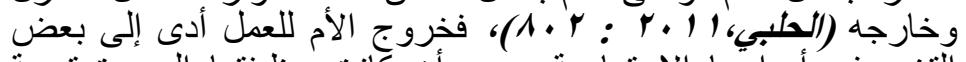

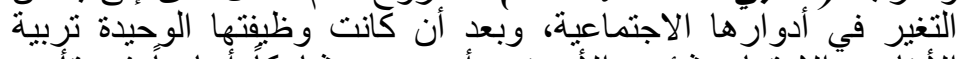

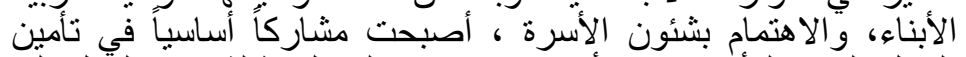

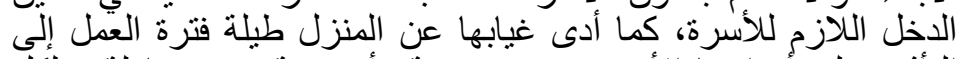

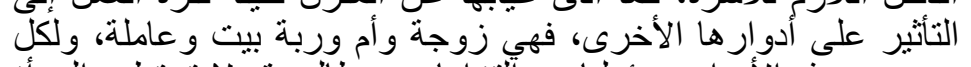

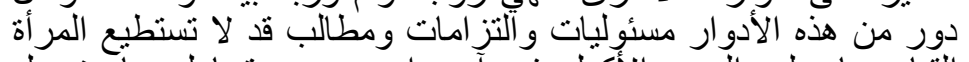

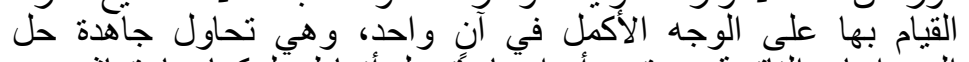

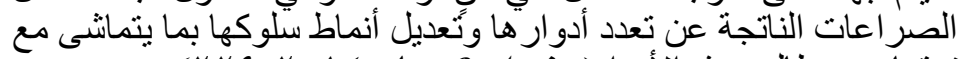

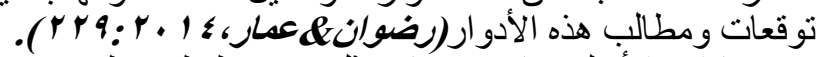

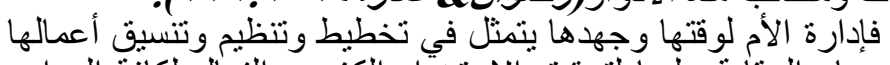

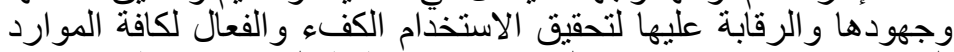

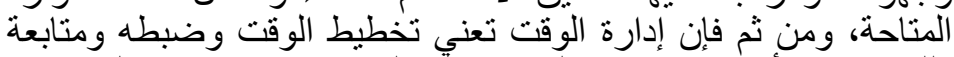

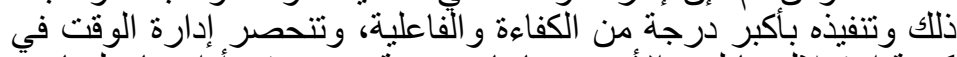

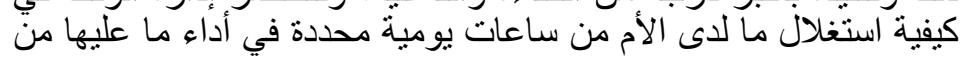




$$
\text { مجلة الاقتصاد المنزلي - مجلد · ب - العدد (؟) • ب • م م }
$$

أعمال ومسئوليات مختلفة، فتخطيط الوقت لا يطيل من ساعات اليوم و إنما

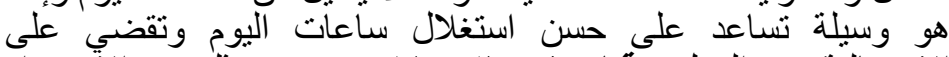

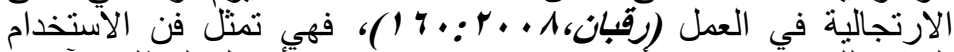

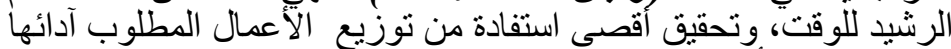

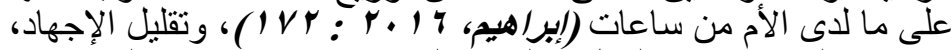

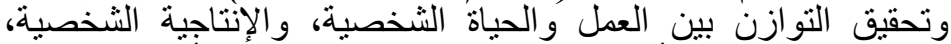

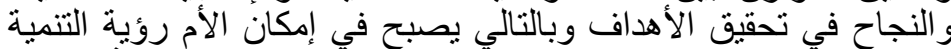

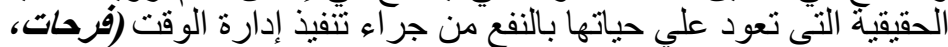

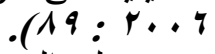

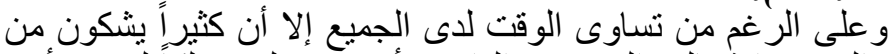

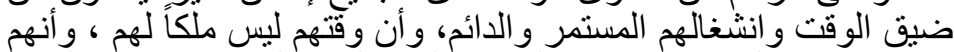

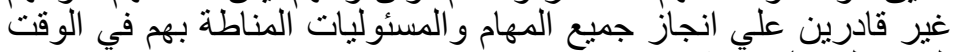

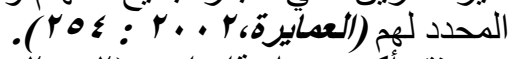

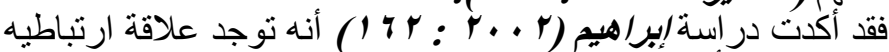

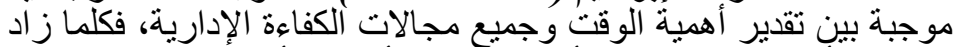

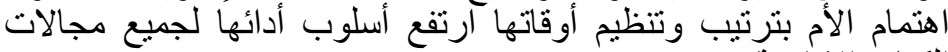

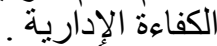

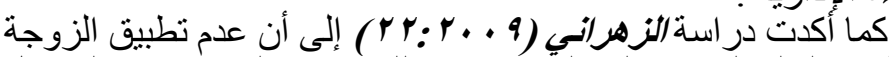

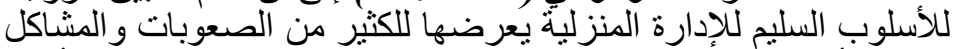

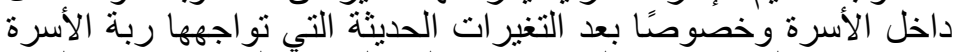

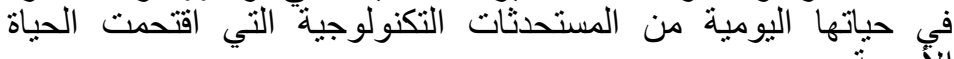

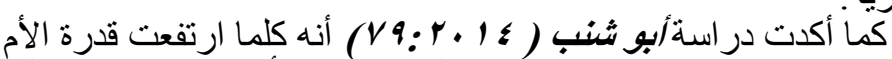

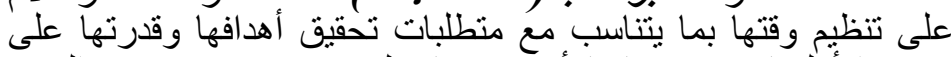

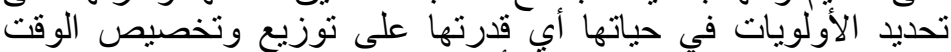

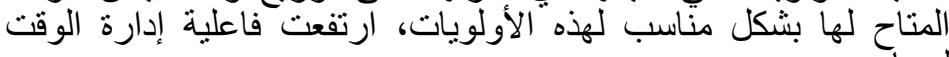

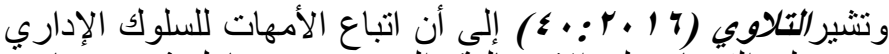

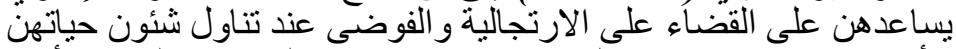

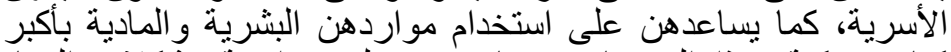

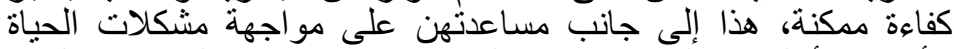

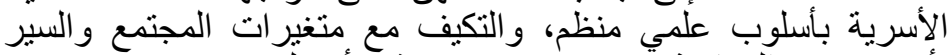

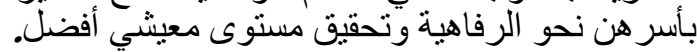




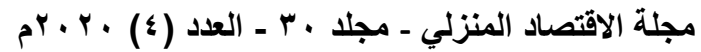

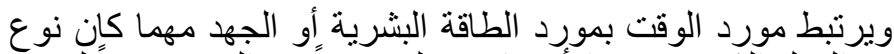

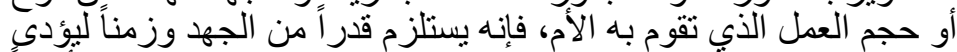

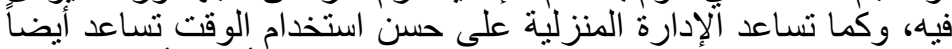

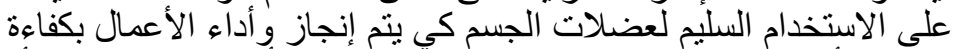

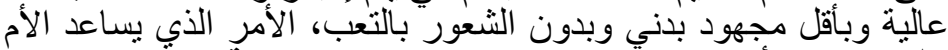

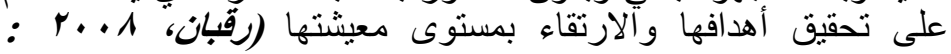
(1)

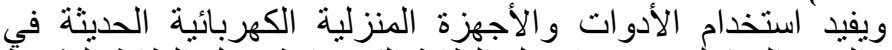

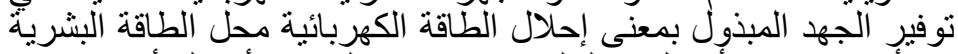

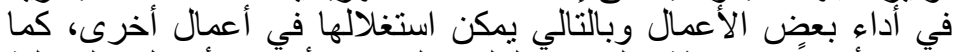

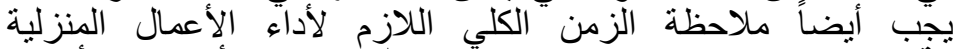

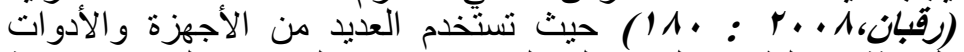

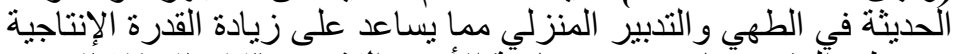

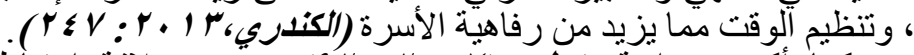

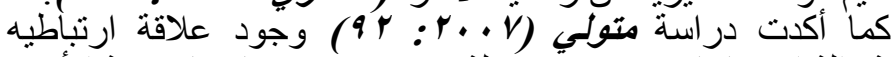

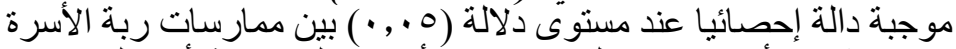

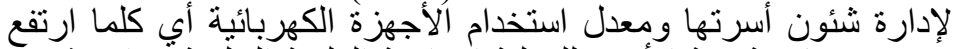

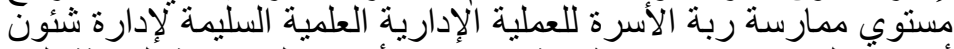

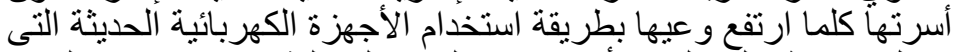

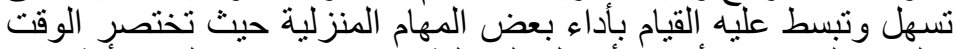

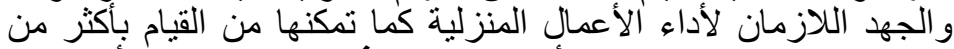

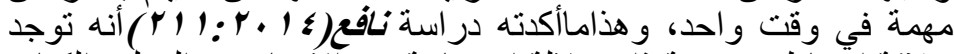

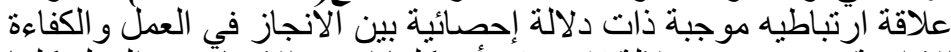

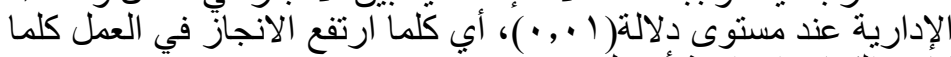

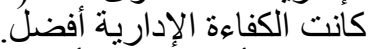

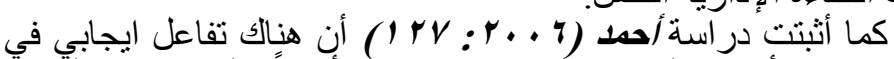

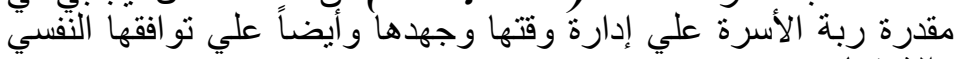

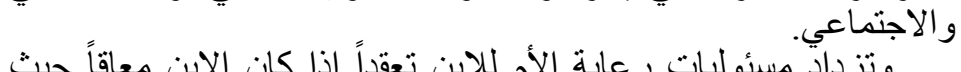

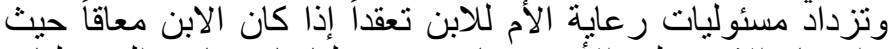

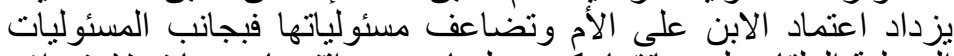

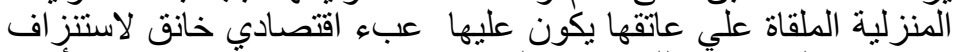

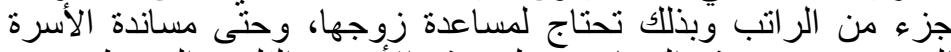

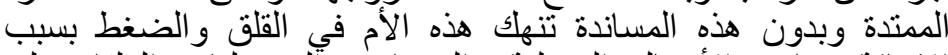

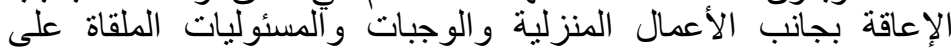




$$
\text { مجلة الاقتصاد المنزلي - مجلد · ب - العدد (؟) • ب • م م }
$$

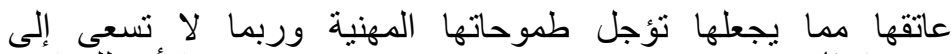

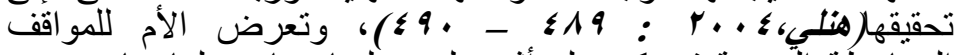

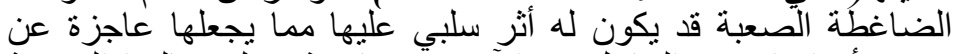

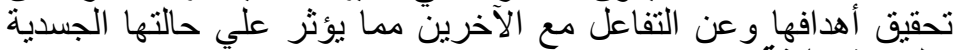

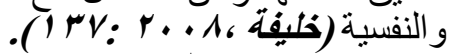

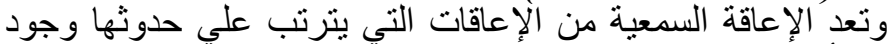

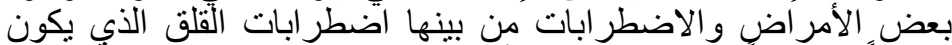

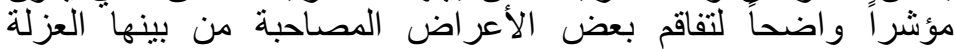
و الانسحاب (Stednitz\&Epkins,2006:151).

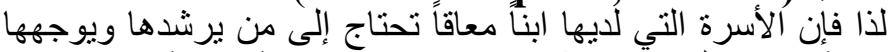

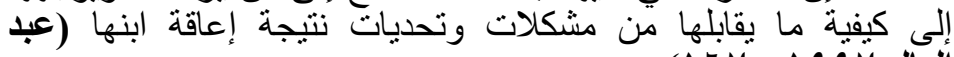

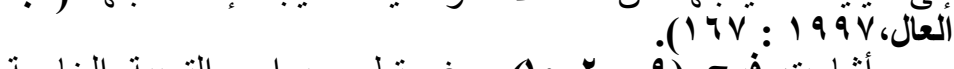

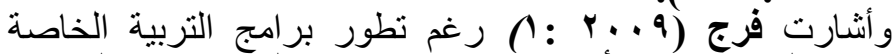

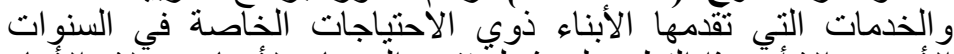

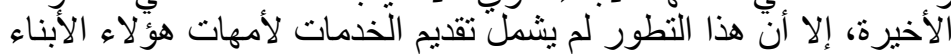

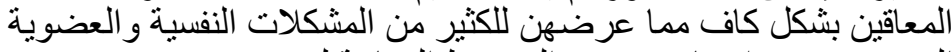

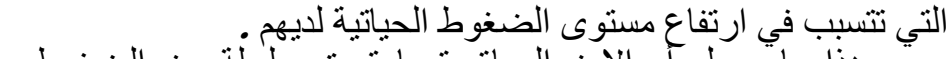

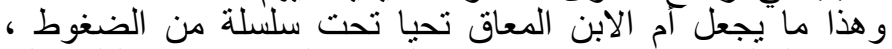

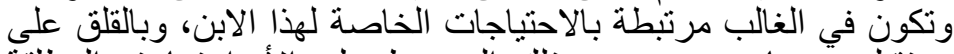

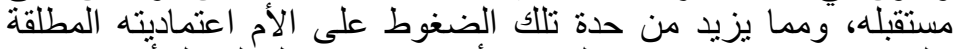

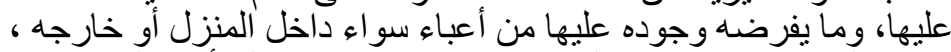

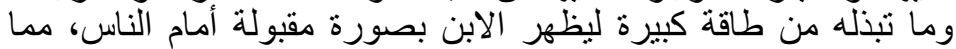

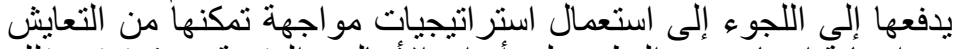

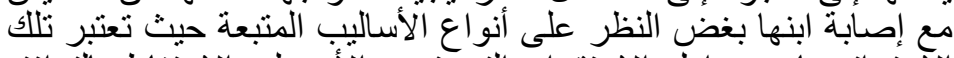

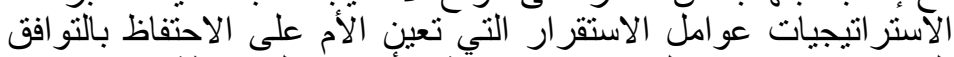

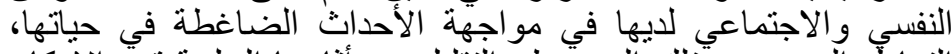

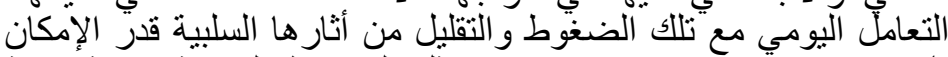

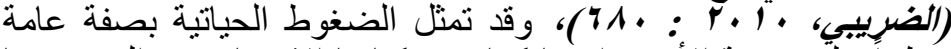

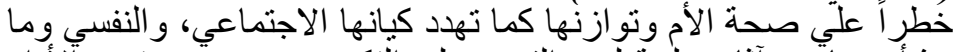

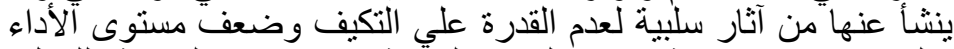

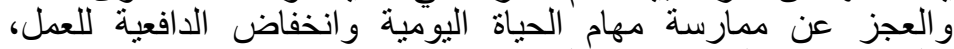

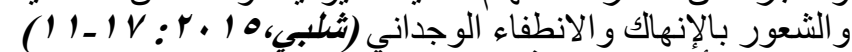

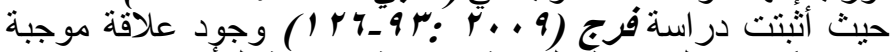
دالة إحصائيًا بين الضغوط النفسية ودرجة الإعاقة لنأبناء، كما توجد مولة 


$$
\text { مجلة الاقتصاد المنزلي - مجلد · r - العدد (؟) • ب • م م }
$$

علاقة طردية دالة احصائيًا بين الضغوط النفسية لأولياء أمور الأبناء المعاقين و احتياجاتهم الحياتية المختلة داتئة

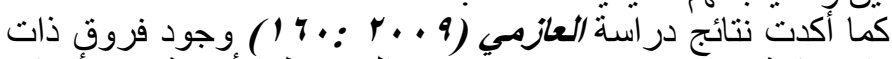

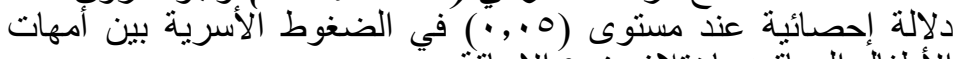
الأطفال المعاقين باختلاف نوع ألوع الإعاقة

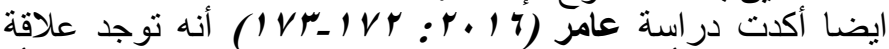

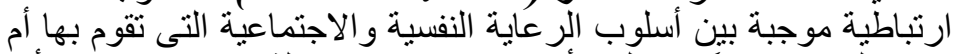

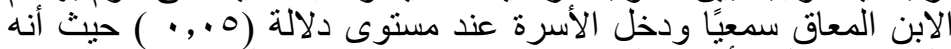

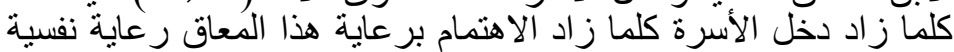

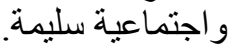

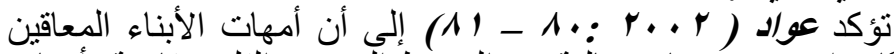

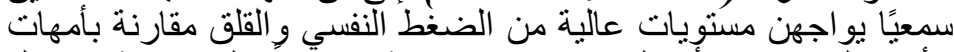

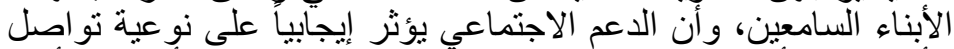

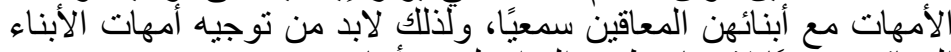

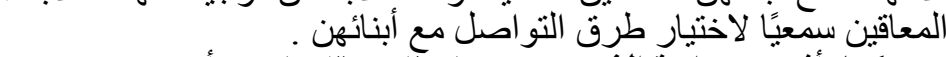

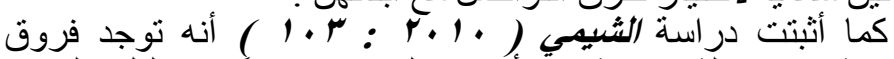

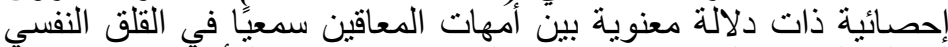

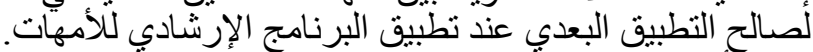

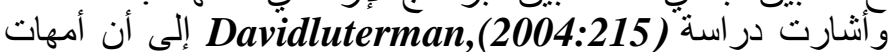

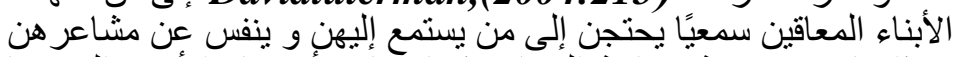

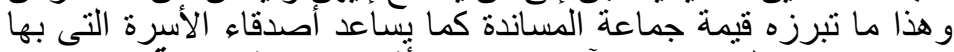

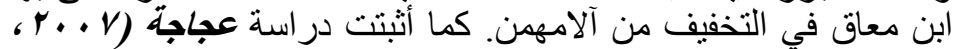

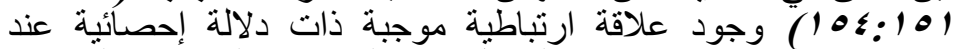

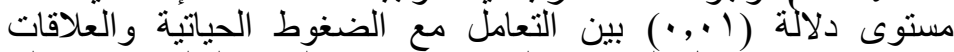

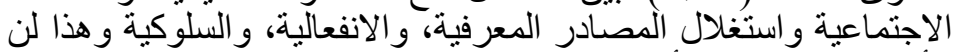

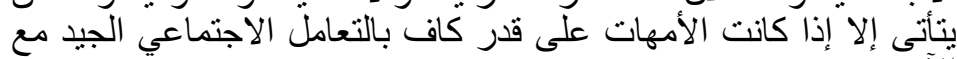

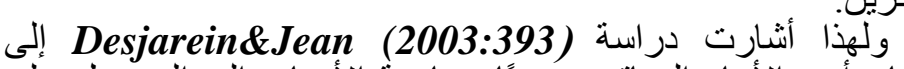

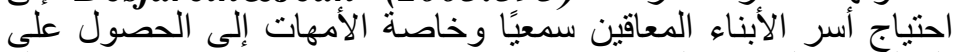

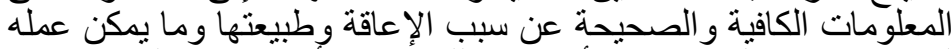

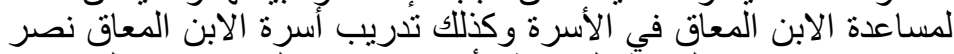

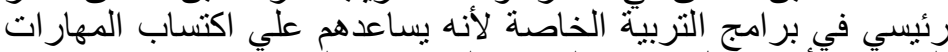

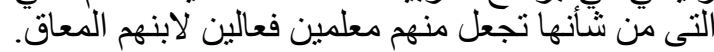




$$
\text { مجلة الاقتصاد المنزلي - مجلد · ب - العدد (؟) • ب • م م }
$$

مما سبق يتضح أن الدراسات السابقة قد تناولت العلاقة بين إدارة

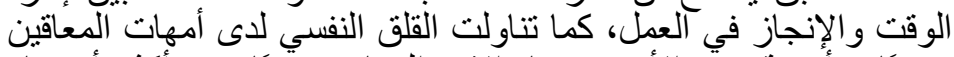

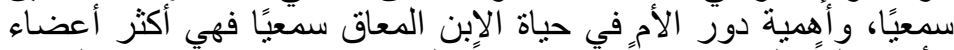

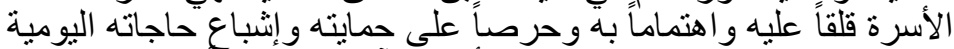

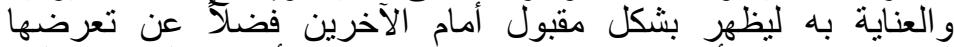

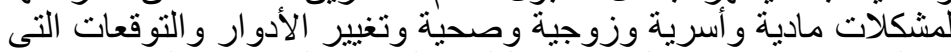

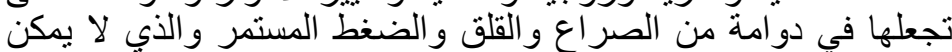

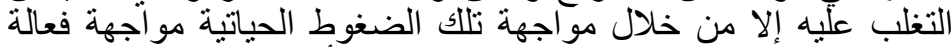

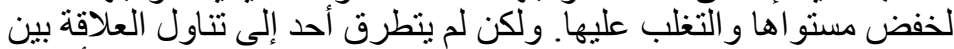

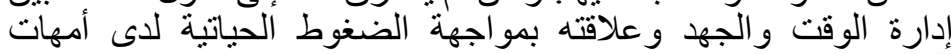
ألمعاقين سمعيًا.

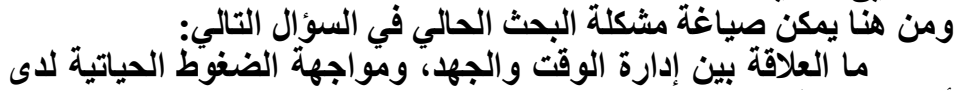

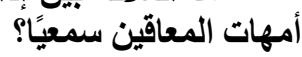

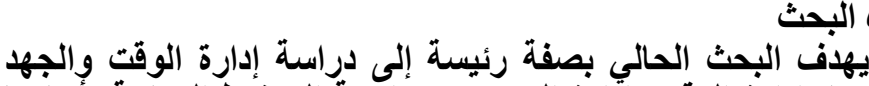

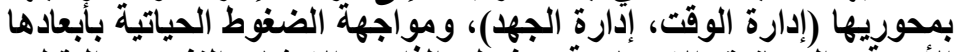

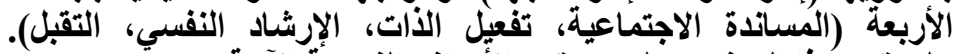

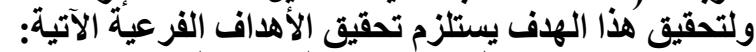

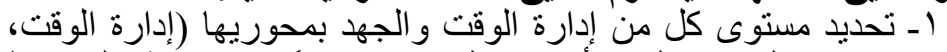

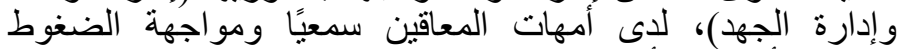

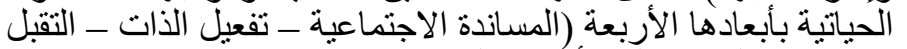

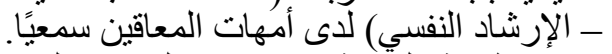

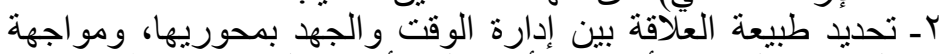

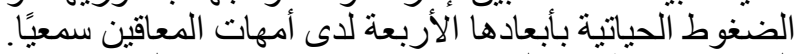

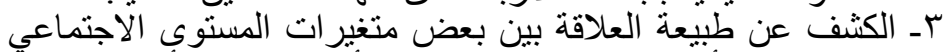

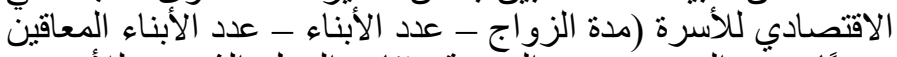

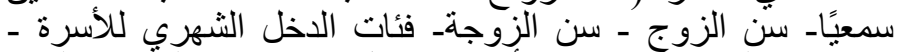

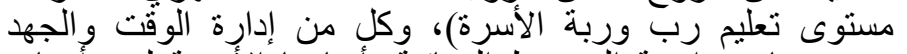

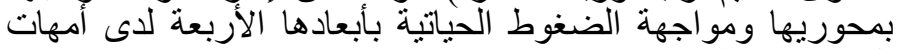
المعاقين سمعيًا. 


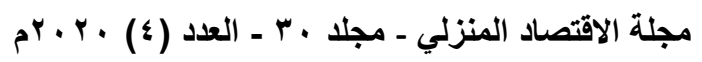

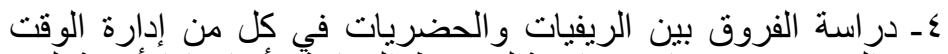

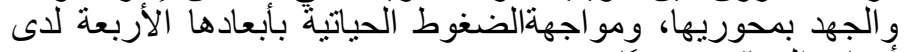
أمهات الجعات المعاقين سمعيًا.

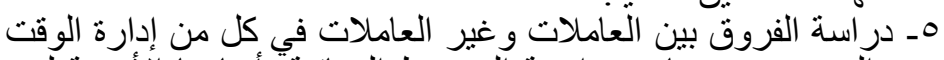

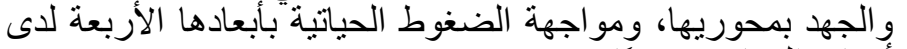
أمهات المعاقين سمعبًا.

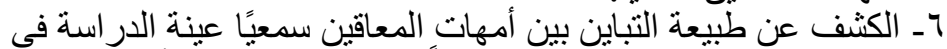

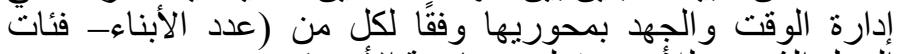

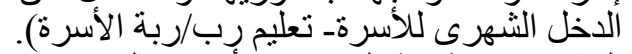

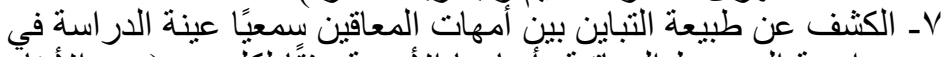

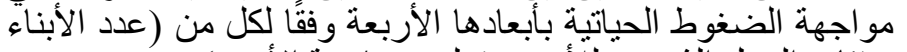

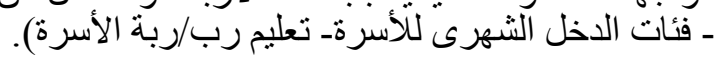

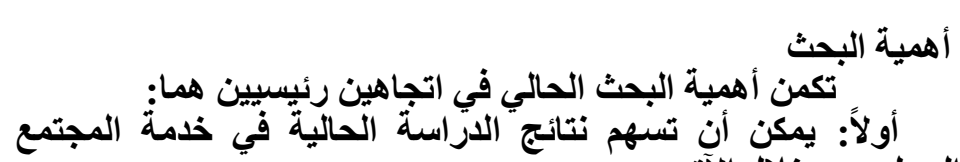

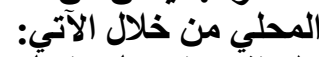

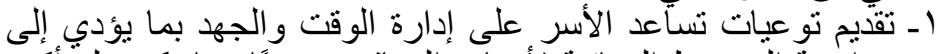

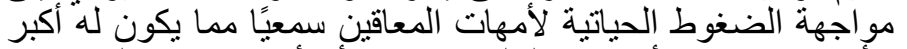

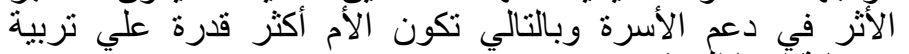

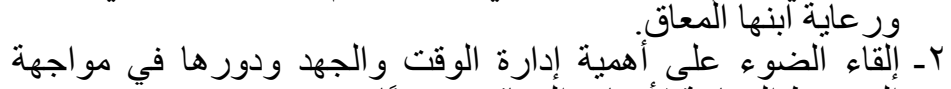

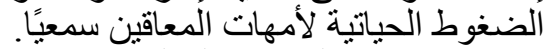

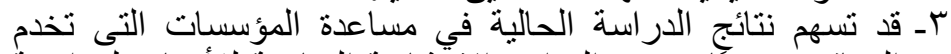

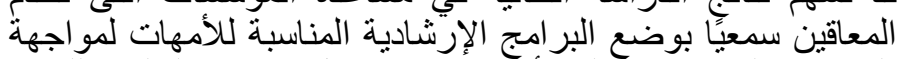

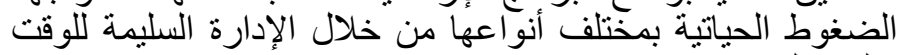
و الجهد لديهن.

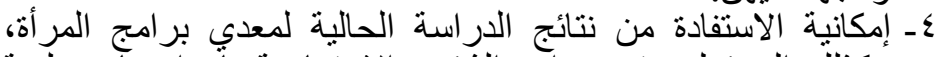

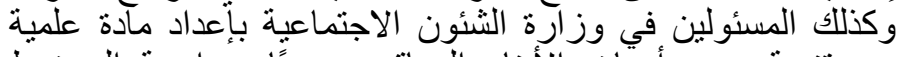

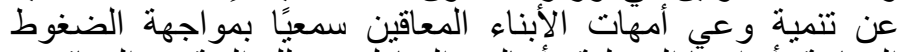
الحياتية بأنو اعهًا المختلفة وأساليب التعامل مع تلك ألفئة من المعاقين. 


$$
\text { مجلة الاقتصاد المنزلي - مجلد · ب - العدد (؟) • ب • م م }
$$

ثانيًا: يمكن أن تسهم نتائج الدراسة الحالية في خدمة مجال التخصص

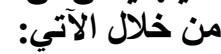
ا ـ تدعيم قنم إلآي: إدارة مؤسسات الأسرة والطفولة في كليات الاقتصاد

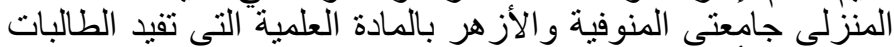

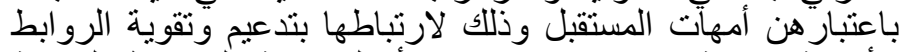

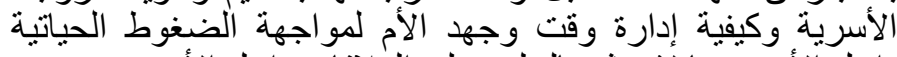

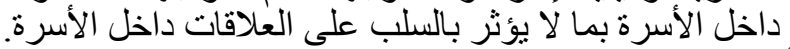

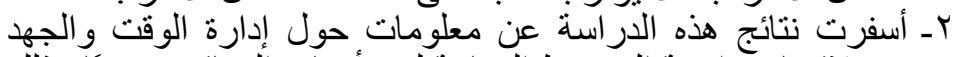

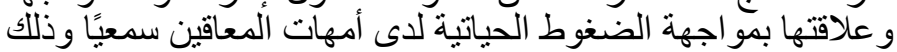

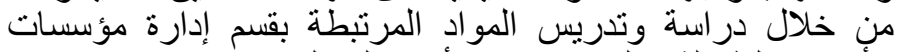

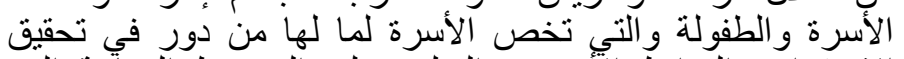

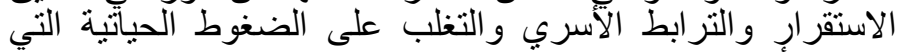
تو اجه الأسرة.

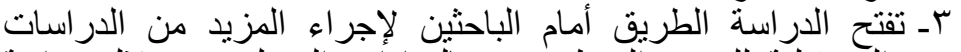

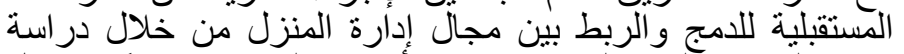

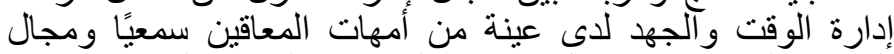

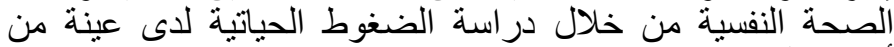
أمهات المعاقين سمعيًا. عـ الاستفادة من نتائج هذه الدراسة الدأة في مو اكبة التطور المعرفي في مجال

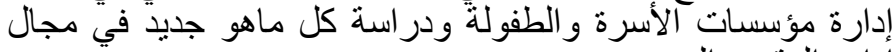

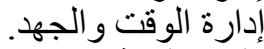

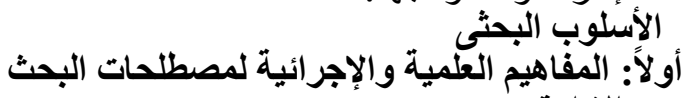

$$
\begin{aligned}
& \text { ــالالادارة المفيم }
\end{aligned}
$$

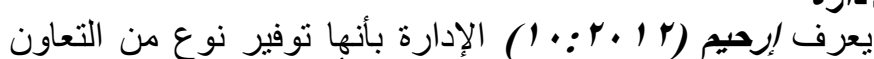

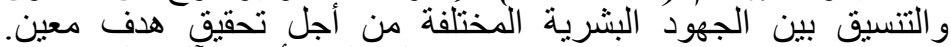

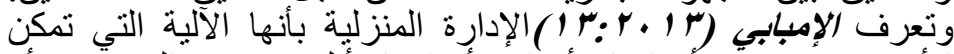

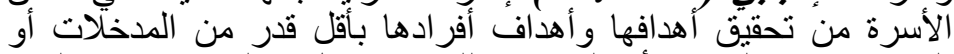

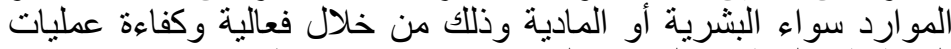

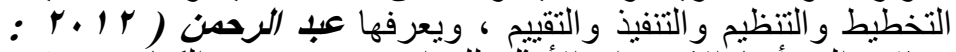

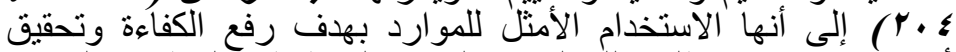

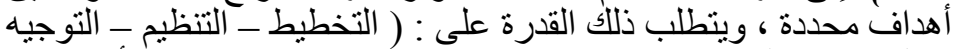

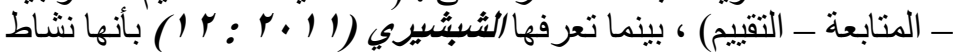




$$
\text { مجلة الاقتصاد المنزلي - مجلد · ب - العدد (؟) • ب • م م }
$$

منظم متكامل بهدف إلى تحقيق أهداف مجددة من خلال تطبيق الخطوات

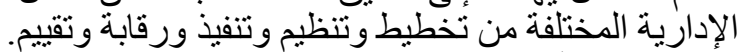

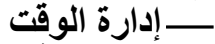

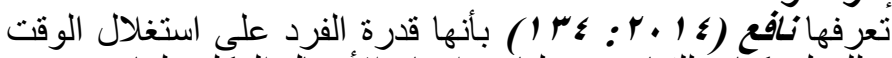

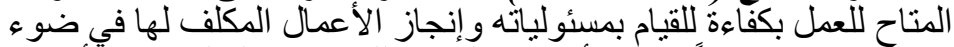

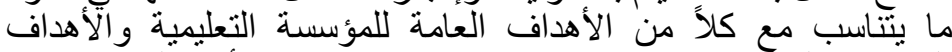

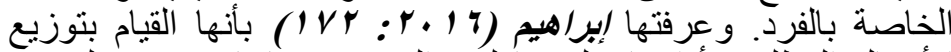

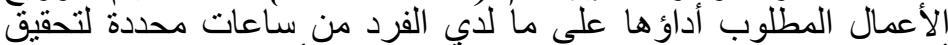

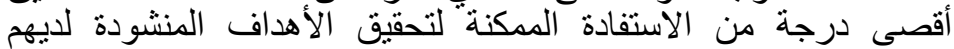

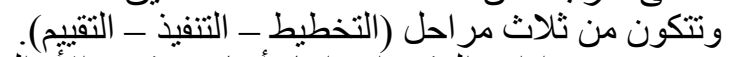

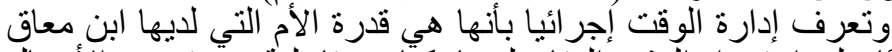

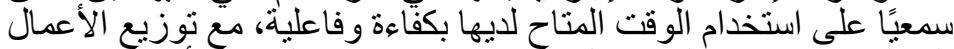

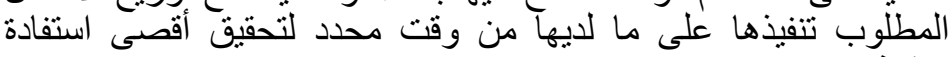

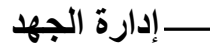

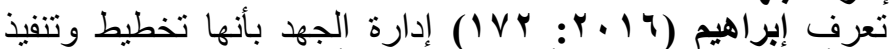

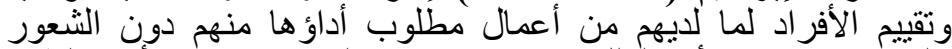

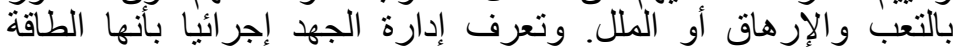

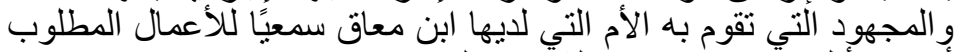

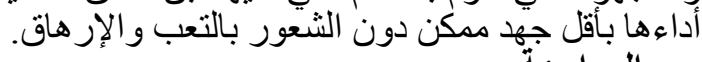

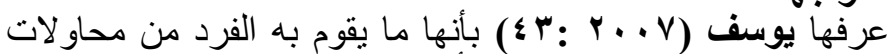

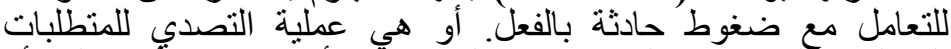

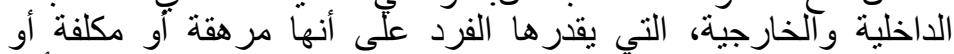

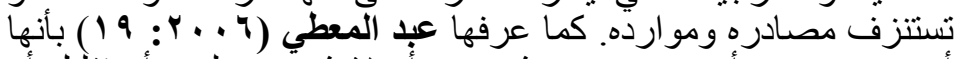

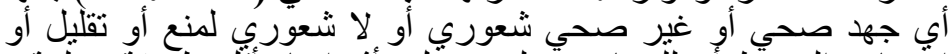

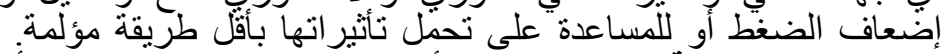

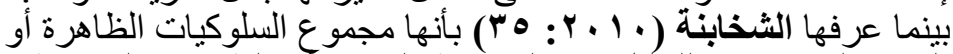

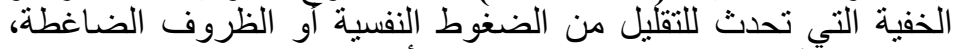

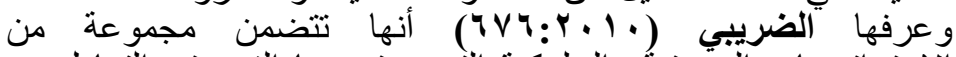

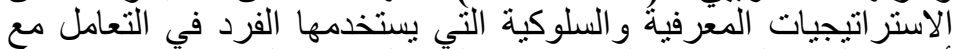

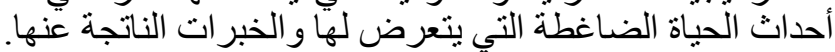




$$
\text { مجلة الاقتصاد المنزلي - مجلد · ب - العدد (؟) • ب • م م }
$$

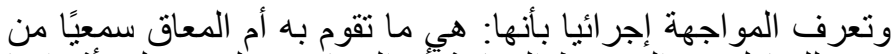

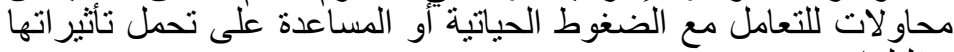
وتقليلها.

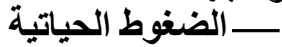

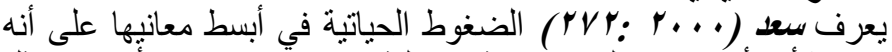

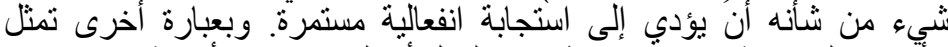

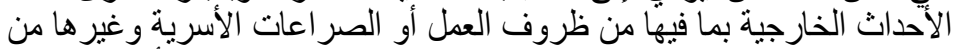

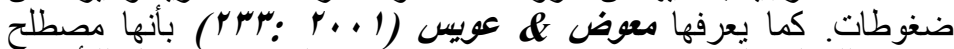

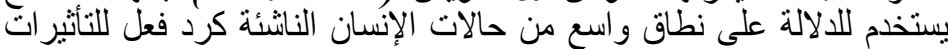

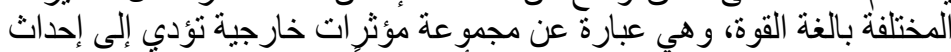

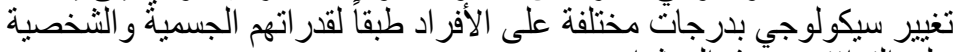

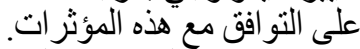

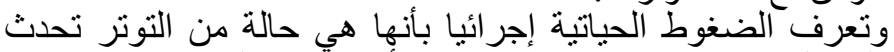

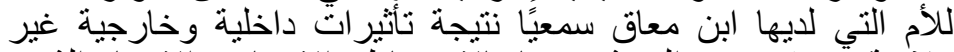

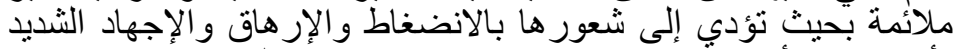

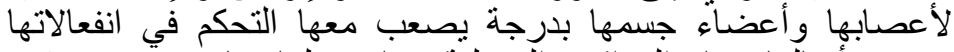

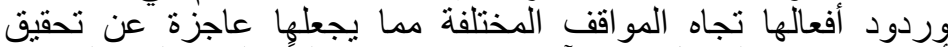

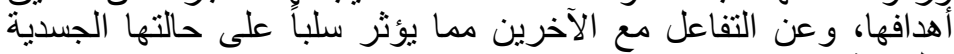

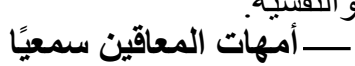

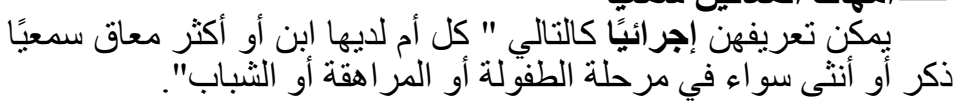
ثنانيًا: فروض البحث

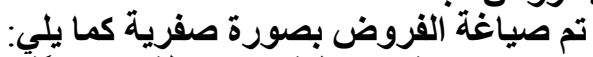

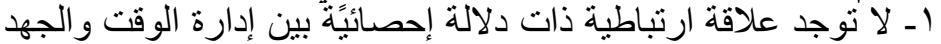

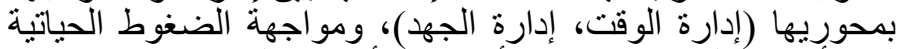

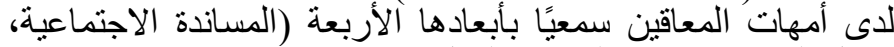

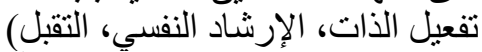

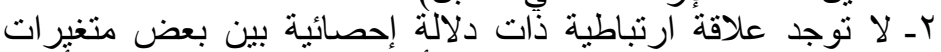

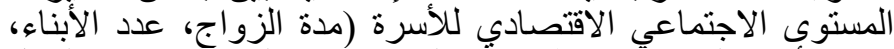

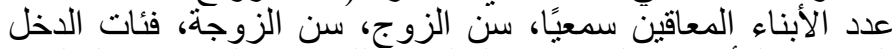

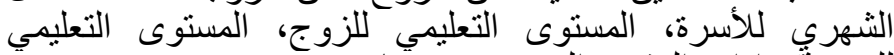

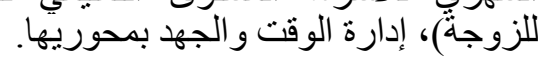




$$
\text { مجلة الاقتصاد المنزلي - مجلد · ب - العدد (؟) • ب • م م }
$$

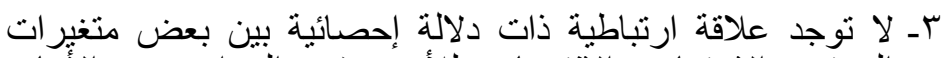

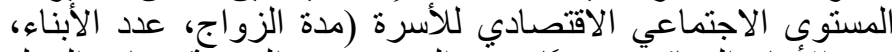

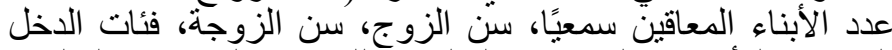

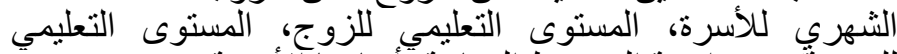

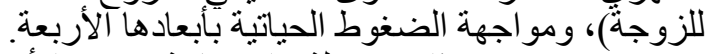

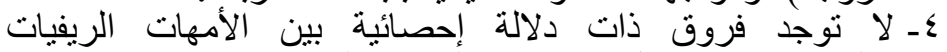

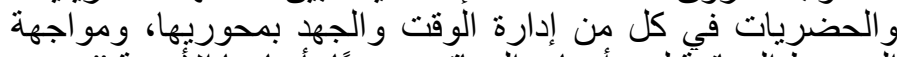

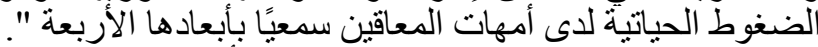

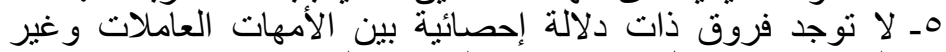

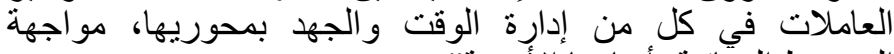

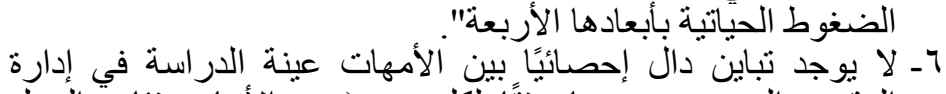

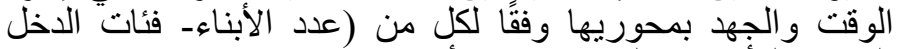

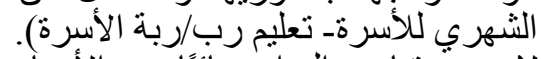

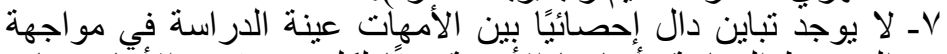

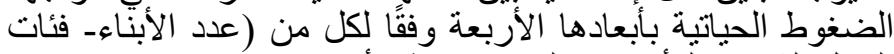

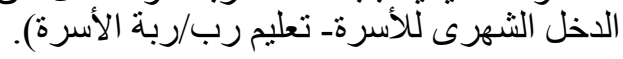

اتبعت هذه البحثة الدة المنهج الوصفي التحليلي وهو المنهج الذي ألي ثالثًا: منهج البحث

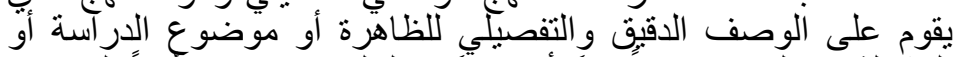

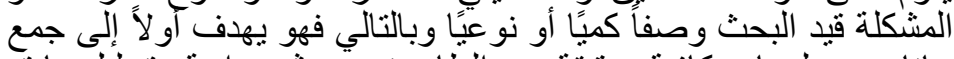

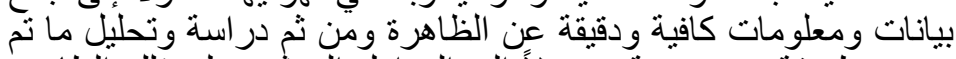

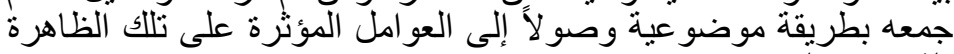

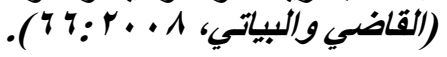

تم تطبيق الدراسة على عينة قو امها ـ م أم ألأبناء معاقين سمعيًا رابعًا: عينة البحث

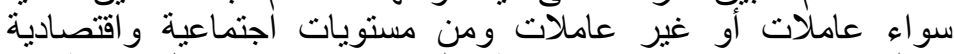
مختلفة ومن ريف وحضر محافظة الغربية وتم اختيار التعينة بطريقة صدفية غرضية. ونم تطبيق الدراسة الحالية على أمهات من ريف وحضر وحضر محافظة الغربية (طنطا - قطور - المحلة الكبرى). 
مجلة الاقتصاد المنزلي - مجلد · r - العدد (ع) • r • r م

خامسًا: أدوات البحث من أجل تحقيق أبداف أبداف الدراسة والتحقق من صحة الفروض قام

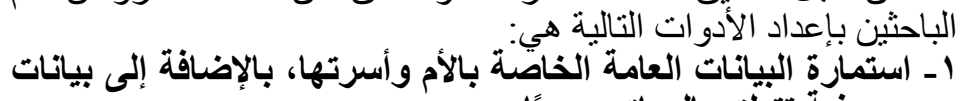
وصفية تتعلق بالمعاق سمعيًا.

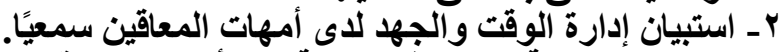

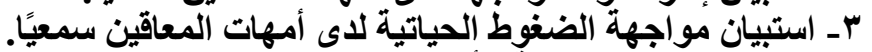

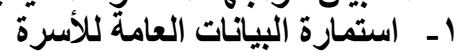

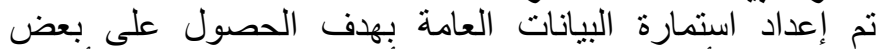

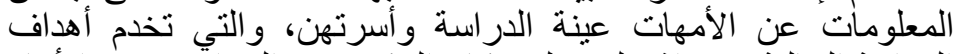

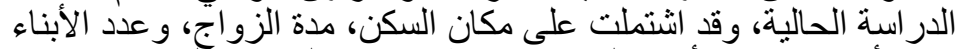

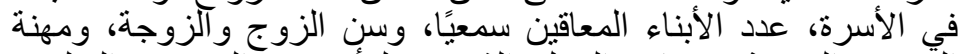

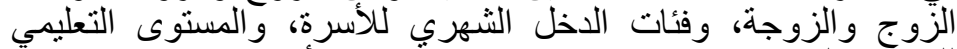
للزوج والزوجة والزوجة، ومدى ومقدار مشاركةٌ ربة الأسرة في الإنفاق، نوع التعين

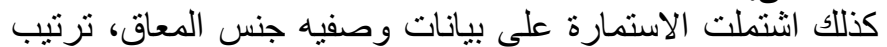
وطبيعة المسكن

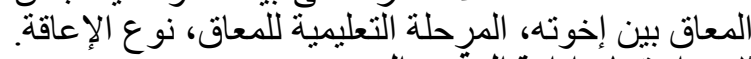

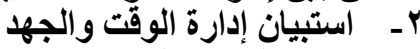

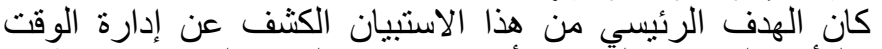

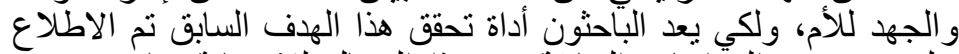

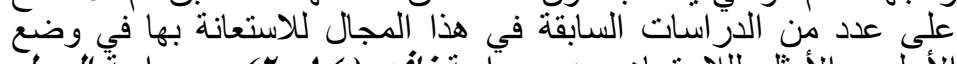

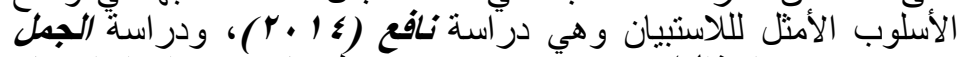

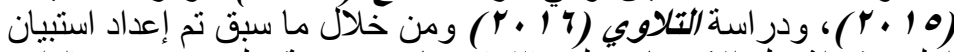

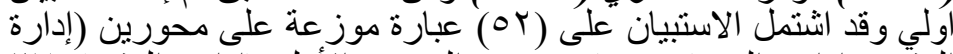

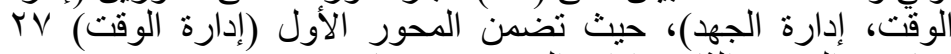

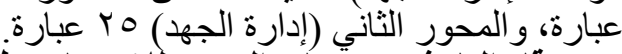

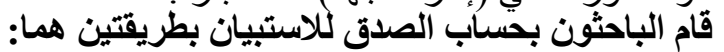

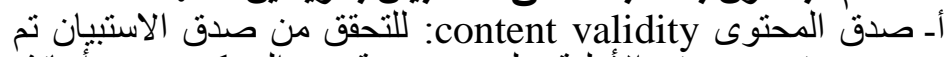

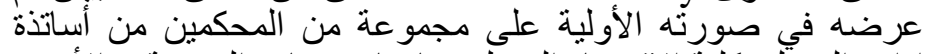

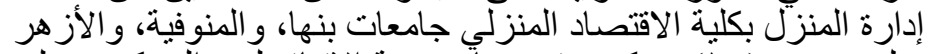

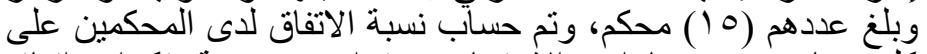

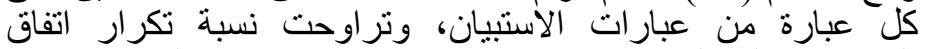

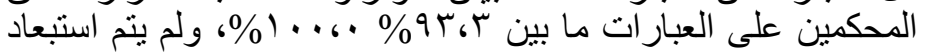


أية عبارة من عبارات محوري إدارة الوقت وإدارة الجهد، وتم التعديل

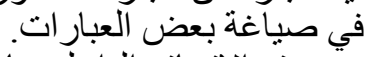

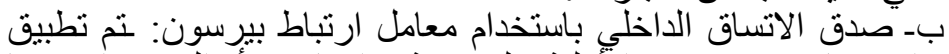

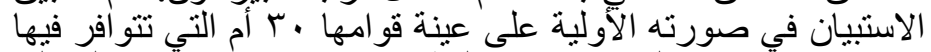

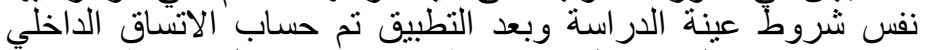

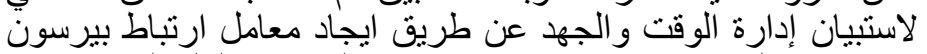

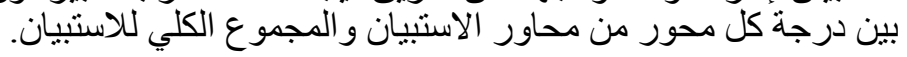

جذول (1) معاملات الارتباط بين عبارات كل محور من محاور استبيان

\begin{tabular}{|c|c|c|c|c|c|c|c|}
\hline \multicolumn{4}{|c|}{ إدارة الجهـ } & \multicolumn{4}{|c|}{ إدارة الوقُت } \\
\hline معامل الارتباط & | العبارة & الارتباط معامل & | العبارة | & الارتباط & | العبارة | & الارتباط معامل & العبارة \\
\hline$* *$, , $\{\leqslant\}$ & $1 \leqslant$ & $* *, ، \varepsilon, r$ & 1 & $* *, 6 \leqslant 70$ & 10 & **, , YYY & 1 \\
\hline ** • เ ะป & 10 & **, , Y $\leqslant$. & r & $* *$, , YYY & 17 & **, , r YVY & $r$ \\
\hline$* ., 1 \%$ & 17 & $* *$, , $\mathrm{MN}$ & $r$ & $\cdot 6 \cdot 17$ & IV & $* *, ، \leqslant Y \cdot$ & $r$ \\
\hline$* *, 6 Y 10$ & IV & $* *, ، \varepsilon \wedge V$ & $\varepsilon$ & $* * \ldots \leqslant 19$ & 11 & $* *, 6 \leqslant 01$ & $\varepsilon$ \\
\hline$* * .617 \%$ & 11 & $* *, 6 \leq M Y$ & 0 & **.6\%9V & 19 & $* *$, , YYO & 0 \\
\hline **, , YTY & 19 & $* *$, , rMt & 7 & $* *, 6 r \circ \Lambda$ & $r \cdot$ & $* *, 6 r \leq$ & 7 \\
\hline$* * .6799$ & $r \cdot$ & $* *, 64 \leq 9$ & $\mathrm{~V}$ & $* *$, rVVO & YI & $* *, 6 r \leq 9$ & $\mathrm{~V}$ \\
\hline$* * ., r V$. & YI & $* *, 0,0,0$ & $\Lambda$ & $* *, .0 Y \leqslant$ & YY & $* *$, *OY & $\Lambda$ \\
\hline$* *, 6 r \ldots$ & YY & $* *, ، 0 \wedge \leq$ & 9 & $* *, 6 \leq 7$. & YT & $* *, ، \leq 1 \wedge$ & 9 \\
\hline$* *$, * YOY & $r r$ & $* *, 6 Y 0 V$ & 1. & $* * ., Y V V$ & $Y \leq$ & $* *, \mathrm{YTN}^{\prime}$ & 1. \\
\hline$* *$ * , \&Y & $r \varepsilon$ & $.610 V_{-}$ & 11 & $* *$, *YYq & Yo & $* *, ، \varepsilon \mid T$ & 11 \\
\hline \multirow[t]{3}{*}{$* * .6190$} & Yo & $* * .6 \% q$. & Ir & $* *$, * YAV & Y7 & $* *$, *Y7 & $1 r$ \\
\hline & & $* *$, *Yษ & 14 & $* * .6 Y 7 V$ & rV & $* *,{ }^{\prime} Y V \cdot$ & 14 \\
\hline & & & & & & $* *, 6 \% \circ 4$ & $1 \varepsilon$ \\
\hline
\end{tabular}

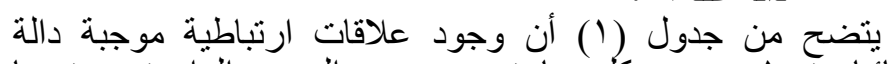

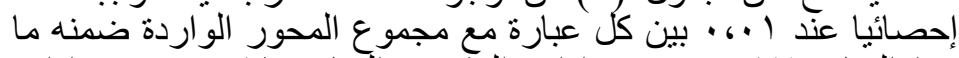

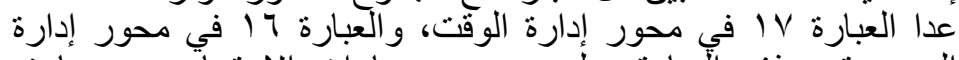

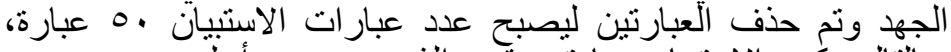

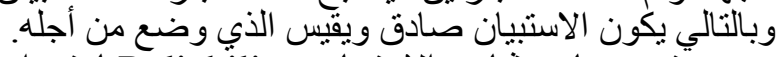

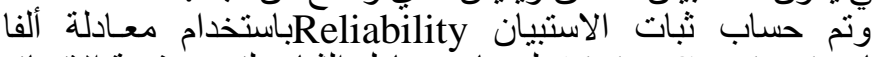
كرونباخ Alpha-Cronbach لُحساب معامل الثبات لتحديد قيمة الاتساق

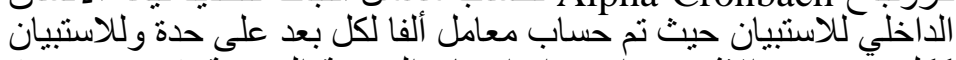
ككل بمحوريه الاثنين، واستخدام اختبار التجزئة النصفية (Split-half) 
مجلة الاقتصاد المنزلي - مجلد · r - العدد (ع) • r • r م

وللتصحيح من أثر التجزئة النصفية تم استخدام معادلة التصحيح لسبيرمان

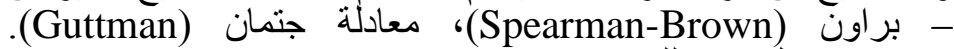
ويوضح جدول (1) ذللك:

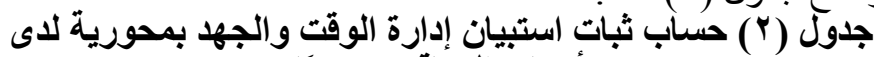

\begin{tabular}{|c|c|c|c|c|}
\hline \multicolumn{2}{|c|}{ التجزئة النصفية } & \multirow{2}{*}{ معامل ألفا } & \multirow{2}{*}{ العبارات } & \multirow{2}{*}{ البيان } \\
\hline جتمان & سبيرمان- براون & & & \\
\hline . VYOY & . rVOr & , ,Vr. & T & إدارة الوقت \\
\hline . . & . .\$17 &., 701 & $r \varepsilon$ & إدارة الجهر \\
\hline ד4 & $.67 \leqslant$. & $\cdot, V q Y$ & o. & إجمائي إدارة الوقت والجهر \\
\hline
\end{tabular}

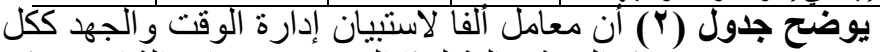

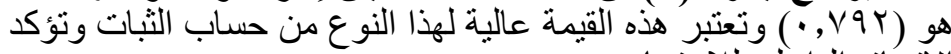

الاتساق الداخلي للاستبيان.

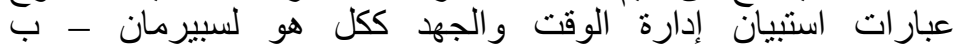

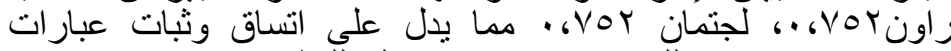

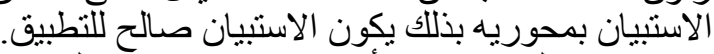

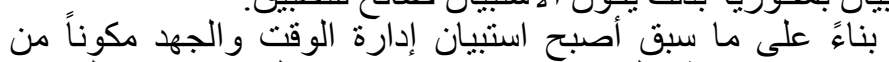

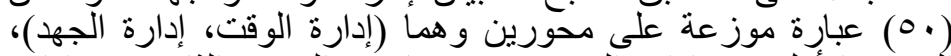

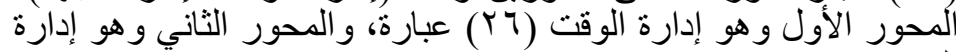

وتتحدد استجابات الأمهات عينة الدارة استة على كل عبارة وفق ثلاث الجهد ( المحور) عبارة.

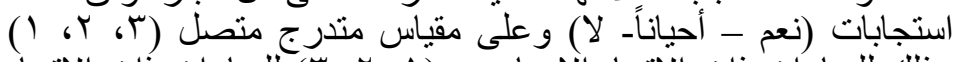

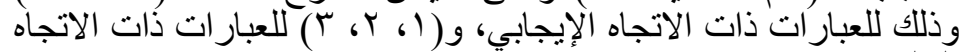

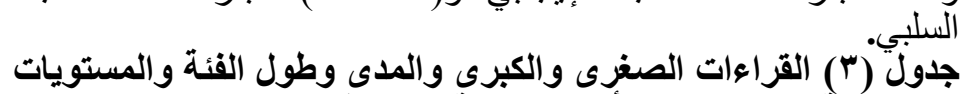

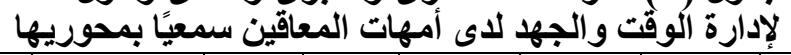

\begin{tabular}{|c|c|c|c|c|c|c|c|c|}
\hline مرتفع & مستوى متوسط & منخفضوي & طولئة & المدى & الكبرى القرة & الصغرى القرة & العبارات & البيان \\
\hline با بأكثر & $(I r-O r)$ & $(\Delta r-\varepsilon r)$ & 1. & $r$ & $V \varepsilon$ & $\varepsilon r$ & rq & إدارة الوقت \\
\hline צه فأكثر & $(00-\leq \eta)$ & $(\varepsilon 0-r q)$ & 1. & $r \varepsilon$ & $v$. & $r_{4}$ & $r \varepsilon$ & إدارة الجهر \\
\hline • r ا فأكثر & $(119-1 . r)$ & $(1.1-\wedge \xi)$ & 11 & 07 & $1 \leq$. & $\Lambda \varepsilon$ & 0 . & إجمتالي وإدارة \\
\hline
\end{tabular}




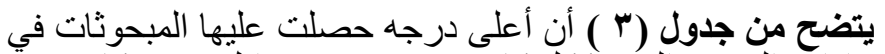

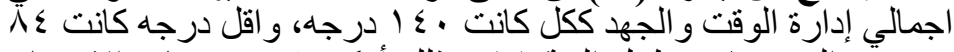

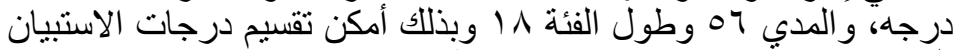

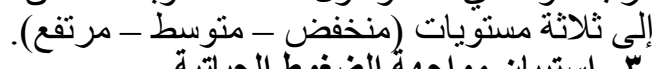

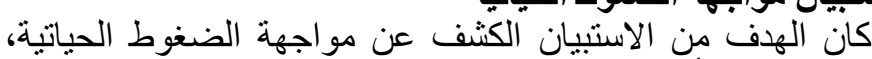

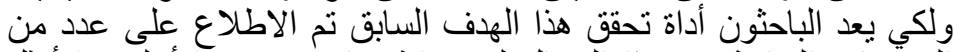

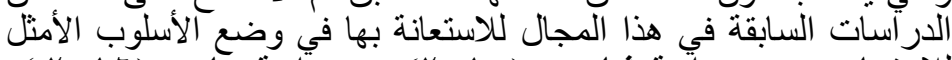

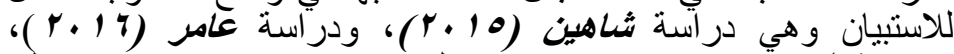

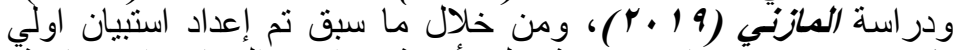

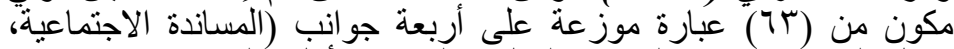

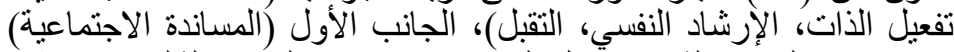

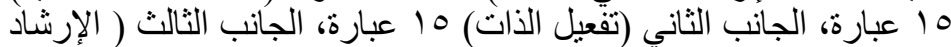

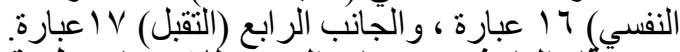

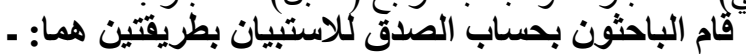

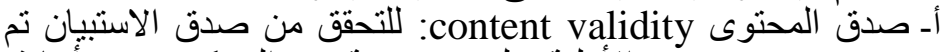

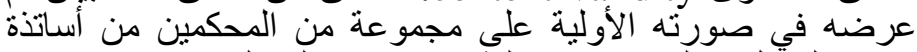

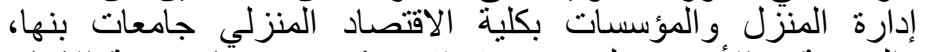

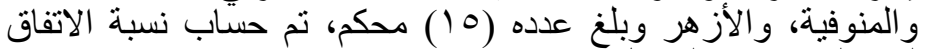

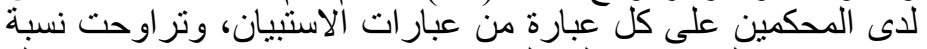

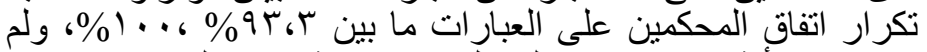

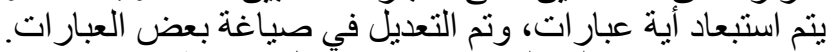

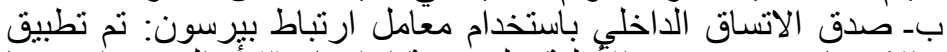

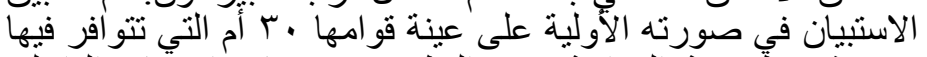

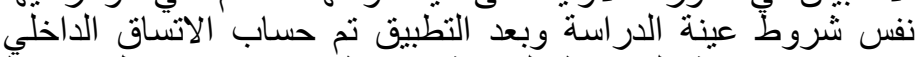

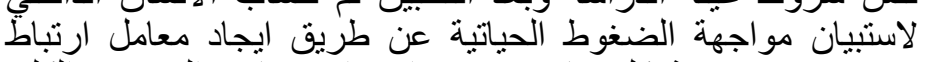

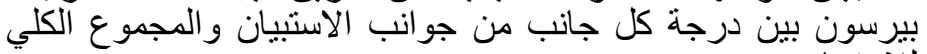
للاستبيان. 
مجلة الاقتصاد المنزلي - مجلد · r - العدد (ع) • r • r م

جول (ع) معاملات الارتباط بين عبارات كل بعد من أبعاد استبيان

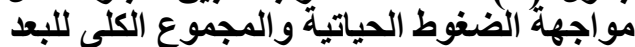

\begin{tabular}{|c|c|c|c|c|c|c|c|}
\hline \multicolumn{2}{|l|}{ بعد التقبل } & \multicolumn{2}{|c|}{ بعد الإرشاد النفسى } & \multicolumn{2}{|c|}{ بعد تفعيل الأات } & \multicolumn{2}{|c|}{ بُعد المساندة الاجتماعية } \\
\hline معامل الارتباط & | - ل العبارة & معامل الارتبَاط & | - لعبارة| & معامل الارتباط & العبارة & معامل الارتباط & 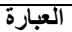 \\
\hline$* * \ldots \leqslant 70$ & $T$ & $* * .0 \vee \wedge$ & $T$ & **. . rTा & $T$ & $* *$, . OVV & $T$ \\
\hline$* * ., 0 \ldots$ & Y & **. . 704 & r & **, . & Y & $* * .6740$ & Y \\
\hline$* *, ، \leq \leqslant 7$ & $r$ & $* * .6 \vee \leqslant 1$ & $\Gamma$ & **. . TYY & $\Gamma$ & $* * .6 \leq 9 \leq$ & $r$ \\
\hline **, ، $57 Y$ & $\xi$ & ** . ، $\leqslant \leq$ & $\xi$ & **. . rq & $\xi$ & $* * .094$ & $\varepsilon$ \\
\hline **, , YYVI & 0 & $* * .6790$ & 0 & $* * \cdot ، \leqslant \cdot Y$ & 0 & $* * .6990$ & 0 \\
\hline$* *, ، \leqslant \Gamma \wedge$ & 7 & $* * .7 T V$ & 7 & $* * .6 \Omega Y Y$ & 7 & **, . Y T & 7 \\
\hline **. , Y Y & $\mathrm{V}$ & $* * .6797$ & $\mathrm{~V}$ & $* * .699$ & $\mathrm{~V}$ & **, , Y & $\mathrm{v}$ \\
\hline$* * .619$ & $\Lambda$ & $* * .671$ & $\Lambda$ & $* * .6 \leqslant 7 \%$ & $\Lambda$ & $* *, 6 \% 0 \leq$ & $\Lambda$ \\
\hline **. . ०४व & 9 & $* * .67 .7$ & 9 & **., YYY & 9 & **.، & 9 \\
\hline$* * .079$ & 1. & $* * .67 \vee 9$ & 1. & $* * .0$, & 1. & $* * \cdot ، \leqslant Y \wedge$ & 1. \\
\hline$* * ., 004$ & 11 & $* * . ، \leqslant \leq 0$ & 11 & $* * \cdot, 6 \leqslant 9$ & 11 & **, , TYO & 11 \\
\hline **, , YY & TY & $* * .670$. & Tr & $* * \cdot 64 \pi$ & Tr & **, הTY & TY \\
\hline$* *, 6 \leqslant 19$ & $1 \pi$ & $* *, ، \leqslant \vee \wedge$ & $1 T$ & **., & 14 & $.6 .1 \mathrm{~V}$ & Tr \\
\hline$* * .019$ & $T \leq$ & **., RTI & $1 \leq$ & **. . \&Y & Tई & **.6\%99 & Tा \\
\hline$* * \cdot, 0 \leqslant Y$ & 10 & $* * . ، £ \wedge 9$ & 10 & **.6Y人9 & 10 & $* * .69 V$ & 10 \\
\hline **, . YYY & 17 & $* * \cdot r \cdot r$ & 17 & & & & \\
\hline$* *, ، 7, V$ & IV & & & & & & \\
\hline
\end{tabular}

يتضح من جدول (ع ) وجود علاقات ارتباطية موجبة بين جميع أبعاد

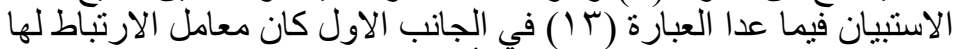

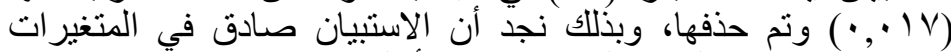

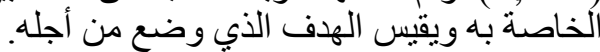

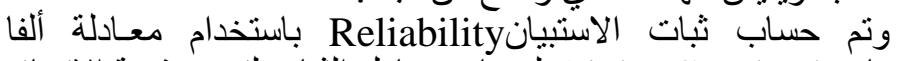
كرونباخ Alpha-Cronbach لحساب معامل الثبات لتحديد قيمة الاتساق

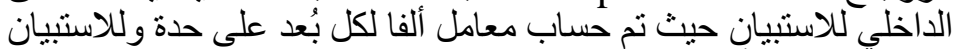

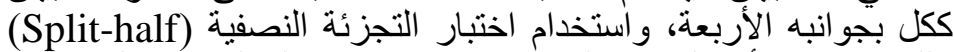
وللتصحيح من أثز التجزئة النصفية تم استخدام معادلة التصحيح لسبيرمان التهان

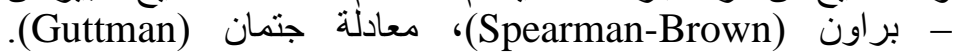
ويوضح جدول (0) ذلك: 
مجلة الاقتصاد المنزلي - مجلد · r - العدد (ع) • r • r م

جدول (0) اختبار معامل ألفا كرونباخ، والتجزئة النصفية لاستبيان

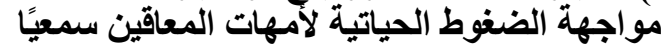

\begin{tabular}{|c|c|c|c|c|}
\hline \multicolumn{2}{|c|}{ التجزئة النصفية } & \multirow{2}{*}{ كرونباخ } & \multirow{2}{*}{ العبارات } & \multirow[b]{2}{*}{ البيان } \\
\hline جتمان & سبيرمان-براون & & & \\
\hline .670. & .6700 & $.674 \%$ & $1 \leqslant$ & المساندة الاجتماعية \\
\hline .10 .0 & .60 .7 & $.00 Y$ & 10 & تفعيل الأات \\
\hline $.60 \leqslant$. & $.00 \leqslant$ & $.6 \wedge 00$ & 17 & الإرشاد النفسي \\
\hline $.67 \leqslant 9$ &., 704 & . $6 \mathrm{VYN}$ & IV & التقبل \\
\hline מ & - $\vee \vee \wedge 9$ & 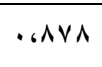 & r & إجمالي الضتبيان مواجهة \\
\hline
\end{tabular}

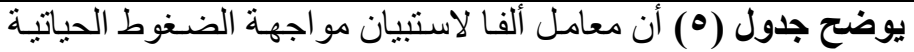

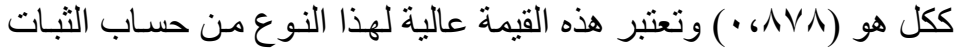
وتؤكد الاتساق الداخلي للاستبيان.

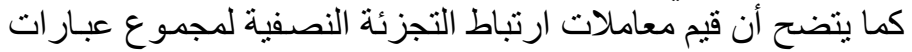

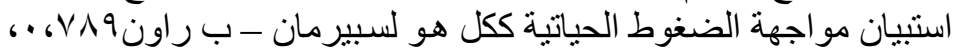

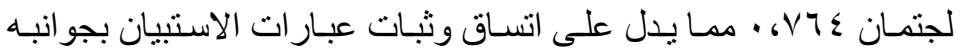

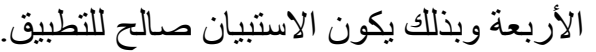

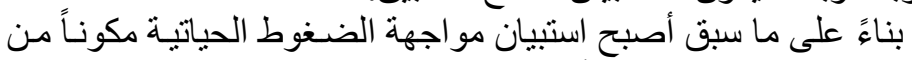

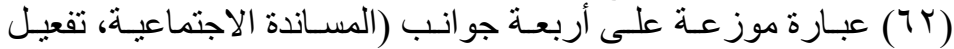

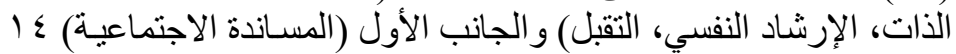

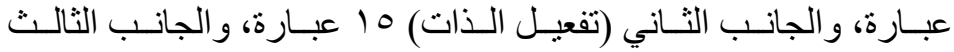

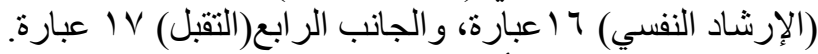

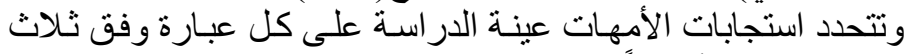

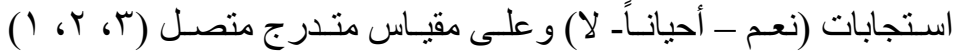

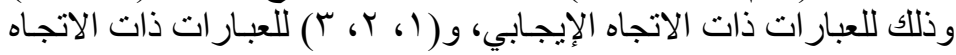




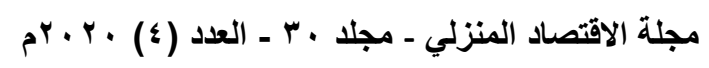

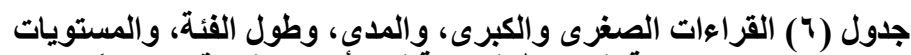

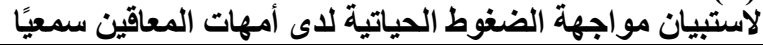

\begin{tabular}{|c|c|c|c|c|c|c|c|c|}
\hline مرتفوى & متستوى & منخفتوي & الفئة & المدى & الكبرى القرة & الصغرى & العبارات & البيان \\
\hline فأكثر & $(r \mid-r \varepsilon)$ & $(r r-17)$ & $\wedge$ & Y & $\leq r$ & 17 & $1 \varepsilon$ & الاجتماعية \\
\hline $\begin{array}{l}\text { فأكثر } \\
1 \\
\text { ف }\end{array}$ & $(r v-r l)$ & $(r \cdot-r \varepsilon)$ & $v$ & ri & $\leq 0$ & $r \leq$ & 10 & تفعيل الأات \\
\hline فأكثر & $\left(r V_{-} r Y\right)$ & $(r \mid-Y \leq)$ & $\wedge$ & $r \leq$ & $\leq \wedge$ & $r \varepsilon$ & 17 & الإرشياد \\
\hline فأكثر & $(\leqslant 1-r 0)$ & $(r \leq-r \wedge)$ & $v$ & r & 01 & rA & iv & التقبل \\
\hline $\begin{array}{l}100 \\
\text { فاكثر }\end{array}$ & $(10 \leq-1+1)$ & $(1+\cdot-1 \cdot v)$ & $r \varepsilon$ & $V \leqslant$ & $1 \wedge 1$ & $1 . v$ & 4 & الضواجنية \\
\hline
\end{tabular}

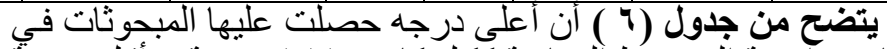

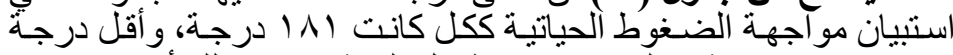

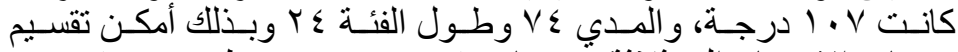

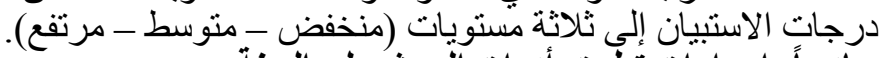

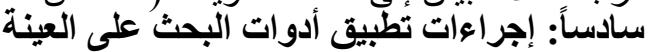

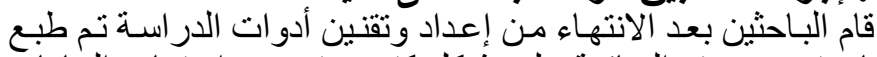

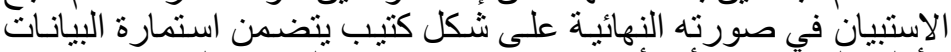

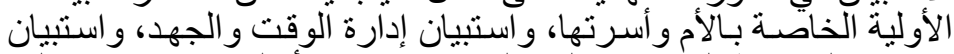

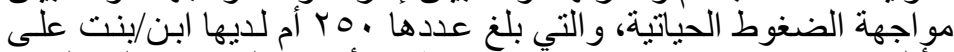

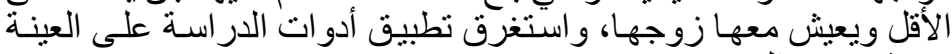

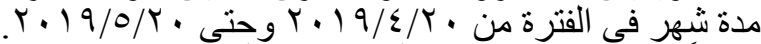
سابعاً: المعاملات الإحصائية المستخدمة في في البحت البحث

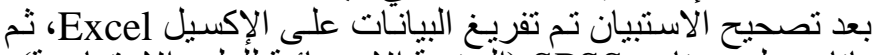

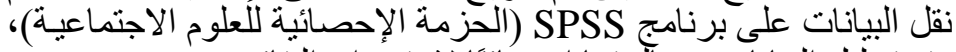

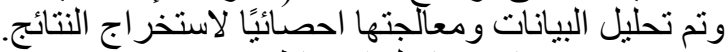

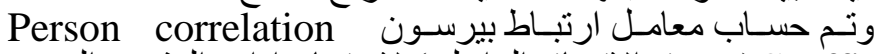
Coefficient

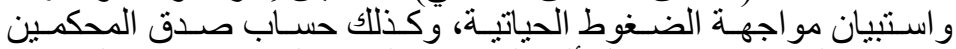

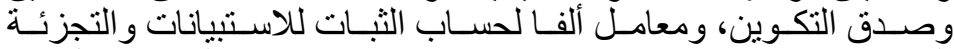

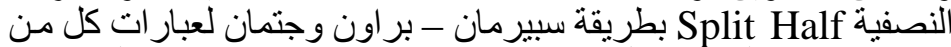

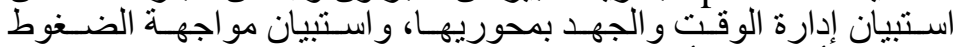

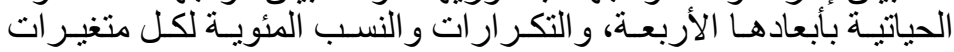




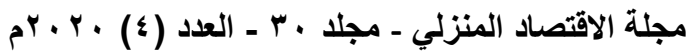

الدر اسـة، والعلاقات الارتباطية بطريقة بيرسون Person correlation

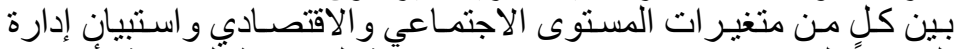

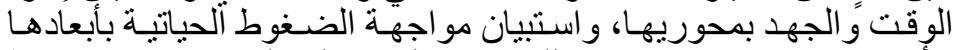

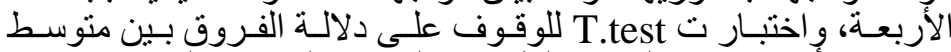

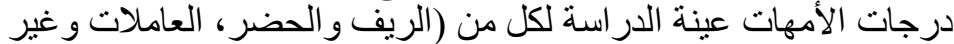

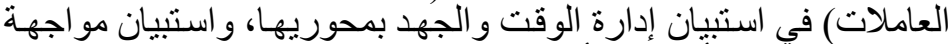

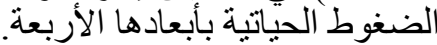

\section{نتائج البحث الميدانية أولا: وصف عينة البحث التراسة}

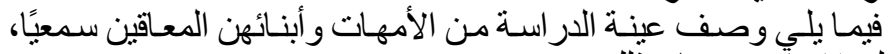

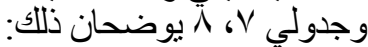

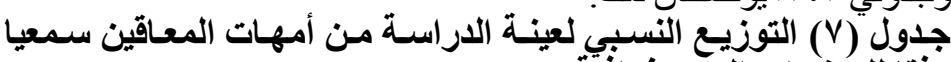
وفقا للمتغير ات الإيموغ الفيبية

\begin{tabular}{|c|c|c|c|c|c|}
\hline المئويّة & العدد العد & المتغير & المئويّة & العدد & المتغير \\
\hline \multicolumn{3}{|c|}{ ب - مدة الزواج } & \multicolumn{3}{|c|}{ 1 - مكان السكن } \\
\hline$\varepsilon$ & $1 \cdot$ & من 0 وحتى اقل من • اسنوات & 0 or،八 & ITr & ريف \\
\hline$\Gamma \cdot 6 \Lambda$ & VV & من · اوحتى أل من 10 سنة & $\sum 7,1$ & $11 \mathrm{~V}$ & حضر \\
\hline TA. & 97 & من 10 وحتى أل من · آسنة & $1 \cdots \cdot$ & ro. & المجموع \\
\hline TY, & 07 & 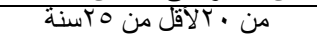 & \multicolumn{3}{|c|}{ "ا ـ _عدد الأبناء المعاقين سمعيا } \\
\hline$\varepsilon_{6} \varepsilon$ & 11 & • باسنة فاكتر & NT، & $Y \cdot T$ & ابن واحد \\
\hline $1 \cdots 6$ & TO. & المجموع & 176 & \&. & التنان \\
\hline \multicolumn{3}{|c|}{ ع ـ- عدد الابناء } & 1.7 & $\varepsilon$ & تثلاثة \\
\hline r & 0 & ابن واحد & $1 \cdots \cdot \cdot$ & ro. & المجموع \\
\hline $0 \varepsilon$ & 1150 & تُلاتخة ابناء & \multicolumn{3}{|c|}{ 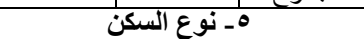 } \\
\hline 11 & $\varepsilon 0$ & اربعة أبناء & $V 96 r$ & 191 & ملأك \\
\hline T.7 & 9 & خمسة ابناء فاكثر & 1967 & $\varepsilon 9$ & إيجار \\
\hline $1 \cdots 6$ & ro. & المجموع & $1, T$ & $r$ & تابع للعمل \\
\hline T & 0 & ابن و احذّ & $1 \cdots \cdot$ & ro. & المجموع \\
\hline
\end{tabular}

تابع جدول (V) التوزيع النسبي لعينة الدراسة من أمهات المعاقين سمعيا وفقا للمتنغيرات الديموغرافية

\begin{tabular}{|c|c|c|c|c|c|c|c|}
\hline \multicolumn{4}{|c|}{ V- مستوى تعليم الزوجة } & \multicolumn{4}{|c|}{ 7- مستوى تعليم الزووج } \\
\hline \multirow[t]{3}{*}{19,7} & $1 \leqslant, \cdot$ & To & 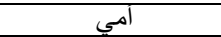 & \multirow[t]{3}{*}{ T1,7 } & 967 & TE & امي \\
\hline & T,A & $\mathrm{V}$ & يقرا ويكتب & & $7, \cdot$ & 10 & يقرا اويكتب \\
\hline & $T, \Lambda$ & V & حاصل على الابتدائية & & $7, \cdot$ & 10 & الابتدائية \\
\hline \multirow[t]{2}{*}{$0 \leqslant, \wedge$} & $7, \xi$ & 17 & حاصل علي الإعدادية & \multirow[t]{2}{*}{$\sum \wedge, \wedge$} & $0, Y$ & $\pi$ & الإعدادية \\
\hline & $\varepsilon \wedge, \xi$ & $|Y|$ & حاصل على الثانوية & & $\varepsilon r, \tau$ & 1.9 & الثانوية \\
\hline
\end{tabular}




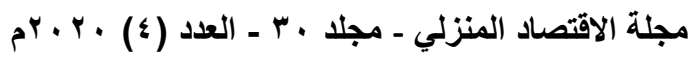

\begin{tabular}{|c|c|c|c|c|c|c|c|}
\hline \multirow[t]{2}{*}{ ro,7 } & $r \xi, \Lambda$ & TT & تعليم جامعي & \multirow[t]{2}{*}{ Tq,7 } & \multirow{2}{*}{$\frac{r \wedge, \cdot}{1,7}$} & \multirow{2}{*}{$\frac{V \cdot}{\varepsilon}$} & \multirow{2}{*}{ مر تلةّة ماجستيّي } \\
\hline & \multirow{3}{*}{$\frac{\cdot, \Lambda}{1 \cdots, \cdot}$} & T & مرحلة ماجستبر & & & & \\
\hline \multirow{2}{*}{\multicolumn{3}{|c|}{ 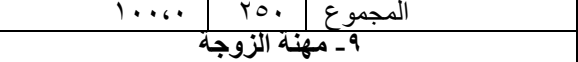 }} & & \multicolumn{2}{|l|}{$1 \cdots \cdot$} & ro. & المجموع \\
\hline & & & & \multicolumn{4}{|c|}{ 1 - مهنة الزوج } \\
\hline \multirow{2}{*}{\multicolumn{2}{|c|}{$\frac{T Y_{6} \varepsilon}{1 Y_{6} T}$}} & 97 & وظيفة حكو ميبة & \multirow{2}{*}{\multicolumn{2}{|c|}{ Y... }} & $9 \varepsilon$ & وظيفةٌ حكو مية \\
\hline & & $\varepsilon \varepsilon$ & قُطاع خاص & & & 0. & قطاع خاص \\
\hline \multicolumn{2}{|c|}{176.9} & $\varepsilon$ & اعمال حرة & \multicolumn{2}{|c|}{$r 7,1$} & बr & اعمال حرة \\
\hline \multicolumn{2}{|c|}{ •، } & 1 & على المعاش & \multicolumn{2}{|c|}{$\varepsilon_{6} \cdot$} & 1. & على المعاثش \\
\hline \multirow{2}{*}{\multicolumn{2}{|c|}{$\begin{array}{l}\because \xi \\
\Gamma 6 Y\end{array}$}} & $T$ & متوفي & \multicolumn{2}{|c|}{1,5} & $r$ & متوفي \\
\hline & & $1 \cdot 1$ & لا يعملَ & \multicolumn{2}{|c|}{ •، } & TE & لا بعقلّ \\
\hline \multicolumn{2}{|c|}{$\frac{\varepsilon r, 4}{1 \cdots, 6}$} & TO. & المجموع & \multicolumn{2}{|c|}{$1 \ldots$} & TO. & المجموع \\
\hline \multicolumn{4}{|c|}{ 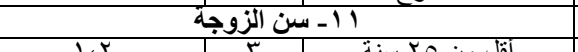 } & \multicolumn{4}{|c|}{ • 1- سن الزوج } \\
\hline & & $r$ & اقل من ه سنة & \multirow{2}{*}{\multicolumn{2}{|c|}{$V_{6} T$}} & - & اقل من ه سنة \\
\hline \multicolumn{2}{|c|}{$r 967$} & V乏 & من من مكنة وحنة أقل & & & IA & وحتي أقل من من \\
\hline \multicolumn{2}{|c|}{$0 \leqslant$ o } & $1 \pi 9$ & من منس هـ سنة وحتي أقل & \multicolumn{2}{|c|}{01.5} & $T Y \Lambda$ & من وحتى أقلة \\
\hline \multicolumn{2}{|c|}{$1 \leqslant 6$} & ro & سنة أقل & \multicolumn{2}{|c|}{$r 0,7$} & 19 & وحني أقل منة من \\
\hline \multicolumn{2}{|c|}{$\cdot$ • 61} & $T$ & منسنة فاكتر & \multicolumn{2}{|c|}{7.7} & 10 & م0رسنة فاكتر \\
\hline & & To. & المجموع & & & ro. & المجموع \\
\hline & الانفاق & لز لزوجة & با ا- مشّارك & & ري ليلاد & ذل الثي ل & ب - \\
\hline & & $\frac{1 T \Lambda}{114}$ & تشارك & $\lambda V, \Lambda$ & 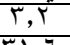 & $\lambda$ & 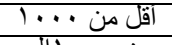 \\
\hline & & 111 & لا تشارك & & T1,7 & v9 & 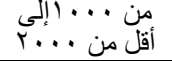 \\
\hline & & TO. & 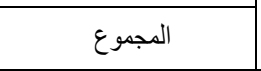 & & or,. & $\pi$. & 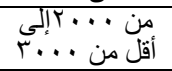 \\
\hline & ل في الانفاً & 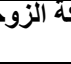 & ؛ ا - مقدار مشّا & 11,7 & $1 \cdot, \cdot$ & TO & 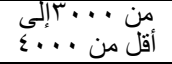 \\
\hline & & Trt & 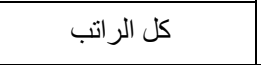 & & 1,7 & $\varepsilon$ & 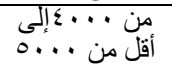 \\
\hline & & 。 & نصف الر اتب & 1,7 & $1, Y$ & $r$ & أقلّ من ..... إلى \\
\hline & & $1 \% 1$ & المجموع & & $\cdot, \varepsilon$ & $T$ & أقل من .... إلى \\
\hline & & ك 6 سكن & -10 & & & To. & المجموع \\
\hline & & IYY & شقة & & & & \\
\hline & & $V \varepsilon$ & لسكن مشترك مع الأقارب & & & & \\
\hline & & ro. & المجموع & & & & \\
\hline
\end{tabular}


مجلة الاقتصاد المنزلي - مجلد · r - العدد (ع) • r • م م

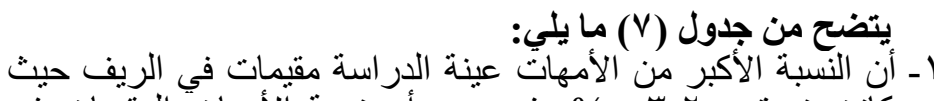

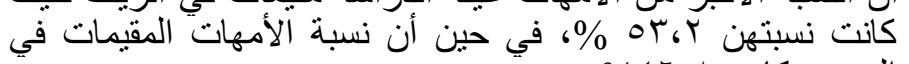
الحضر كانت Y- أن النسبة الأكبر من الأمهات عينة الدراسة منزوجات منذ (10 سنة

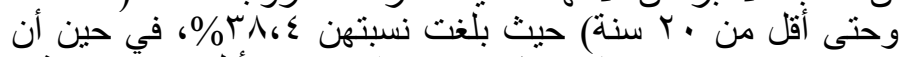

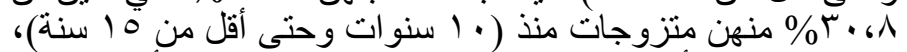

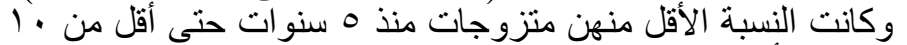

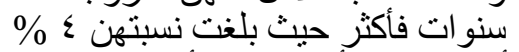

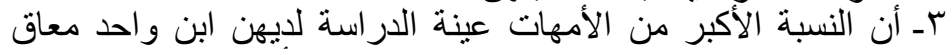

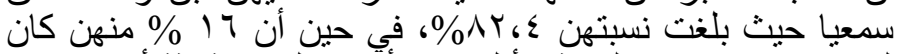

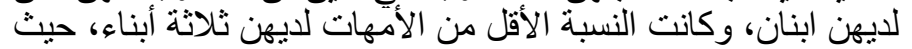

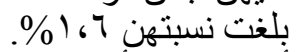

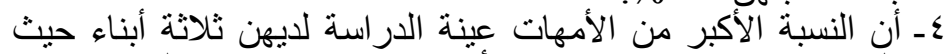

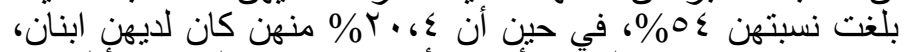

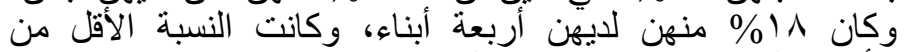

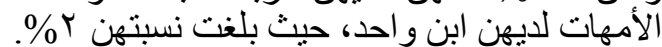

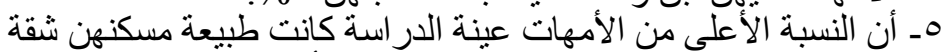

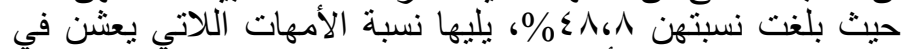

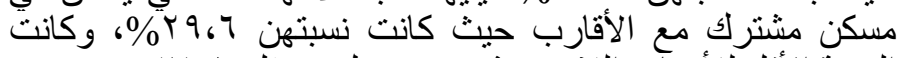

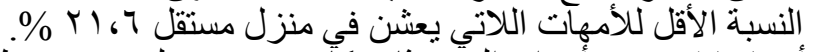

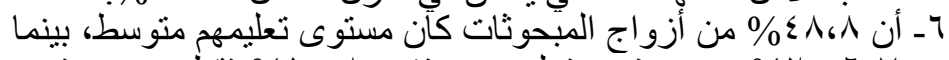

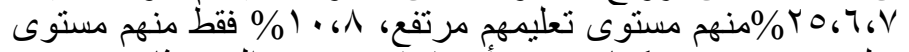

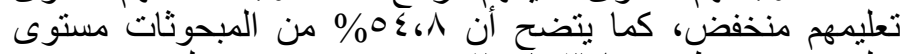

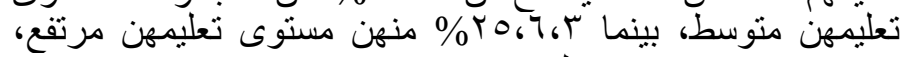

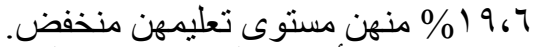
Vـ تقارب نسبة الأزواج الموظفين في القطاع الحكومي ونسبة الأزواج

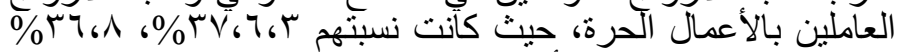

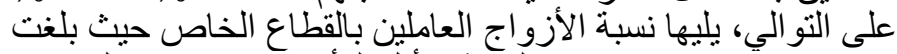

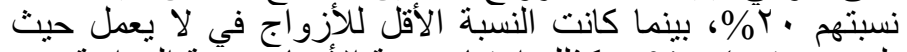

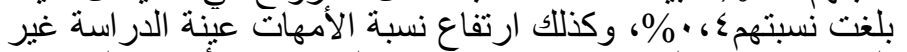

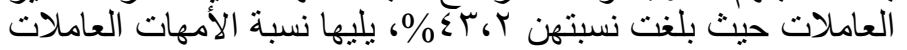

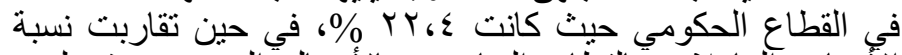

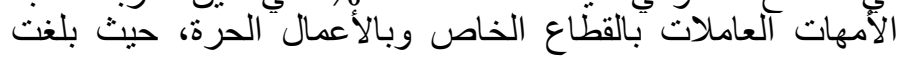




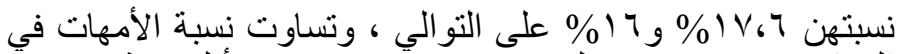

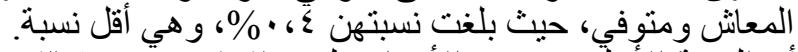

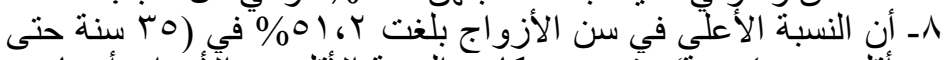

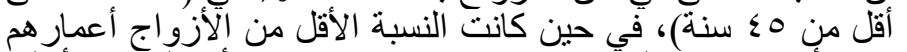

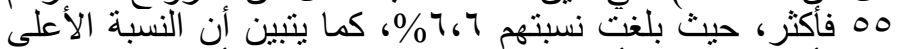

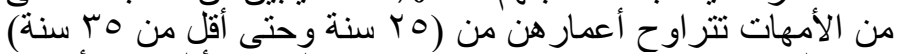

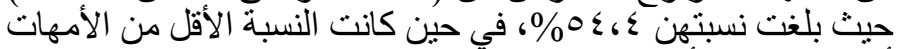

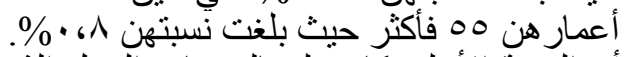

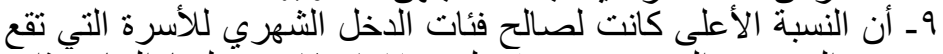

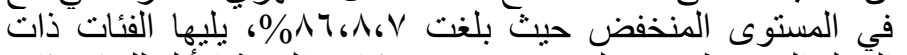

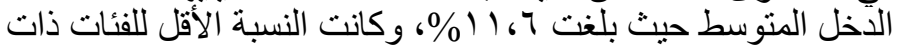

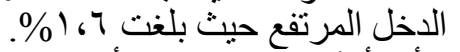

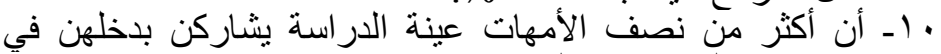

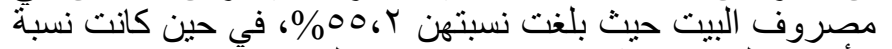

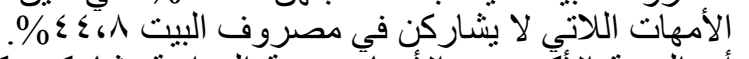

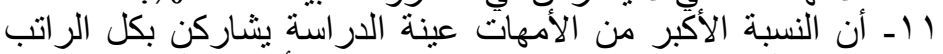

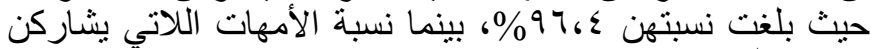

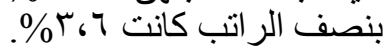

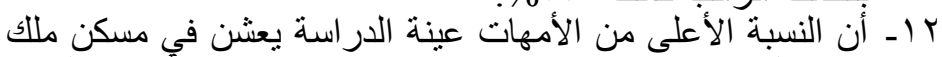

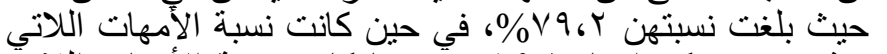

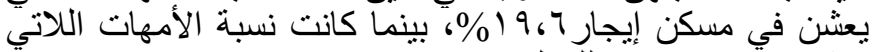

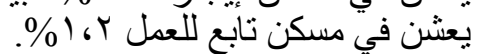

\begin{tabular}{|c|c|c|c|c|c|}
\hline المئنيةية & العدد & المتغيز & المئسيةية & 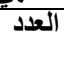 & المتغيز \\
\hline \multicolumn{3}{|c|}{ با ب - نوع الاعاقة } & \multicolumn{3}{|c|}{ 1 - جنس المعاقي } \\
\hline $0 \wedge, \cdot$ & $1 \leqslant 0$ & كلية & 07,1 & $T \leqslant Y$ & ذكر \\
\hline$\varepsilon r, \cdot$ & 1.0 & جزئية & $\varepsilon T_{6} T$ & 1.1 & أنثى \\
\hline $1 \cdots, \cdot$ & To. & 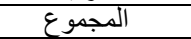 & $1 \cdots \cdot \cdot$ & ro. & المجموع \\
\hline \multicolumn{3}{|c|}{ ـ ــ المرحلة التعليمية للمعاقِ } & \multicolumn{3}{|c|}{ لــ ترتيب المعاق بين اخوته } \\
\hline T.5 & $\Gamma$ & حضانة او كي جي & $\sum \Gamma, 7$ & 1.9 & الاول - الاول \\
\hline T\%، & 91 & ابتدائي & $1 \pi, 7$ & $\Gamma \varepsilon$ & الاخير \\
\hline$\xi \cdot ، \wedge$ & $1 . \mathrm{T}$ & إعدادي & T.T & $T$ & 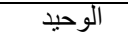 \\
\hline Y1.7 & $\leqslant 0$ & 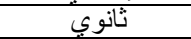 & 51,7 & $1 \cdot \varepsilon$ & ما دون ذللك \\
\hline $1 \cdots \cdot$ & TO. & المجموع & $1 \cdots \cdot$ & ro. & المجموع \\
\hline
\end{tabular}




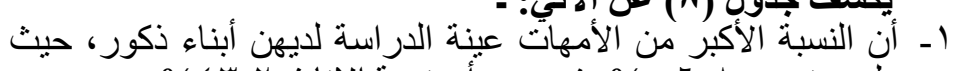

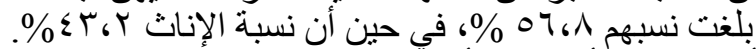

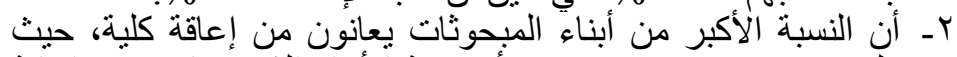

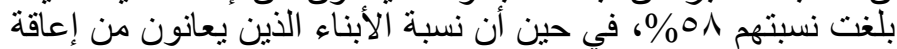
جزئية بلغت الخبته

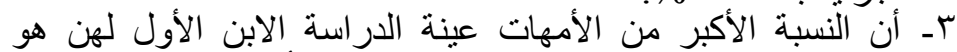

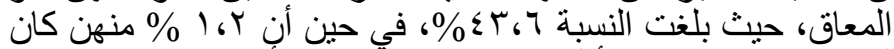

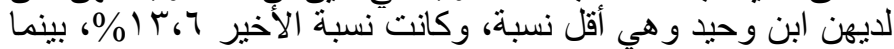

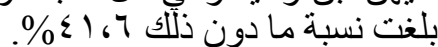

ـ- أن ^، • ـ

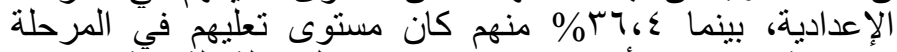

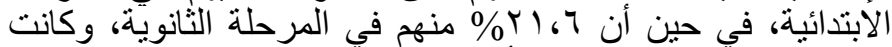

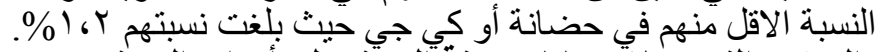

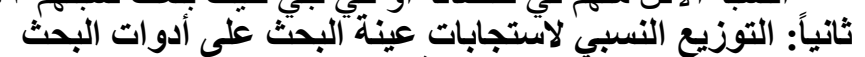

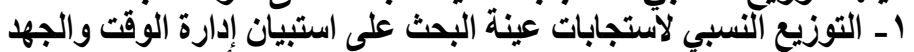

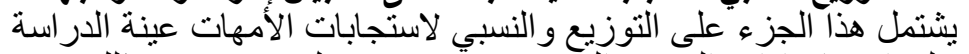

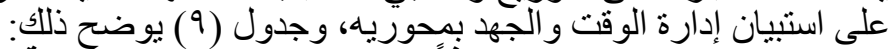

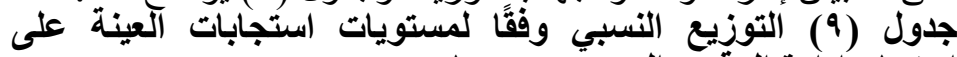

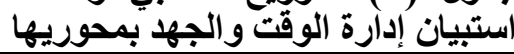

\begin{tabular}{|c|c|c|c|c|c|c|}
\hline \multicolumn{2}{|c|}{ المستوى المرتفع } & \multicolumn{2}{|c|}{ المستوى المتوسط } & \multicolumn{2}{|c|}{ المستوى المنخفض } & \\
\hline$\%$ & العدد & $\%$ & العدد & $\%$ & العدد & \\
\hline rq, r & Vr & $\varepsilon V_{6} 7$ & 119 & MYG & $0 \wedge$ & إدارة الوقت \\
\hline YO,Y & $4 \pi$ & $\Delta \Lambda_{6} \Lambda$ & $1 \leqslant V$ & 176 & $\varepsilon \cdot$ & إدارة الجهـ \\
\hline 10,7 & rq & $\Delta 0_{G} Y$ & $1 \% 1$ & Y9. Y & $V^{r}$ & الوقتبيان والجهارة \\
\hline
\end{tabular}

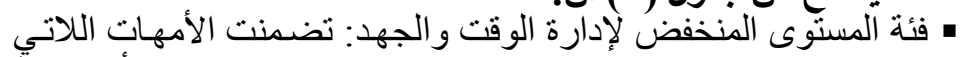

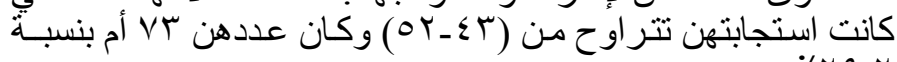
\% $\%, r$

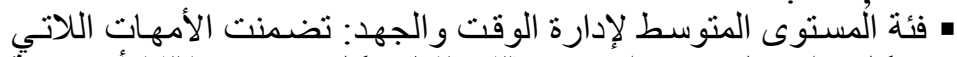

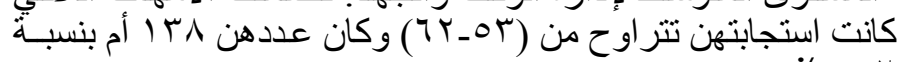
$\% 006 \mathrm{Y}$ 
مجلة الاقتصاد المنزلي - مجلد · r - العدد (ع) • r • م م

• فئة المستوى المرتفع لإدارة الوقت و الجهد: تضمنت الأمهات اللاتي

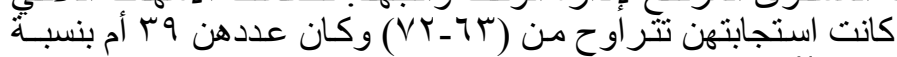
\% 10.7 ץ- التوزيـع النسبـي لاسـتجابات عينة الاراسـة على استبيان مواجهة الضـغوط الحياتية: يشتنمل هذا الجزء على على التوزيع والنسبي لاستجابات عينة الدراسة

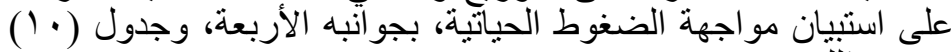
يوضتح ذلك:

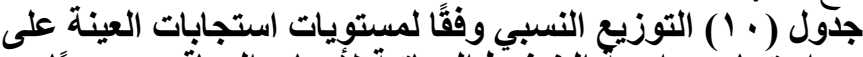

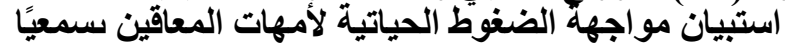

\begin{tabular}{|c|c|c|c|c|c|c|}
\hline \multicolumn{2}{|c|}{ المستوى المرتفع } & \multicolumn{2}{|c|}{ المستوى المتوسط } & \multicolumn{2}{|c|}{ المنخفتوى } & \\
\hline$\%$ & العدد & $\%$ & العدد & $\%$ & العدد & \\
\hline $1 \Lambda_{6} \varepsilon$ & $\varepsilon 7$ & 7967 & IVT & Ylas & $M$ & الاجتماعية \\
\hline 11,5 & $r \wedge$ & $V 76$. & 19. & 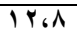 & Mr & تفعيل الأات \\
\hline$\leqslant T, 7$ & 1.9 & $\varepsilon Y_{6} \varepsilon$ & 1.7 & $1 \leq 6$ & ro & الإرشاد التفسي \\
\hline$\sum Y_{6} \cdot$ & 1.0 & $\sum 0, Y$ & 114 & $Y 1, \Lambda$ & ru & التقبل \\
\hline $1 \cdot 62$ & YY & $7 \varepsilon 68$ & 171 & YO, & $7 r$ & الضنتيان مواجهة الضياتة \\
\hline
\end{tabular}

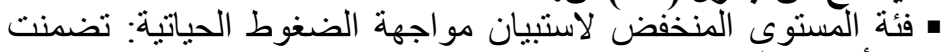

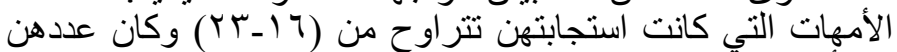

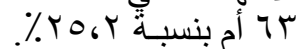

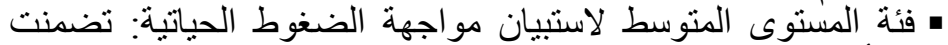

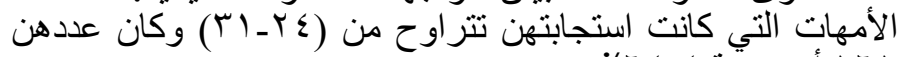

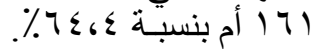

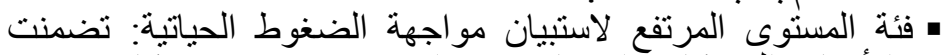

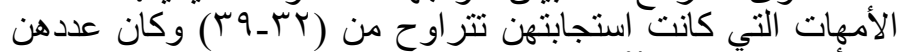

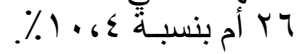

ثالثثاً: النتائج في ضوع فروض البحث يتضمن هذا الجزء فئناء فتائج الأراسة الميدانية التي أجريت على عينة

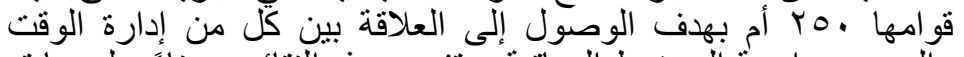

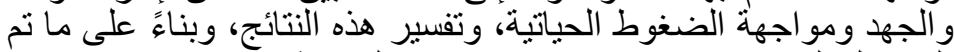

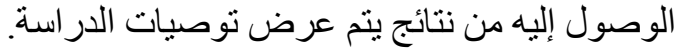


مجلة الاقتصاد المنزلي - مجلد · r - العدد (ع) • r • r م

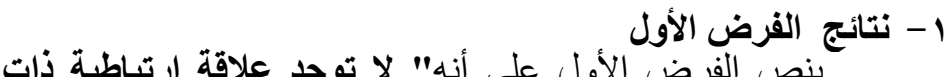

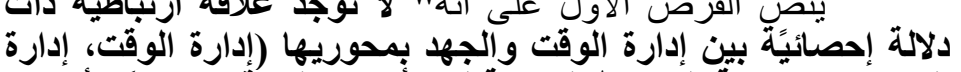

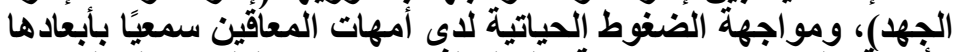

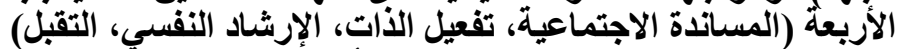

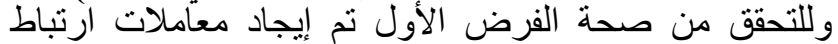

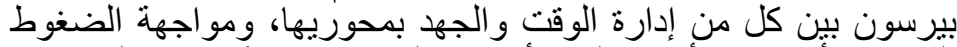

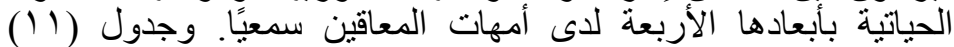
بوضح ذلك:

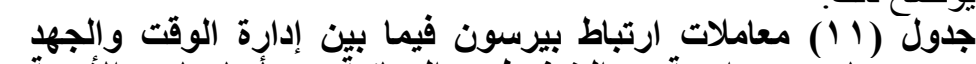

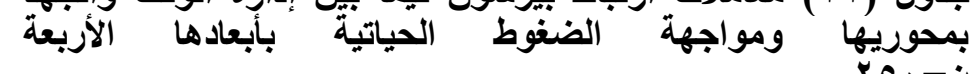

\begin{tabular}{|c|c|c|c|c|c|}
\hline اجمالي مواجهة & التقبل & الإرشسي & تلفعيل & الاجتماعية & المتغيرات \\
\hline **. . & $* *$, $6 \leqslant \vee \leqslant$ & $* *, 01 \leqslant$ & $* * ., 01 \leqslant$ & $* *, ، \leqslant 0 \leqslant$ & إدارة الوقُت \\
\hline$* * .071$ & **., Y & $* * .094$ & **.6\%7 & $* *, ، \varepsilon \Psi \varepsilon$ & إدارة الجها \\
\hline$* * ., v \cdot 1$ & $* * .6 \leqslant \leqslant V$ & $* *$. . Tะ। & $* * ., \Delta Y$. & $* * ., 011$ & الوقمالي إدارة \\
\hline
\end{tabular}

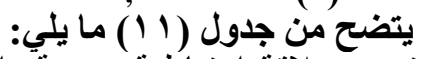

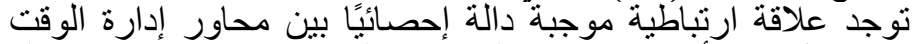

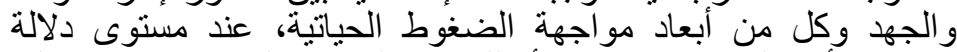

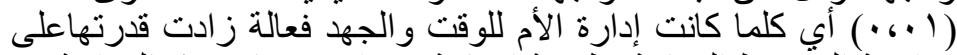

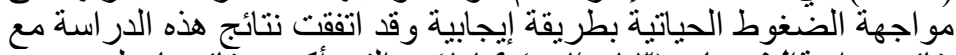

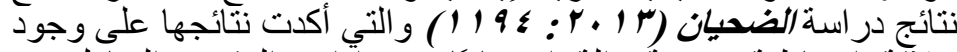

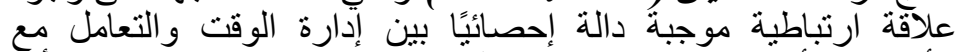

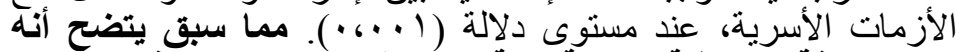

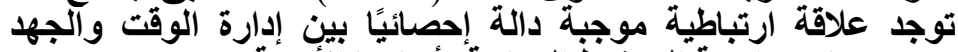

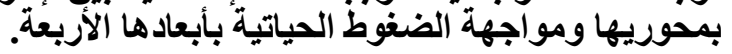

r - نتائج الفرض الثاني

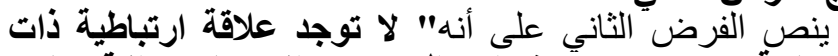

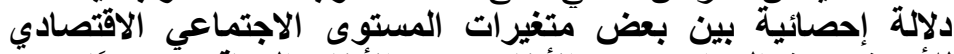

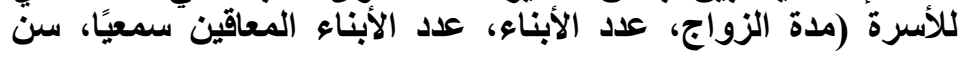




$$
\text { مجلة الاقتصاد المنزلي - مجلد · r - العدد (؟) • ب • م م }
$$

الزوج، سن الزوجة، فئات الاخل الشهري للأسرة، المستوى التعليمي

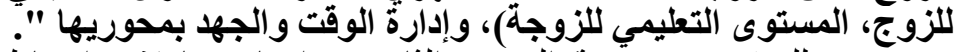

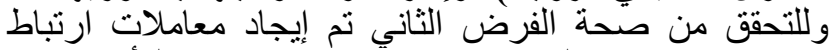

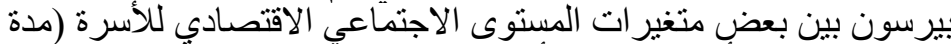

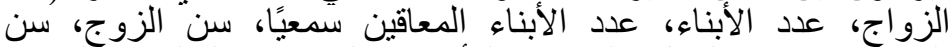

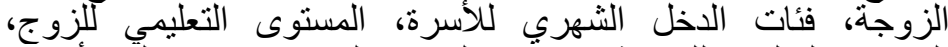

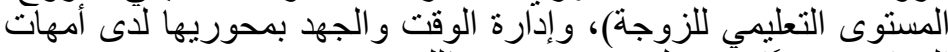

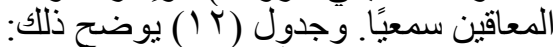

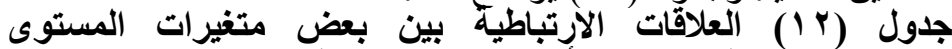

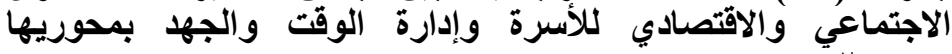

\begin{tabular}{|c|c|c|c|}
\hline الوقتالي إدارة & إدارة الجهر & الدارةت & المحاور \\
\hline .694 & $.61 \leq$ & $* .61 \% 4$ & مدة الزواج \\
\hline .6 .70 & $\cdots \cdots 7$ & $.61 \ldots$ & عدد الابناء \\
\hline ...r. & . . $\leq \leqslant \leq-$ & $.6 \wedge 4$ & عدد الأبناء المعاقين سمعيًا \\
\hline $.6 \cdot 74$ & $\because 6 \vee v 0$ & $.6+47$ & سن الزوج \\
\hline$* * .6119$ & $\cdots \vee V \wedge$ &., $1 Y T$ & سن الزوجة \\
\hline$* *, r \mu \wedge$ &, 110 & $* *, r, q$ & فئات الاخل الشهري \\
\hline$* *, Y Y O$ & $* *, Y Y Y$ & $* *, 170$ & المستوى التعليمي للزوج \\
\hline$* *, r, r$ & $* *, \mid \vee \wedge$ & $* *,|V|$ & المستوى التعليمي للزوجة \\
\hline
\end{tabular}

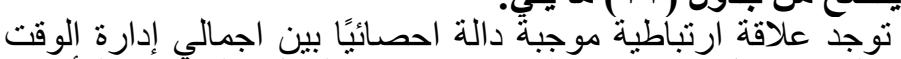

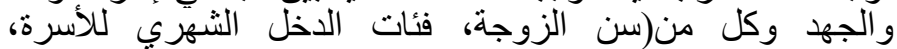

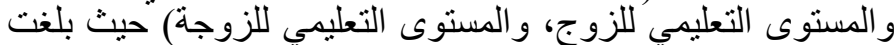

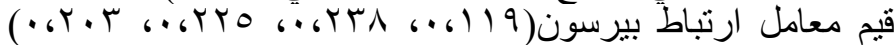

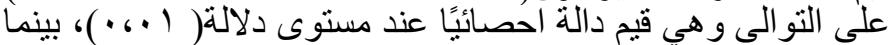

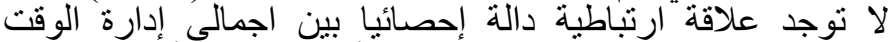

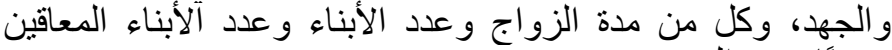

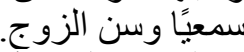

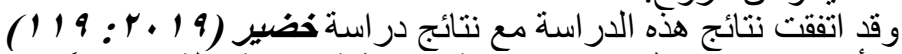

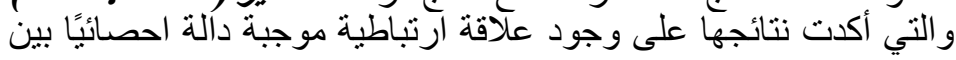




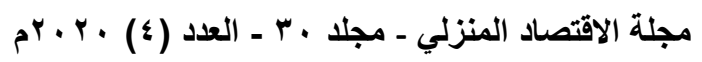

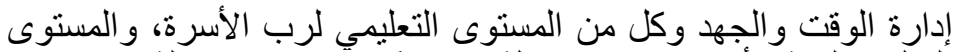

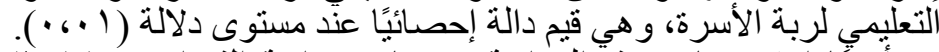

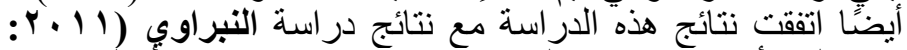
و Y \& V

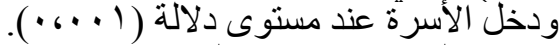

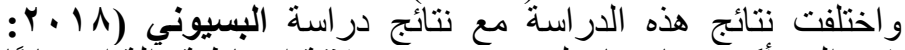

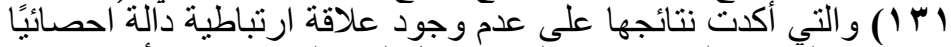

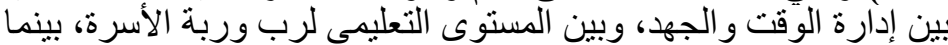

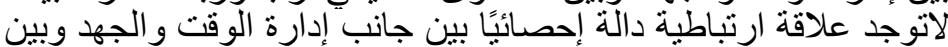
سن ربة الأسرة، فئات الدخل الثة الثهري للأسرة

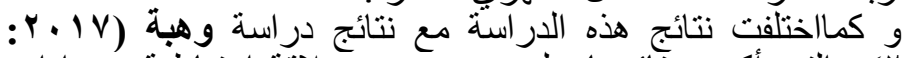

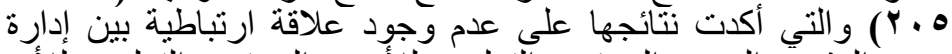

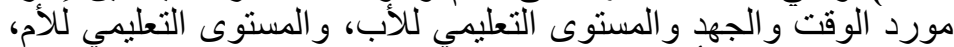

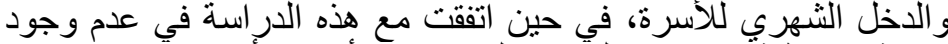
علاقة ارتباطية بين إدارة الوقت ولتي والجهد و عدد أفر اد الأسرة.

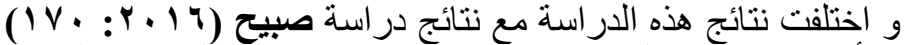

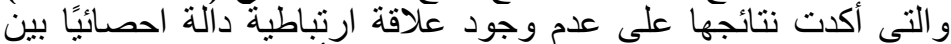
مهارة" إدارة الوقت و الجهد ولته والمستوى التعليمي للأم.

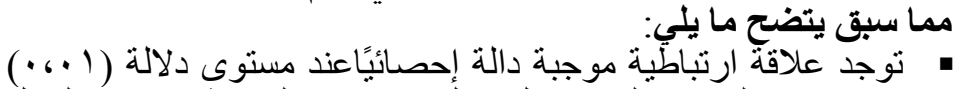

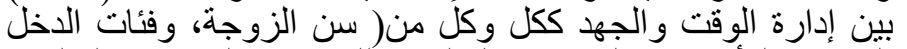

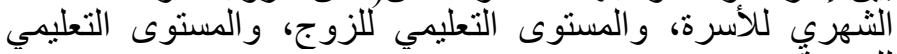
للازوجة).

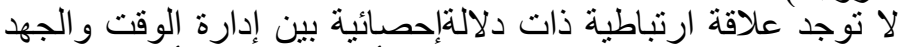

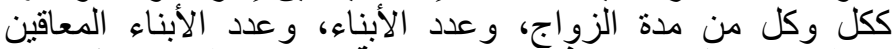

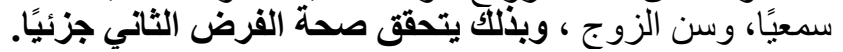

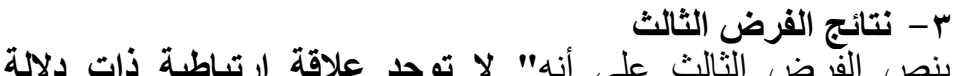

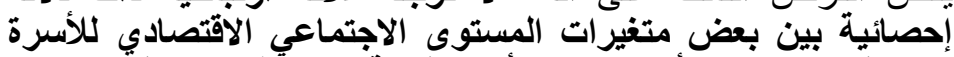

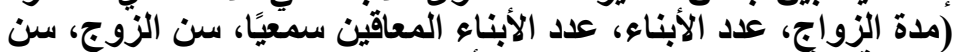

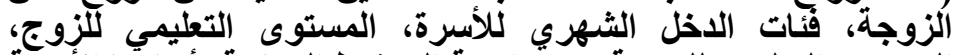

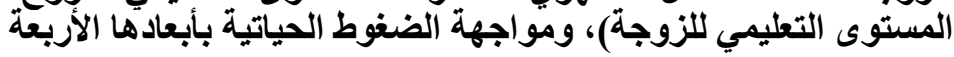


مجلة الاقتصاد المنزلي - مجلد · r - العدد (ع) • r • ب م

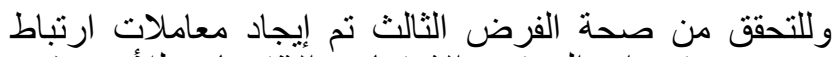

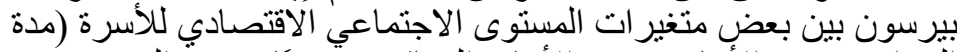

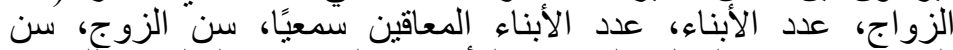

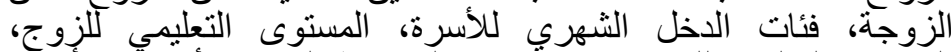

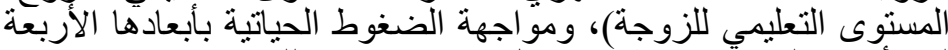

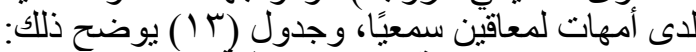

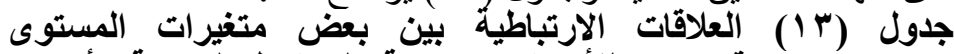
الاجتماعي والاقتصادي للأسرة ومواجهة الأبهابة الضغوط الحياتية بأبعادها

\begin{tabular}{|c|c|c|c|c|c|}
\hline الضمالي مواجهة & التثبل & الإرشاد & تفعيل & الاجتماعية & \\
\hline$\cdots v V$ & $\cdots \ldots$ & $.6 .17-$ & $.6 V_{-}$ & .61 .5 & مدة الزواج \\
\hline$\cdot ., Y r$ & $* .6199$ & $.6 .+4-$ &..$+r$ & $\cdot 6 \leqslant V_{-}$ & عدد الأبناء \\
\hline$\ldots .0_{-}$ & $\cdot 6 \leqslant \wedge$ & $\cdot \ldots \wedge Y_{-}$ & .694 & .6 .40 & عدد الأبناء المعاقين سمعيًا \\
\hline $.6+4 \leq$ & $\cdot 6 \cdot V \cdot=$ & $.61 Y_{-}$ & $.6 \times 1-$ & $\cdot 6 \leq 1$ & سن الزوج \\
\hline $.6 .9 \leq$ & .60 & *. . 1 ro & .671 & $.6 \wedge r$ & سن الزوجة \\
\hline$* * .6174$ & $\cdots \leq 0$ & $* * \cdot G \cdot Y$ &, $1 \cdot 7$ & $*, \cdot 61 \% q$ & فئات الاخل الثهري \\
\hline$* *, r, Y \cdot r$ & .6 .40 & $* *$. ، Y & .6 .19 & $* *, \cdot, r \cdot r$ & المستوى التعليمي للزوج \\
\hline$* * ., I V Y$ & $.6 \cdot r r$ & ** , , YYO & $.61 \cdot r$ & $* ., 1 \leq r$ & المستوى التعليمي للزوجة \\
\hline
\end{tabular}

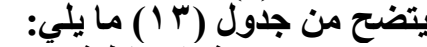

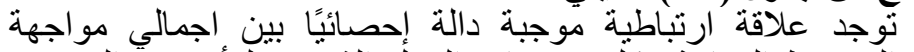

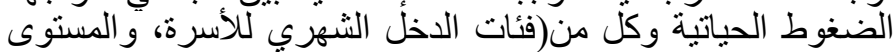

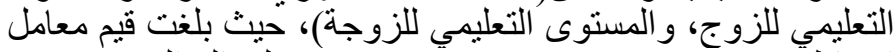

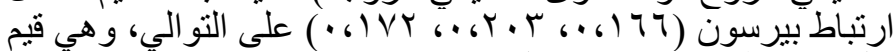

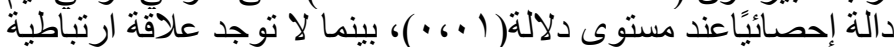

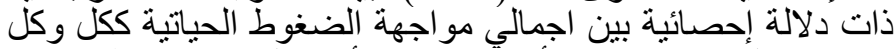

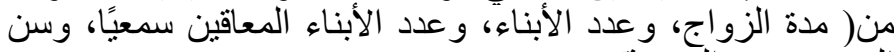

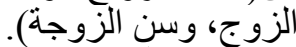

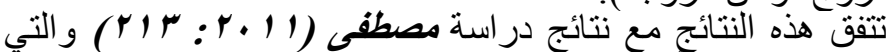

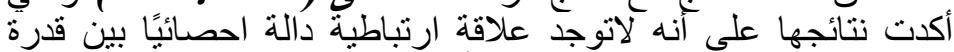

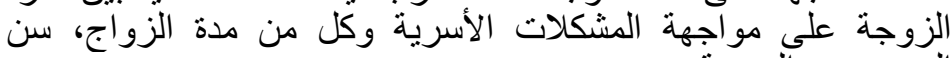
الزوج، سن الزوجة ملنة 


$$
\text { مجلة الاقتصاد المنزلي - مجلد · ب - العدد (؟) • ب • م م }
$$

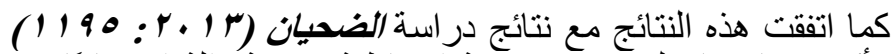

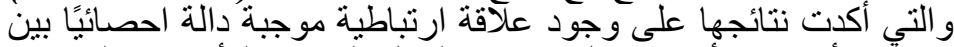

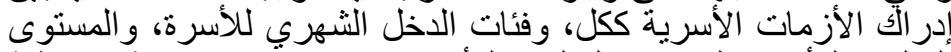

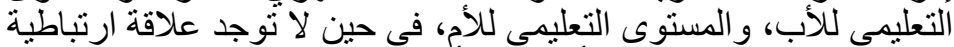

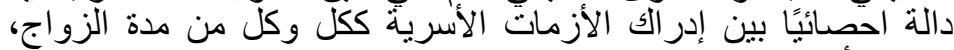
و وعدد الأبناء.

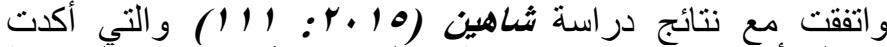

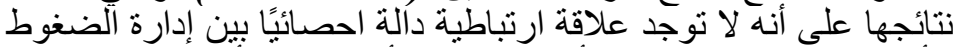

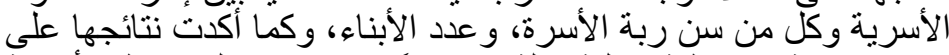

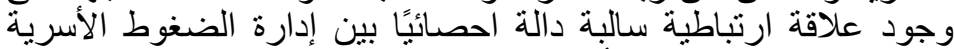
و وإجمالي الاخل الثهري للأسرة.

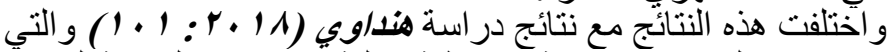

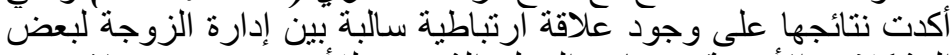

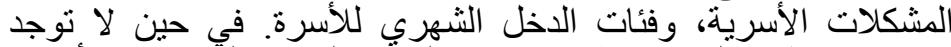

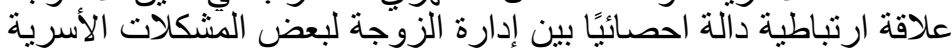

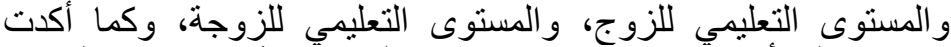

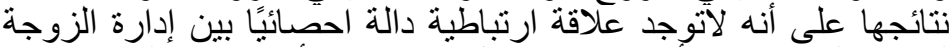

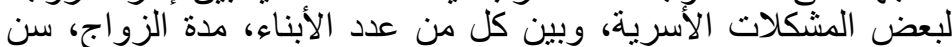

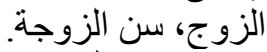

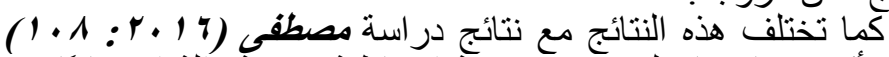

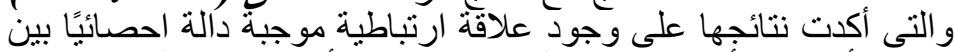

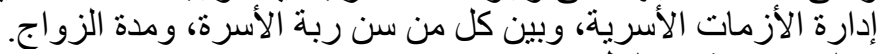

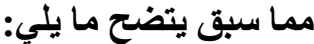

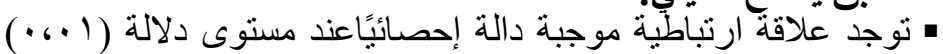

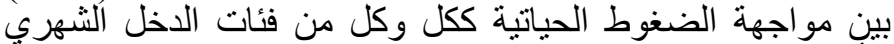

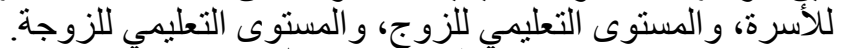

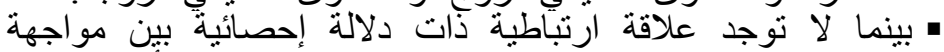

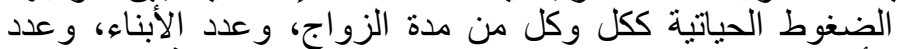

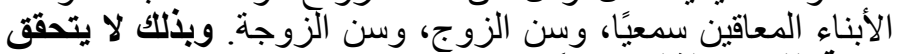
صحة الفرض الفئاء الثالث جزئيًا.

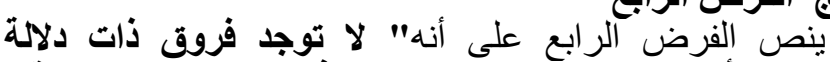
ع - نتائج الفرض الفرض الرابع جزئ

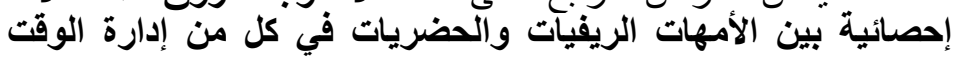


مجلة الاقتصاد المنزلي - مجلد · r - العدد (ع) • r • ب م

والجها بمحوريها، ومواجهة الضغوط الحياتية لاى أمهات المعاقين

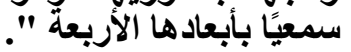

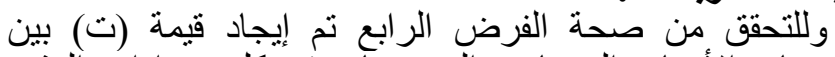

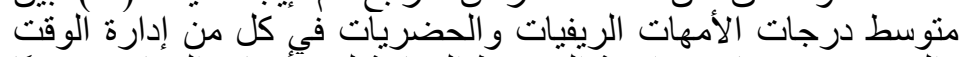

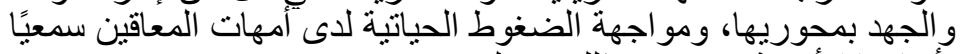

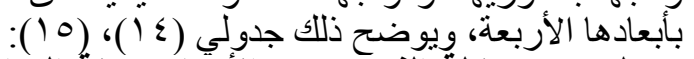

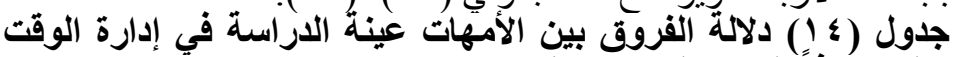

\begin{tabular}{|c|c|c|c|c|c|c|c|}
\hline \multirow{2}{*}{ مستوي } & \multirow[b]{2}{*}{ قيمة ت } & \multirow[b]{2}{*}{ المتوسط بين } & \multicolumn{2}{|c|}{ حضريات ن= IVV } & \multicolumn{2}{|c|}{ ريفيات ن= } & ان \\
\hline & & & الانحرياري & المستوسطي & الالمعياري افـ & المستوسطي & \\
\hline 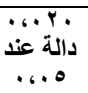 & $Y, r \leq 1-$ & 1.945 & $7, Y r$ & $7 \cdot 6.1$ & $7 . V Y$ & $\left.0 \Lambda_{6}\right)_{0}$ & إدارة الوقت \\
\hline 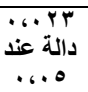 & Y,YqE_ & 1 16 78 & $\varepsilon .99$ & Or.VV & 7.18 & 01,14 & إدارة الجهد \\
\hline 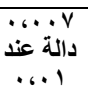 & r.VIr- & $r_{6} \circ V_{-}$ & $9.1 \mathrm{~V}$ & $11 r_{6} \Lambda_{0}$ & سr, 11 & $1.96 \% 1$ & والوقي إدارة \\
\hline
\end{tabular}

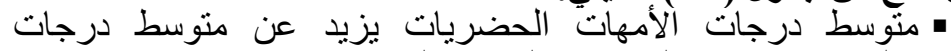

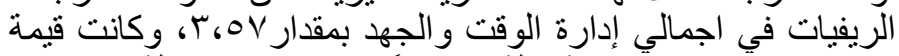

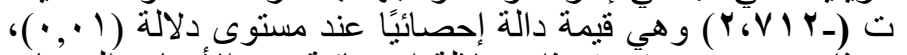

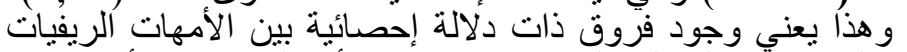

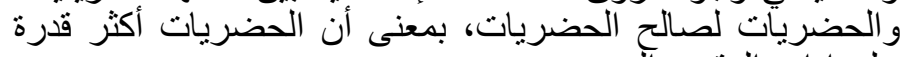

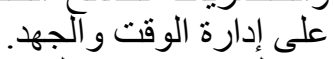

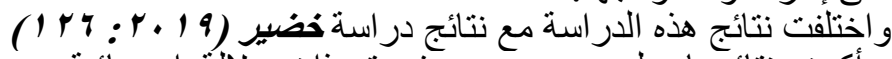

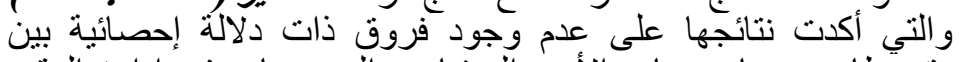

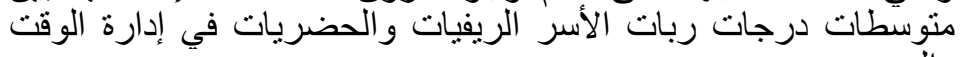

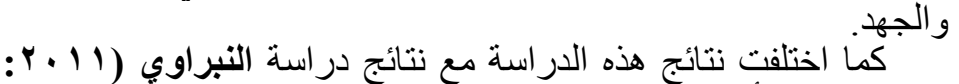

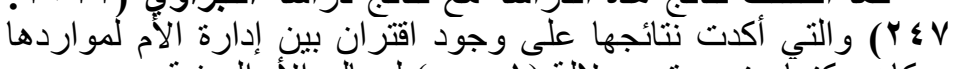

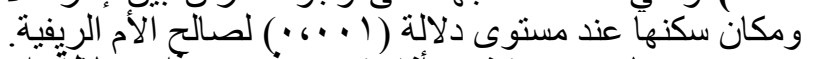

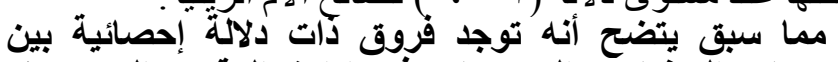

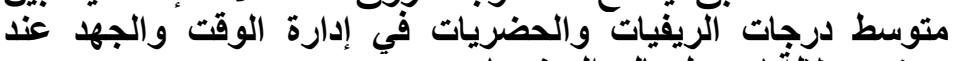

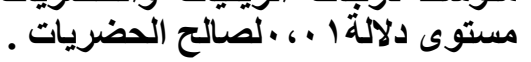


مجلة الاقتصاد المنزلي - مجلد · r - العدد (ع) • r • r م

جدول (10) دلالة الفروق بين الأمهات عينة الدراسة في مواجهة الضغوط (الحياتية وفقًا لمكان السكن (ريف الفرو - حضر)

\begin{tabular}{|c|c|c|c|c|c|c|c|}
\hline \multirow{2}{*}{ مستوى الالالة } & \multirow{2}{*}{ قيمة ت } & \multirow{2}{*}{ المتروق بين } & \multicolumn{2}{|c|}{ حضريات ن = V V } & \multicolumn{2}{|c|}{ ريفيات ن = س } & \\
\hline & & & الاتحراف المعياري & المتوسط & الانحراف المعياري & المستوسطي & \\
\hline غير دالة دالة & _ס & $\cdot \sigma V Y_{-}$ & $\varepsilon 6.0$ & $r$ r.Ar & $\leqslant 6 \leqslant V$ & 1,11 & الاجتماعية \\
\hline غيز دالة + ، & $1 ، \wedge \wedge$. & • ‘یr & MGr & ro, & rov. & M. & تفعيل الذات \\
\hline 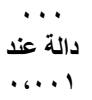 & $r_{6} 0 \leq \Lambda_{-}$ & $r_{6} \wedge \theta_{-}$ & $0, \leqslant 0$ & $\varepsilon .67 q$ & 0.97 & rv,vI & الإرشاد النفسي \\
\hline 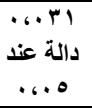 & r.IVY & $1,4 \leq$ & $\varepsilon 6 V$. & $\varepsilon ., 0$. & $0_{6} \ldots$ & $\leq 1,1 \leq$ & التقبل \\
\hline غير دالة، & . & $1,1 \mathrm{H}$ & $1+6,01$ & $1 \leq \Lambda_{6} \leqslant V$ & $1 \leq ، \wedge \wedge$ & $\begin{array}{c}1 \leq V_{6} r \\
\varepsilon\end{array}$ & الضمالي مواجهة الحياتية \\
\hline
\end{tabular}

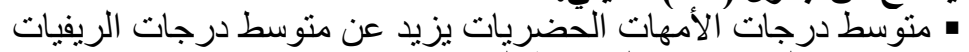

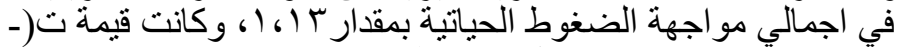

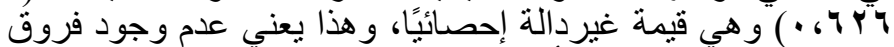

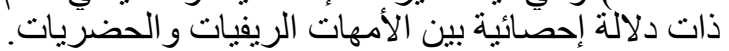

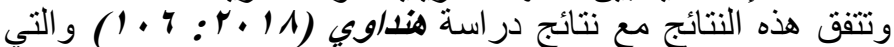

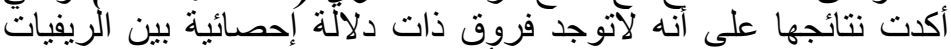

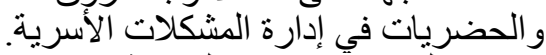

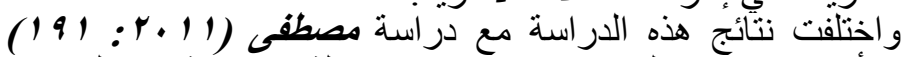

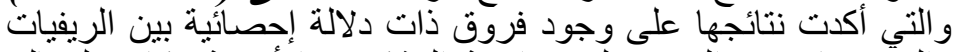

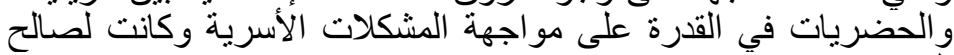

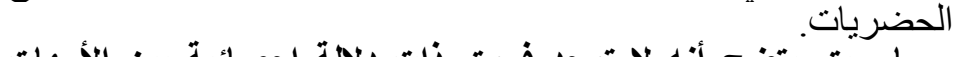
مما سبث يتضح أنه لا توجد فروق ذات دلاتة إحصائية بين الأمهات

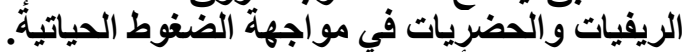
مما سبق يتضح أنها: 


$$
\text { مجلة الاقتصاد المنزلي - مجلد · r - العدد (؟) • ب • م م }
$$

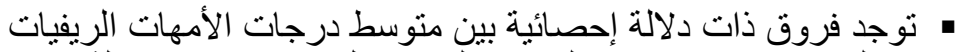

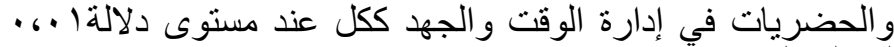

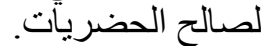
• لا توجد فروق ذات دلالة إحصائية بين متوسط درجات الأمهات

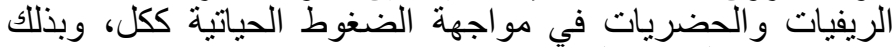

بتحقق صحة الفرض الرضات ابع جزئيًا.

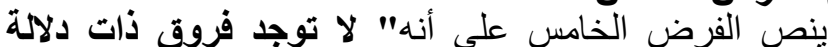

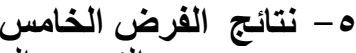

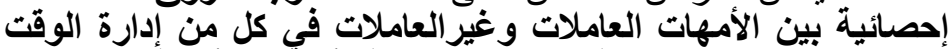

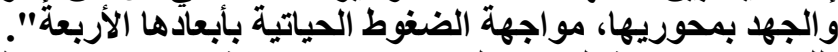

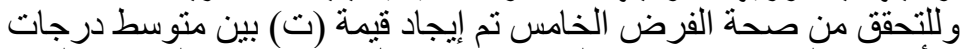

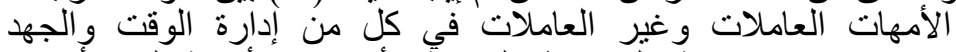

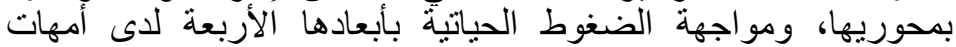

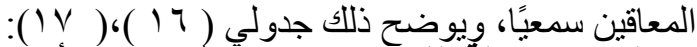

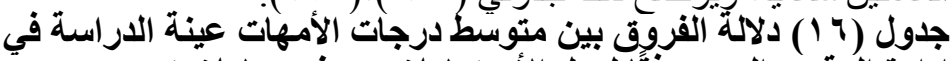

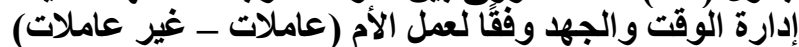

\begin{tabular}{|c|c|c|c|c|c|c|c|}
\hline \multirow[b]{2}{*}{ مستوى الدلالة } & \multirow[b]{2}{*}{ قيمة ت } & \multirow[b]{2}{*}{ المترسطات بين } & \multicolumn{2}{|c|}{ عاملات ن= = ؛ } & \multicolumn{2}{|c|}{ غير عاملات ن=1 + 1 } & \multirow[t]{2}{*}{ البيان } \\
\hline & & & الانحراف & المستوسطي & الأنحراف & الحستوسط الحبي & \\
\hline غير دالة إن & $Y_{6} \leq V T_{-}$ & $r_{6} . \theta_{-}$ & $7 ، \leqslant$ & $09,9 \leq$ & 7,00 & $0 \vee / \wedge q$ & إدارة الوقت \\
\hline 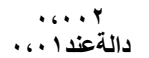 & 1.191- & Y, YN- & $\theta_{6} \Lambda$. & Or،八A & O, $\mu$. & 0.67. & إدارة الذ \\
\hline 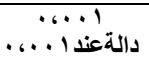 & r.rAV- & E, & $1.6 \mathrm{YV}$ & IIYGAY & 1. & $1 \cdot 1 . \leqslant 89$ & الجمقالّي إدارة \\
\hline
\end{tabular}

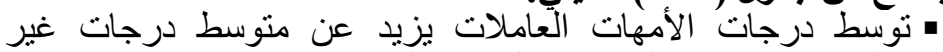

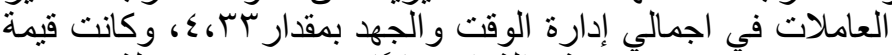

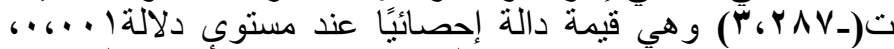

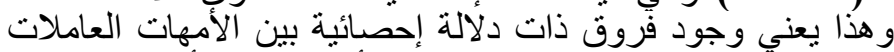

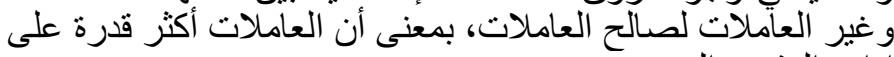

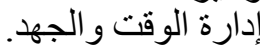

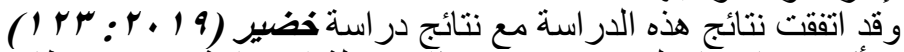

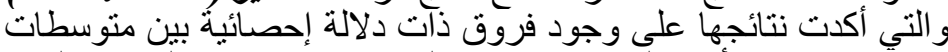

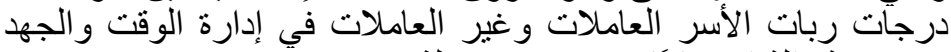

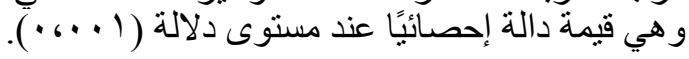


مجلة الاقتصاد المنزلي - مجلد · r - العدد (ع) • r • r م

وقد يرجع ذلك إلى أن خروج الأم للعمل خارج المنزل جعلها تواجه

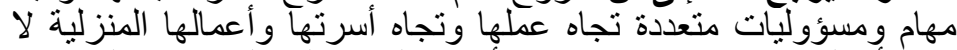

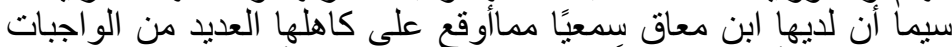

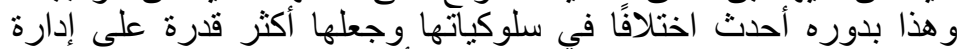

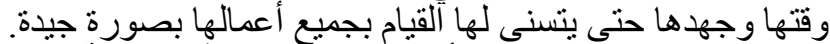

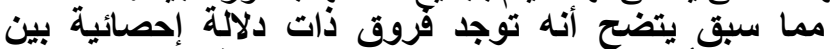

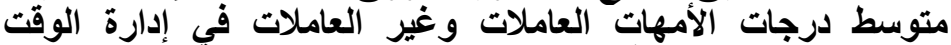

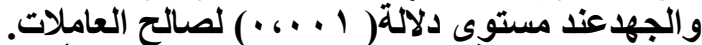

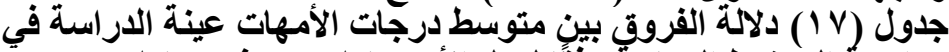

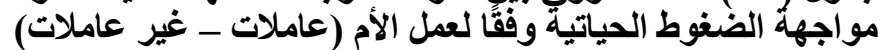

\begin{tabular}{|c|c|c|c|c|c|c|c|}
\hline \multirow[b]{2}{*}{ مستوي الالالة } & \multirow[b]{2}{*}{ قيمة ت } & \multirow{2}{*}{ المترق بين } & \multicolumn{2}{|c|}{ عاملات ن= = 1 = } & \multicolumn{2}{|c|}{ 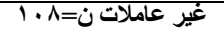 } & \multirow{2}{*}{ البيان } \\
\hline & & & الالمعياري افي & المستابي الحسب & الالنحرياري & الحستابي & \\
\hline 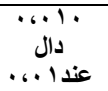 & $r_{6} \circ 9 \cdot-$ & 16. & r.07 & $r_{r_{6}}, 0$ & $\varepsilon 699$ & $r .670$ & الاجتماعية \\
\hline غه هُ، دال & $.60 \wedge 7_{-}$ & . . & ( & rq، & $r . v r$ & Mq، & تفعيل الذات \\
\hline |.... & $0, Y \bullet V_{-}$ & ror & 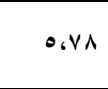 & $\leq \cdot, 0 \leqslant$ & $0, Y \wedge$ & ry. & الإرشاد النفسي \\
\hline 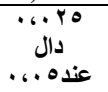 & r, ror & 1699 & $\varepsilon, H$. & 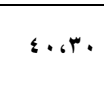 & 0,01 & $\leqslant r_{6} \ldots$ & التقبل \\
\hline 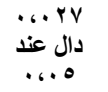 & YGYY.- & $\{6$. & $1+\cdot 601$ & $1 \leq 967$. & $1 \leq 69$. & $1 \leq 0,09$ & \\
\hline
\end{tabular}

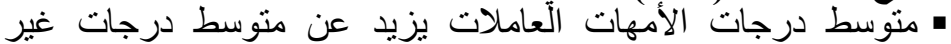

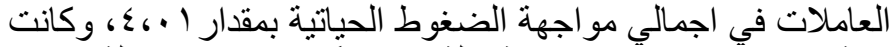

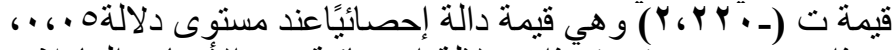

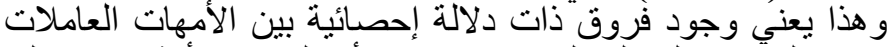

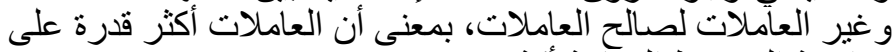

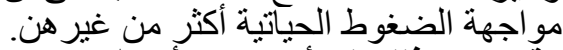

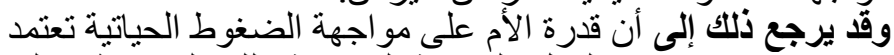

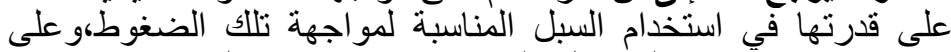

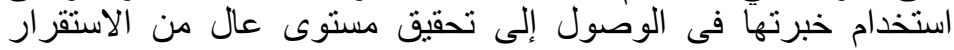




$$
\text { مجلة الاقتصاد المنزلي - مجلد · ب - العدد (؟) • ب • م م }
$$

الأسري، فنجد أن عملها أضاف إليها العديد من تللك الخبرات مما إكا

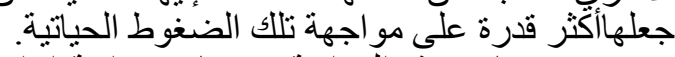

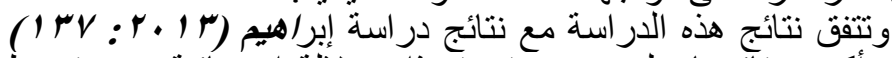

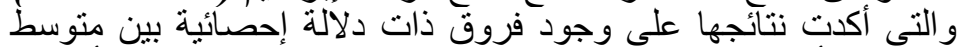

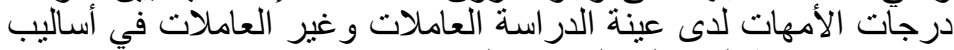

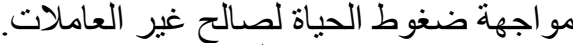

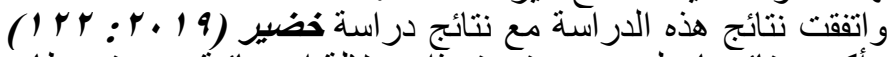

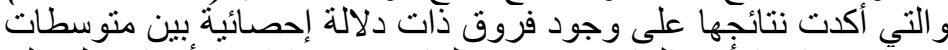

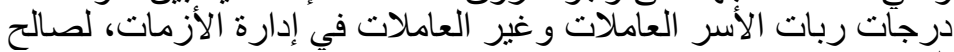

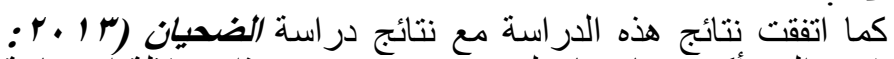

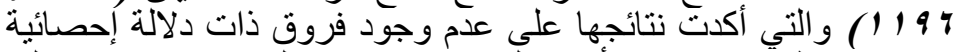

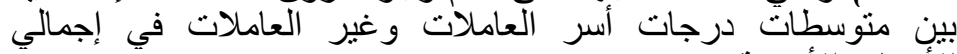
الأزين مات الأسرية.

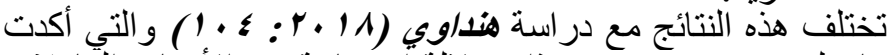

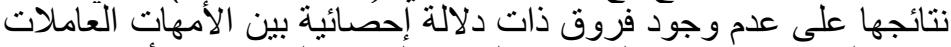

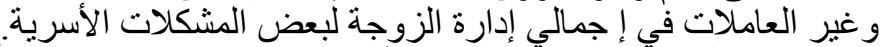

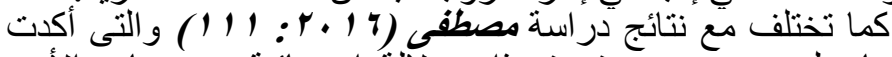

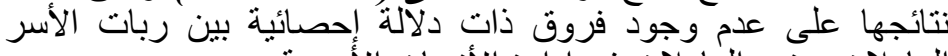

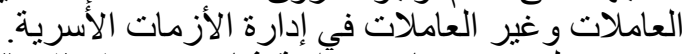

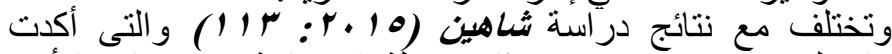

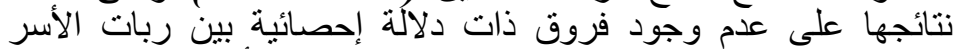

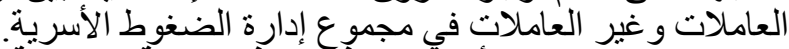

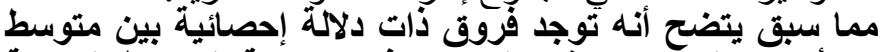

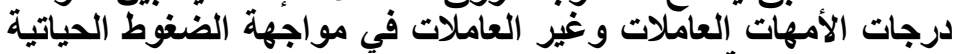

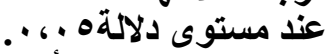

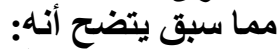

ه توجد فروق ذات دلالة إحصائية بين متوسط درجات الأمهات العاملات

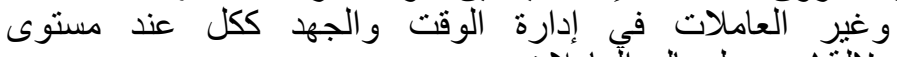

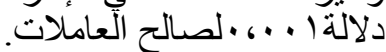

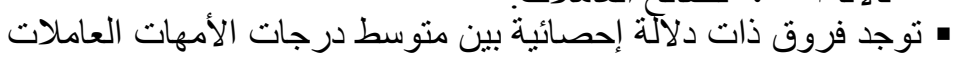

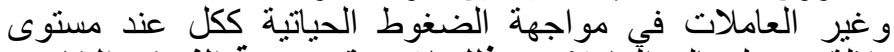

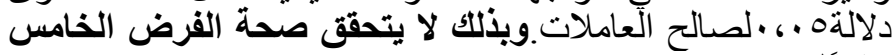


مجلة الاقتصاد المنزلي - مجلد · r - العدد (ع) • r • r م

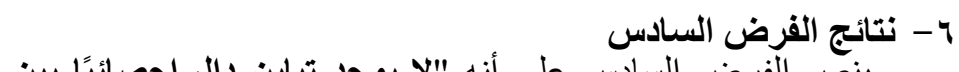

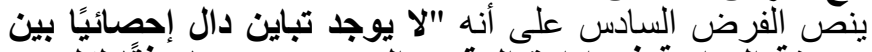

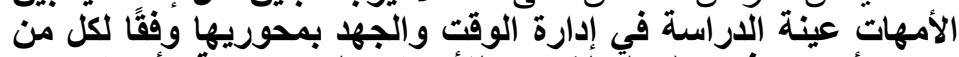

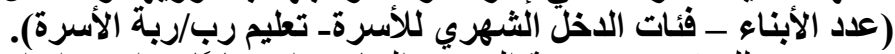

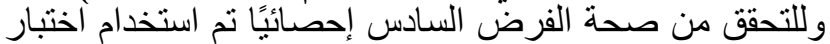

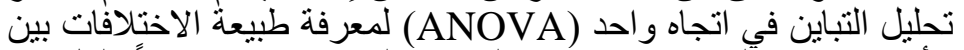

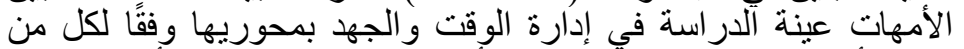

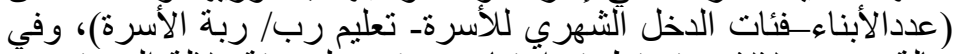

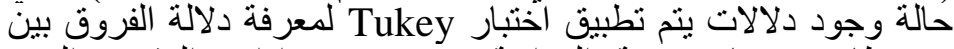

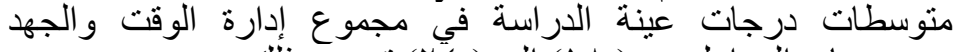

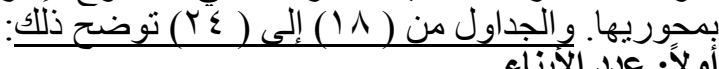
أولاً: عدور الأبناء جدول (1 الأ) تحليل التباين في اتجاه واحد لاستبيان إدارة الوقت و الجها

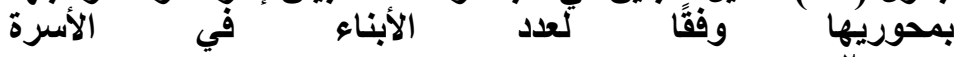

\begin{tabular}{|c|c|c|c|c|c|c|}
\hline مستوي & قيمة ف & المربعات & الحرجية & المجبعوات & مصدر التباين & \\
\hline 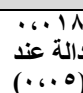 & $r_{6} \Lambda \cdot r$ & $\begin{array}{l}1196 \cdot \wedge V \\
\leqslant 16 \leqslant 11\end{array}$ & $\begin{array}{l}0 \\
r \leq \leqslant \\
r \leq 9\end{array}$ & $\begin{array}{l}0 \wedge \cdot 6 \leqslant Y V \\
1.1 .06 \wedge \wedge V \\
1.4 \wedge 4, r Y \leqslant\end{array}$ & داخل المجموعات المجات & إدارة الوقت \\
\hline غير دالة ؛ & 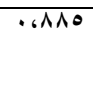 & 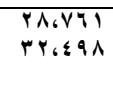 & $\begin{array}{l}0 \\
r \leq \leq \\
r \leq 9\end{array}$ & 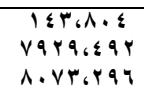 & داخلّ المجموعوعات & إدارة الجها \\
\hline غير دالة باكة & 16117 & $\begin{array}{l}\text { TYY, } \\
11.6 \% 9\end{array}$ & $\begin{array}{l}0 \\
r \leq \leqslant \\
r \leq q\end{array}$ & 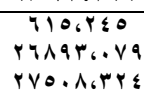 & داخلين المجموعات المجوعات & الوجتوع والجارة \\
\hline
\end{tabular}
الوقت وفُقًا لعدد الأبناء الأباء

\begin{tabular}{|c|c|c|}
\hline المتوسط الحسابي & العدد & عدد الأبناء \\
\hline $07 ، \Lambda$. & $\bullet$ & واحد \\
\hline $076 \leqslant 0$ & 01 & اثنان \\
\hline $7.61 Y$ & $1 \% 0$ & ثُلاثة \\
\hline $0 q_{6} \varepsilon$. & $\varepsilon 0$ & أربعة \\
\hline $07 . \mathrm{VA}$ & 9 & خمسة \\
\hline $7 \cdot \ldots$ & 0 & ستّة فَأكثر \\
\hline
\end{tabular}


مجلة الاقتصاد المنزلي - مجلد · r - العدد (ع) • r • r م

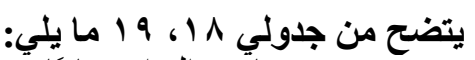

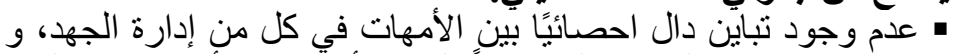

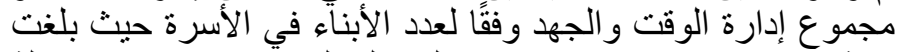

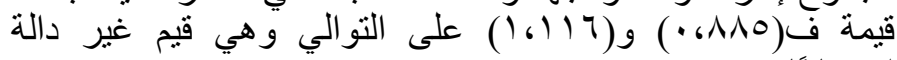

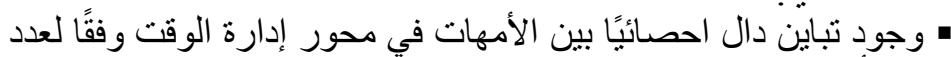

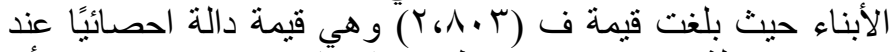

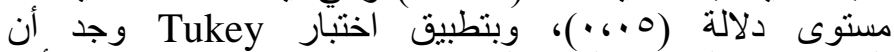

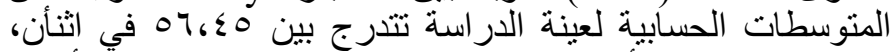
أبناه، ، VA

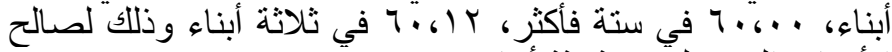
الأمهات اللاتى لديهن ثلاثنة أبناء.

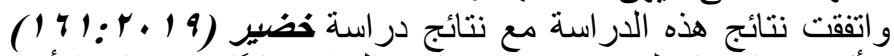

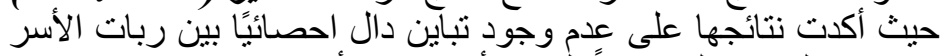

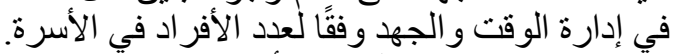

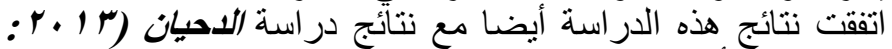

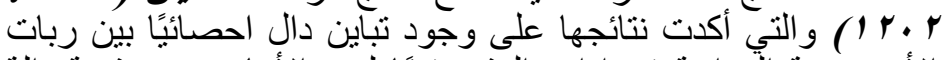

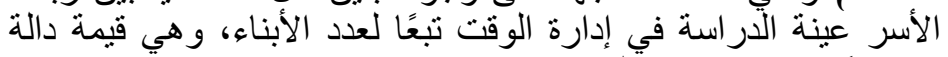

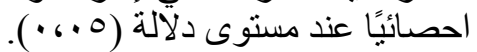

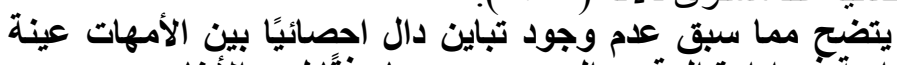

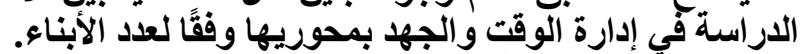

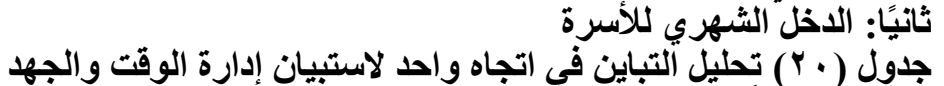

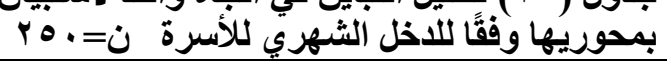

\begin{tabular}{|c|c|c|c|c|c|c|}
\hline اللالالةو & قيمة ف & متوسطات & الدرجية & مجموعت & مصدر التباين & المخدان \\
\hline غير دالة & T.9Y० & 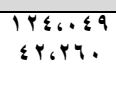 & $\begin{array}{l}r \\
r \leqslant v \\
r \leqslant q\end{array}$ & $\begin{array}{l}r \& \Lambda_{G}, q V \\
1 . \& Y_{G} Y Y Y Y\end{array}$ & داخلّ المجموعات & إدارة الوقت \\
\hline غير دالة & $1 . v \cdot 1$ & $\begin{array}{l}00600 \leqslant \\
\text { MY,Y }\end{array}$ & $\begin{array}{r}r \\
r \leq v \\
r \leq q\end{array}$ & 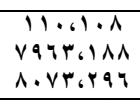 & دأخل المجموعات المجوعات & إدارة الجها \\
\hline غير دالة & .6144 & $\begin{array}{l}10,1 \mathrm{Yq} \\
111, \mathrm{r} \leqslant \mathrm{V}\end{array}$ & $\begin{array}{r}r \\
r \leqslant v \\
r \leqslant q\end{array}$ & 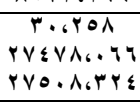 & داخلّ المجموعوعات & 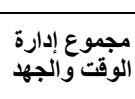 \\
\hline
\end{tabular}


مجلة الاقتصاد المنزلي - مجلد · r - العدد (ع) • r • r م

يتضح من جدول ( • ( ) ما يلي:

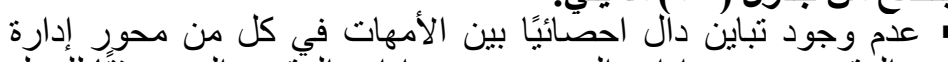

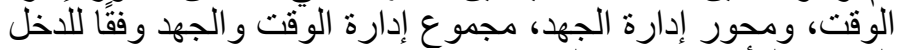

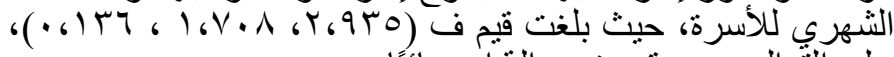

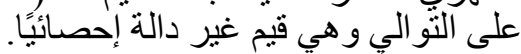

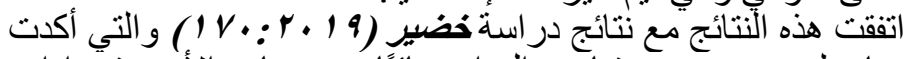

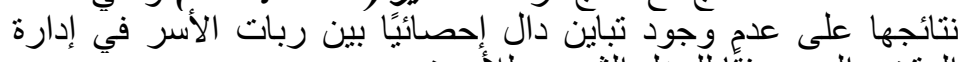

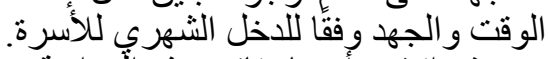

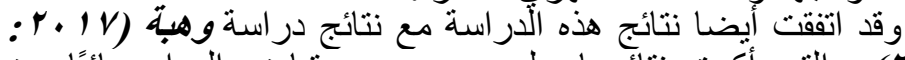

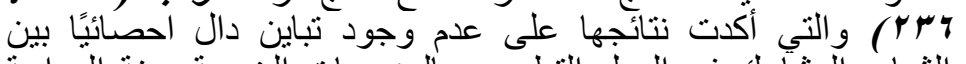

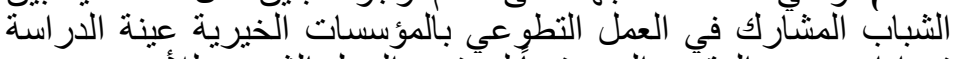

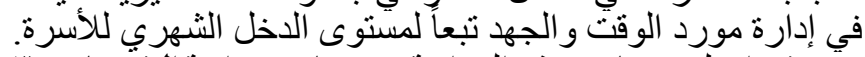

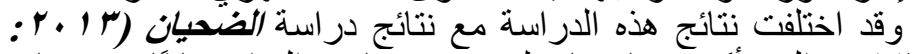

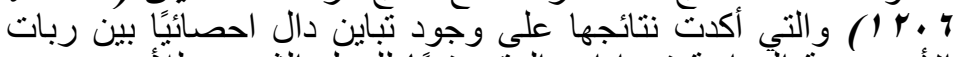

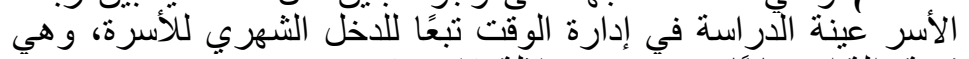

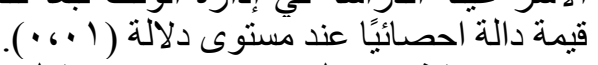

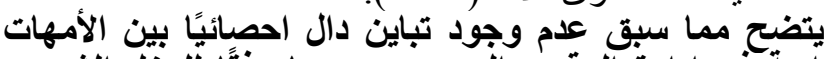

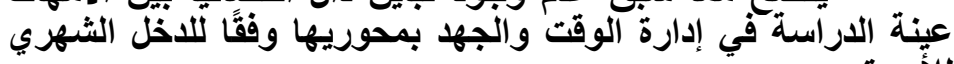

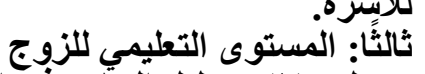

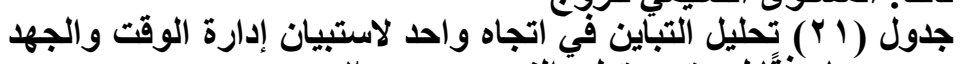

\begin{tabular}{|c|c|c|c|c|c|c|}
\hline الدالائة & قيمة ف & متوسطات & لدرجات & المربعوع & مصدر التباين & المحاوكر \\
\hline 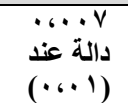 & $r_{6 .} r_{0}$ & $\begin{array}{l}\text { TYYVANV } \\
\text { \&.GQY. }\end{array}$ & $\begin{array}{l}r \\
r \leq r \\
r \leq 4 \\
r \leq q\end{array}$ & $\begin{array}{l}\text { VEYGVYY } \\
99 \leqslant Y, Y . Y \\
1 . Y \wedge \checkmark, r Y \leqslant\end{array}$ & داخل المجموعات المجوعات & الؤقت \\
\hline 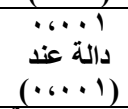 & \&617 & 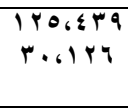 & $\begin{array}{c}r \\
r \leq r \\
r \leq 9\end{array}$ & 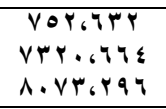 & داخل المجموعات المجلى & إدارة الجهد \\
\hline 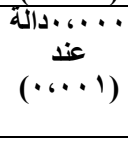 & E.V & $\begin{array}{l}\text { \&AY,AQV } \\
\text { 1.1.YA. }\end{array}$ & $\begin{array}{c}r \\
r \leq r \\
r \leq q\end{array}$ & 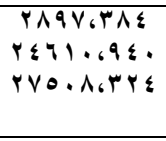 & داخل المجموعوعات & والدارةت \\
\hline
\end{tabular}




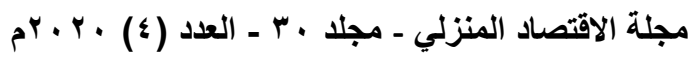

جدول (Y r المتوسطات الحسابية لارجات الأمهات على إدارة الوقت والجها

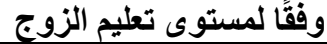

\begin{tabular}{|c|c|c|c|c|c|c|}
\hline \multicolumn{2}{|c|}{ مجموع إدارة الوقتّ } & \multicolumn{2}{|c|}{ إدارة الجهر } & \multicolumn{2}{|c|}{ إدارة الوقت } & \\
\hline الحستوسط & العدد & المسابي & العدد & الحستبطي & العدد & \\
\hline 1.8689 & $r \leq$ & $0.61 T$ & $r \varepsilon$ & $0 V_{6} 7 \mathrm{~V}$ & rs & أمي \\
\hline $1 . \Lambda_{6} \wedge \mathrm{V}$ & 10 & $0 . r r r$ & 10 & OA.Or & 10 & يقرأ ويكتب \\
\hline $1 \cdot \Lambda_{6} \wedge \mathrm{V}$ & 10 & Tr. & 10 & OV.AV & 10 & ابتأيلة على \\
\hline $1 . v_{6} 10$ & ir & $01 \ldots$ & ir & 04,10 & ir & إعدادية على \\
\hline $1.9, \mathrm{rV}$ & 1.9 & $01, .7$ & 1.9 & OA,r. & 1.9 & حاصل على ثنانوية \\
\hline 110,99 & $v \cdot$ & $0 \leqslant, T 4$ & $v$. & 71.7. & $v$. & تعليم جامعي \\
\hline $111,0$. & $\varepsilon$ & $04 . \mathrm{V} 0$ & $\varepsilon$ & 71.80 & $\varepsilon$ & مرحلة الماجستير \\
\hline
\end{tabular}

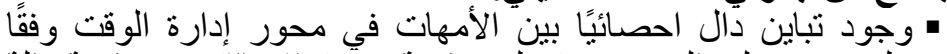

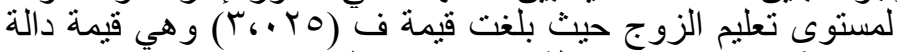

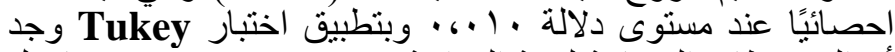

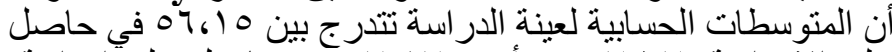

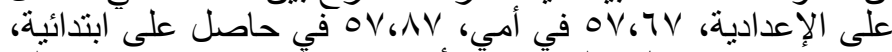

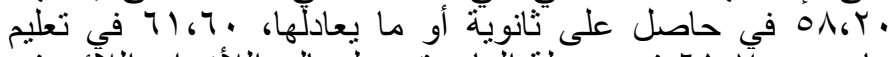

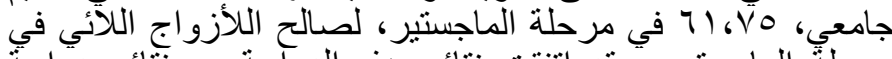

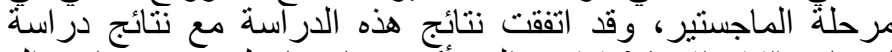

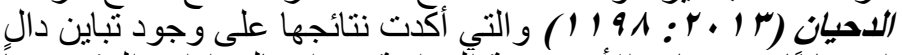

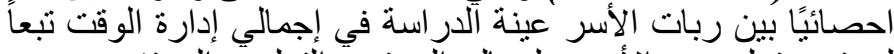

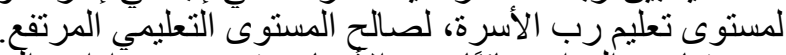

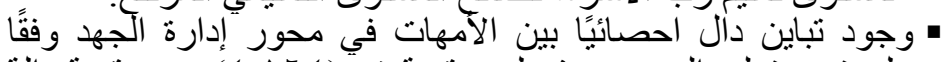

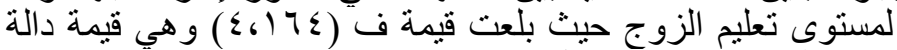

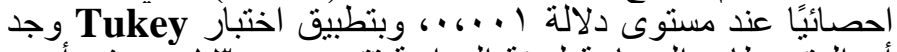

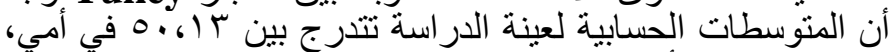

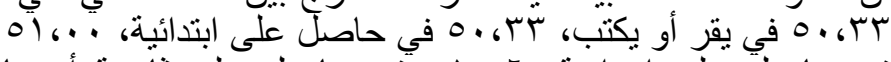

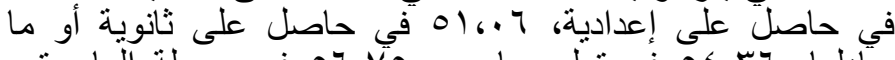

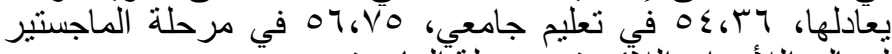
لصالح اللأزو اج اللأئي في مرحلة فئة الماجستير. 
مجلة الاقتصاد المنزلي - مجلد · r - العدد (ع) • r • r م

• وجود تباين دال احصائيًا بين الأمهات في اجمالي إدارة الوقت والجها

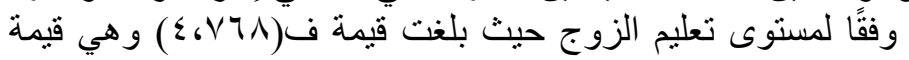

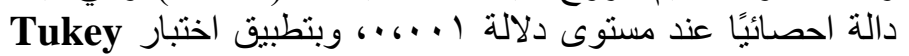

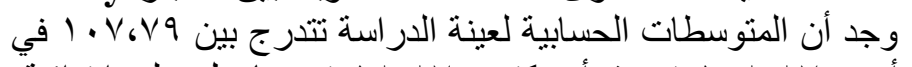

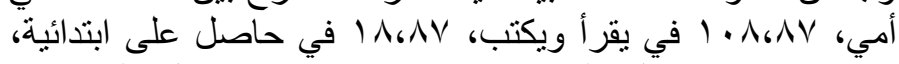

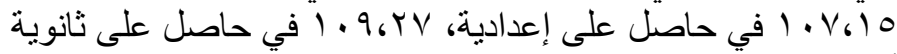

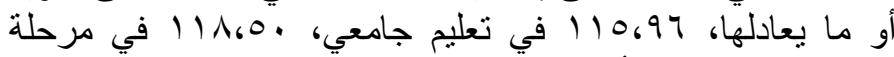

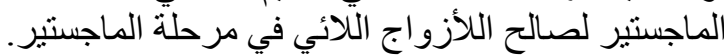

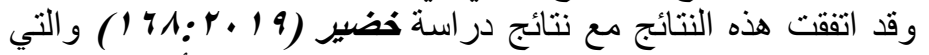

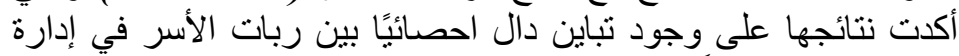

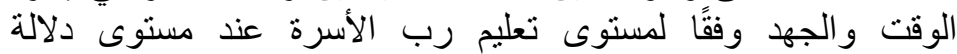
يتضح مما سبق وجود تباين دال احصائيًا بين الأمهات عينة الدراسة (*...1)

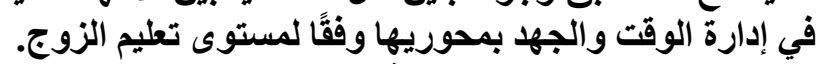

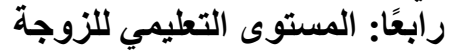

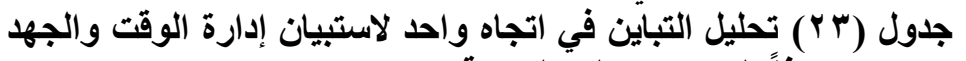

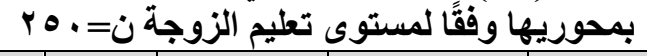

\begin{tabular}{|c|c|c|c|c|c|c|}
\hline مستوي & قيمة ف & متوسطات & الحرجية & المربعوع & مصدر التباين & \\
\hline 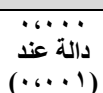 & $0, \Lambda 1$. & 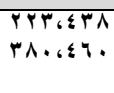 & $\begin{array}{l}q \\
r \leq r \\
r \leq q\end{array}$ & 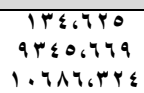 & دأخل المجموعات المجات & إدارة الوقت \\
\hline غير دالة' بالة & $1, v \leqslant r$ & $\begin{array}{l}00 \text { OOYY } \\
\text { M.AOY }\end{array}$ & $\begin{array}{l}r \\
r \leq r \\
r \leq q\end{array}$ & 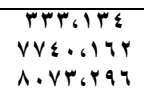 & داخلين المجموعوعات & إدارة الجهد \\
\hline دالذة عَد. & 26479 & $\begin{array}{l}\leq \leqslant 7 ، \leqslant \leqslant 0 \\
1 . Y_{6} 11 .\end{array}$ & $\begin{array}{l}r \\
r \leq r \\
r \leq q\end{array}$ & $\begin{array}{l}\text { rYVA,74A } \\
r \leq \Lambda Y 96704 \\
r V 0 . \Lambda 6 r Y \leq 8\end{array}$ & دأخل المجموعات المجات & مجموع وإلجارة \\
\hline
\end{tabular}


مجلة الاقتصاد المنزلي - مجلد · r - العدد (ع) • r • م م

جدول (צY) المتوسطات الحسابية لارجات الأمهات على إدارة الوقت

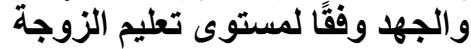

\begin{tabular}{|c|c|c|c|c|}
\hline \multicolumn{2}{|c|}{ مجموع إدارة الوقت والجها } & \multicolumn{2}{|c|}{ إدارة الوقت } & ور \\
\hline المتوسط الحسابي & 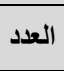 & المستوسبي & العدد & \\
\hline $1 \cdot V .79$ & ro & $0 V_{6} q \leq$ & ro & 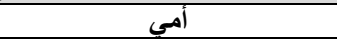 \\
\hline 111614 & $\mathrm{~V}$ & 09.71 & $\mathrm{v}$ & يقرأ ويكتب \\
\hline I.V.rq & $\mathrm{v}$ & 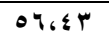 & $\mathrm{V}$ & حاصل على ابتائية \\
\hline $1.0 ، 11$ & 17 & $00,0$. & 17 & حاصل على إعدادية \\
\hline $11 \cdot 614$ & IYI & $0 \Lambda_{6} .0$ & $|r|$ & حاصل على الثُانويةٌة أو ما يعادلها \\
\hline 117,10 & Th & IY,AV & 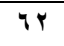 & تعليم جامعي \\
\hline $1.7,0$. & $Y$ & $09 .$. & Y & مرحلة أماجستير \\
\hline
\end{tabular}

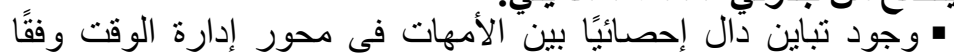

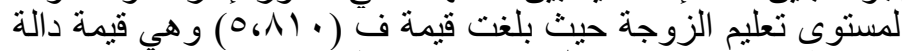

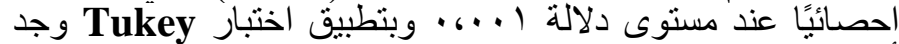

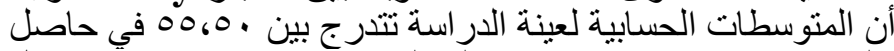

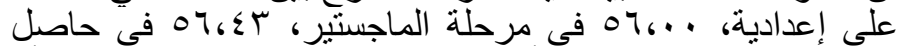

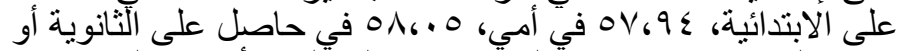

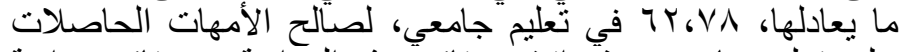

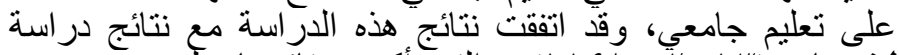

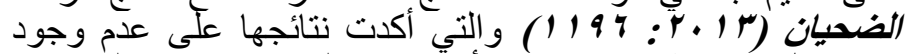

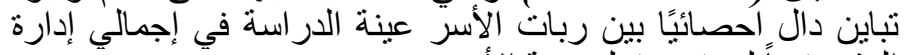

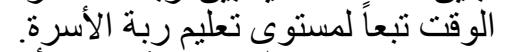

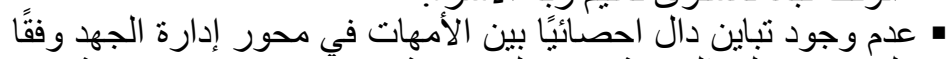

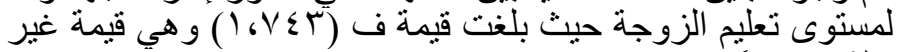
دالة احصائيًا.

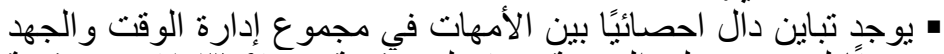

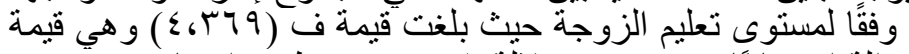

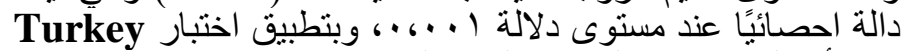

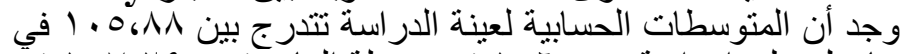

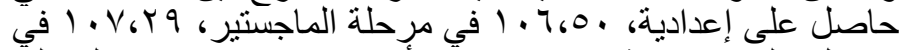

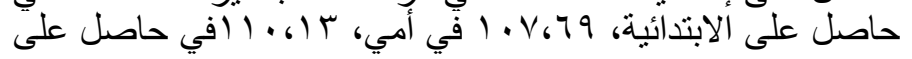




$$
\text { مجلة الاقتصاد المنزلي - مجلد · ب - العدد (؛) • r • م م }
$$

ثانوية أو ما يعادلها، 10، 117 في تعليم جامعي لصالح الأمهات الحاصلات على تعليم جامعي.

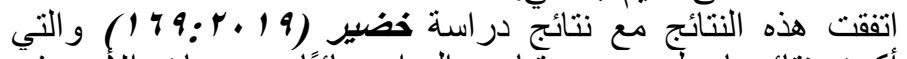

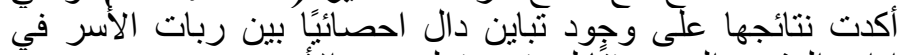

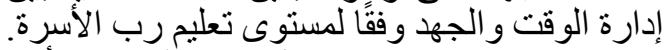

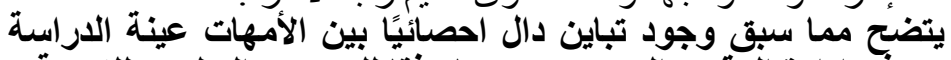

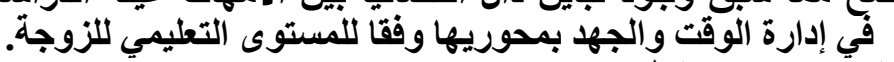

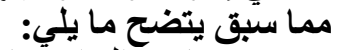

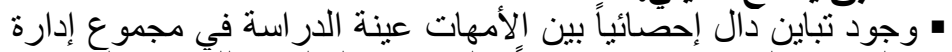

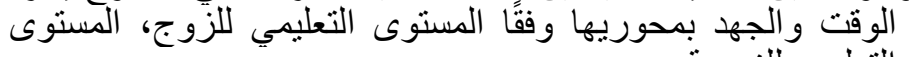

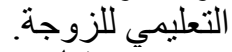

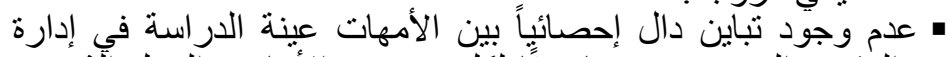

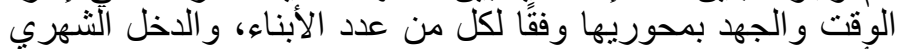
للأسرة، وبذلك بتحقق صحة صدة الفرض السادس جزئيًا.

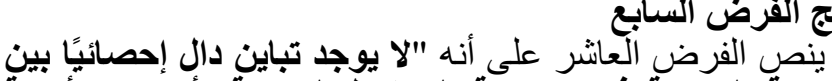

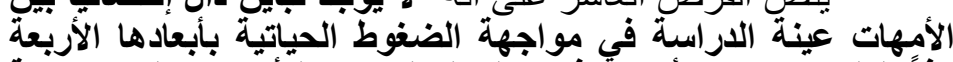

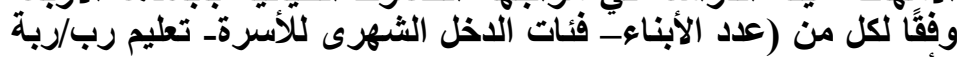
وللتحقق من صحة الفرض السابع إحصائيًا تم استخدام اختبار (الأسرة).

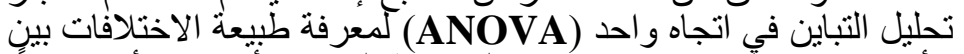

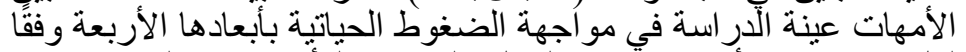

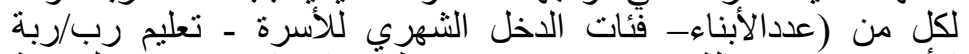

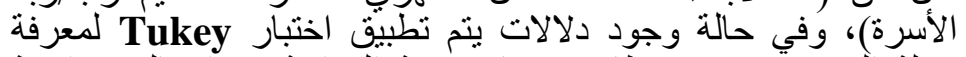

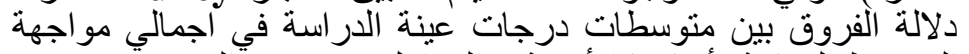

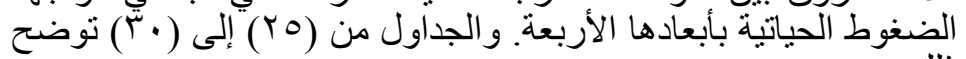


مجلة الاقتصاد المنزلي - مجلد · r - العدد (ع) • r • r م

\begin{tabular}{|c|c|c|c|c|c|c|}
\hline \multicolumn{7}{|c|}{ 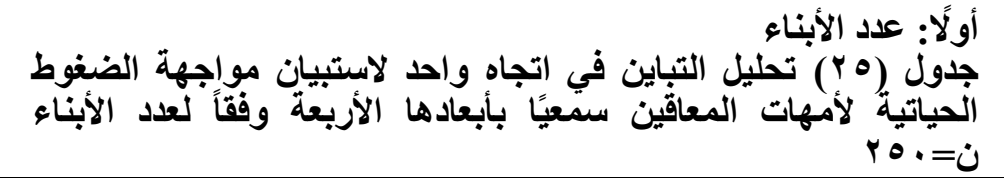 } \\
\hline مستوي & قيمة ف & المربعات & الرجيةت & المزبموت & مصدر التباين & \\
\hline غير دآلة & T,YAY & $\begin{array}{l}\text { YM, \&.Y } \\
\text { in,YOV }\end{array}$ & $\begin{array}{l}0 \\
r \leqslant \leqslant s \\
r \leqslant 9\end{array}$ & 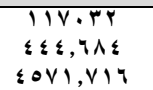 & دأخلن المجمموعات & الاجتما \\
\hline غير دائة & $\cdot, 904$ & $\begin{array}{l}\text { TI,VEE } \\
\text { WY,YAY }\end{array}$ & $\begin{array}{l}0 \\
r \leq \leqslant \\
r \leqslant 9\end{array}$ & $\begin{array}{l}01,019 \\
r 997, V \leq 0 \\
r .00, Y Y \leq\end{array}$ & دأخل المجموعات & تفعيل الذات \\
\hline غير دادة, & $\cdot, \mathrm{VV}$. & $\begin{array}{l}Y q, O V O \\
Y \leq, 01 \leqslant\end{array}$ & $\begin{array}{l}0 \\
r \leq \leqslant \leq \\
r \leqslant 9\end{array}$ & 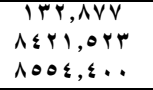 & دأخل المجمموعات & الإرشاد النفسي \\
\hline غَير دالْة & $r, \cdot \wedge \lambda$ & 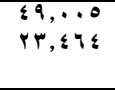 & $\begin{array}{l}0 \\
r \leq \leqslant \leq \\
r \leq 9\end{array}$ & $\begin{array}{l}\text { rEo,.ry } \\
\text { ovro,rl. } \\
\text { oqv.,rrq }\end{array}$ & داخين المجمموعات & التقبل \\
\hline غير دائة & $\cdot, \wedge \wedge$ Q & 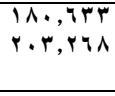 & $\begin{array}{l}0 \\
r \leq \leqslant \\
r \leq 9\end{array}$ & $\begin{array}{l}9 . r, 17 r \\
\leqslant 909 \vee, \leqslant \wedge 1 \\
0.0 \ldots, 7 \leq \leqslant\end{array}$ & داخلن المجموعات & الضغوط الحواجتية \\
\hline قانهة & 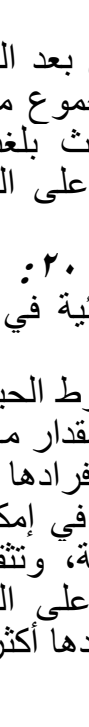 & 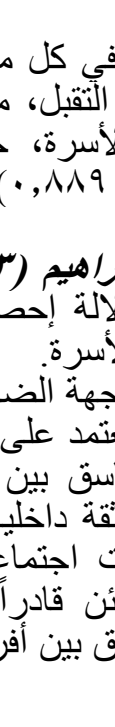 & هل & 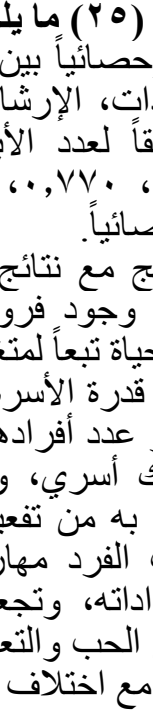 & 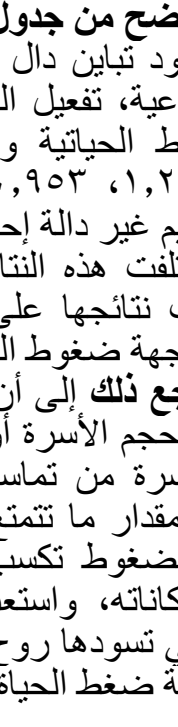 & 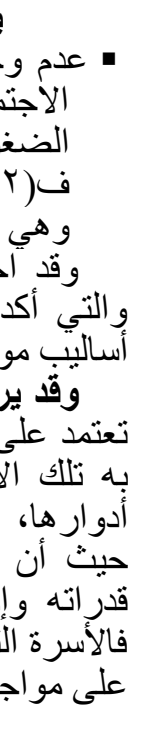 \\
\hline
\end{tabular}


مجلة الاقتصاد المنزلي - مجلد · r - العدد (ع) • r • r م

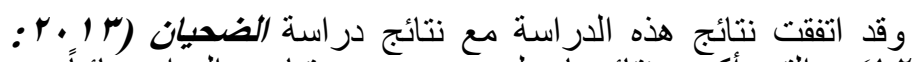

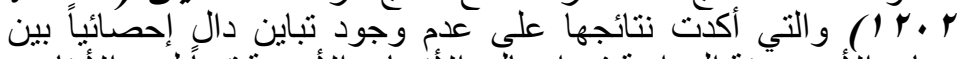

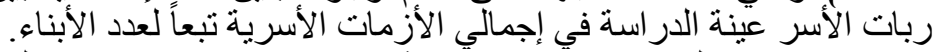

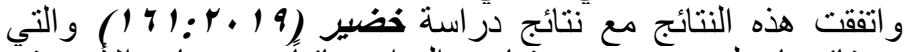

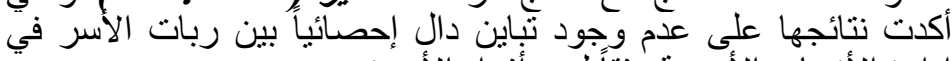

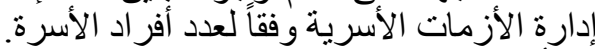

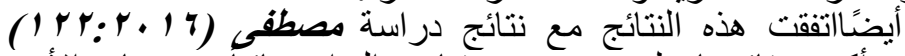

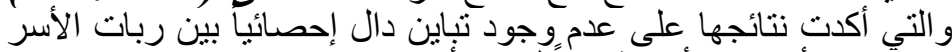

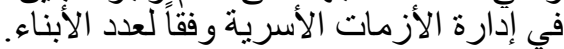

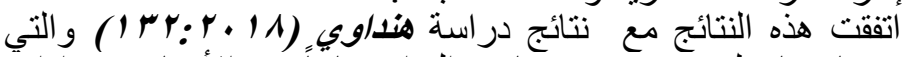

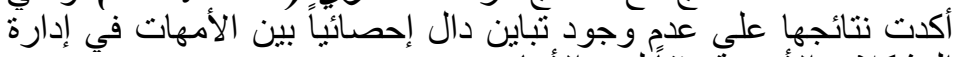
المشكلات الأسرية وفقاً لعدد الأبناء.

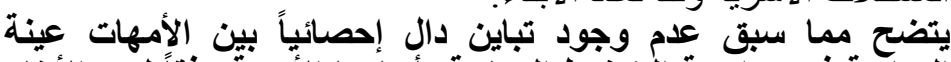

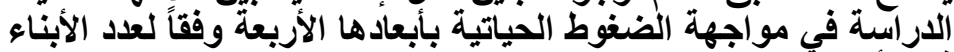

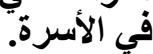
ثنانتيًا: الاخخل الشهرة

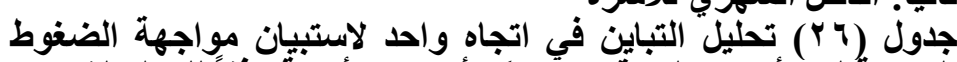

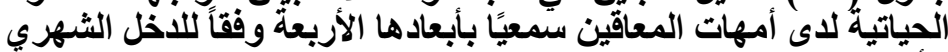

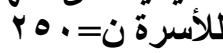

\begin{tabular}{|c|c|c|c|c|c|c|}
\hline مستوي & قيمة ف & مترسطات & الدرجية & المربعوع & مصدر التباين & بعاد \\
\hline غير دالة Y" & IIEYY & $\begin{array}{l}\text { YY,.YYO } \\
1 \Lambda_{6} Y 9 \Lambda\end{array}$ & $\begin{array}{l}r \\
r \leqslant v \\
r \leqslant q\end{array}$ & $\begin{array}{l}0 Y 6,0 \leqslant 9 \\
\leqslant 019674 V \\
\leqslant 0 Y 161417\end{array}$ & داخل المجموعات & الاجتماعية \\
\hline غير دالة 979 هُ & $.004 \leqslant$ & $\begin{array}{l}7,9 \leq 1 \\
1 Y, r \mid r\end{array}$ & $\begin{array}{l}r \\
r \leq V \\
r \leq q\end{array}$ & $\begin{array}{l}\text { lT.N9V } \\
r .51,47 V \\
r .00,47 \leq\end{array}$ & داخل المجموعات المجوعات & تفعيل الأت \\
\hline غير دالة & . "V94 & 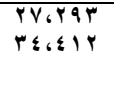 & $\begin{array}{l}r \\
r \leq V \\
r \leq q\end{array}$ & $\begin{array}{c}0 \leqslant 60 \wedge q \\
\wedge \leq 996 \wedge 1 \leq \\
\Lambda 00 \leqslant 6 \leqslant \ldots\end{array}$ & داخخل المجموعات & الإرشاد النفسي \\
\hline غير دالة & $\cdot . Y+1$ & $\begin{array}{l}\varepsilon, \wedge O Y \\
Y \varepsilon_{6} \mid r Y Y\end{array}$ & $\begin{array}{l}r \\
r \leq v \\
r \leq q\end{array}$ & 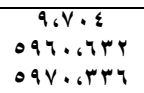 & داخل المجموعات المجل & التقبل \\
\hline غير دالة & 16.09 & $\begin{array}{l}Y Y \leq 60 \Lambda \leq \\
Y \cdot r_{6} V 19\end{array}$ & $\begin{array}{l}r \\
r \leq v \\
r \leq q\end{array}$ & 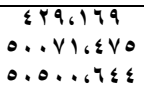 & داخلن المجموعات & موجموعة مواجوط \\
\hline
\end{tabular}


مجلة الاقتصاد المنزلي - مجلد · r - العدد (ع) • r • r م

يتضح من جدول (Y Y ) ما يلي:

• عدم وجود تباين دال إحصائياً بين الأمهات في في بعد المالئ المساندة

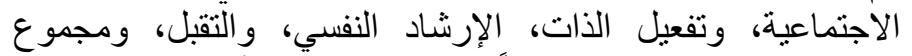

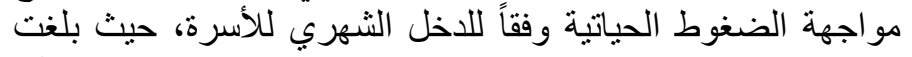

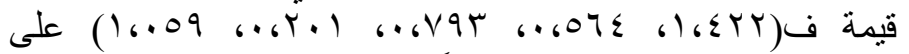

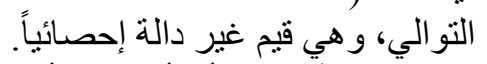
وقد يرجع ذلتك إلى أن أمهات الأبناء المعاقين سمعيًا يبحثن عن كافة المانة

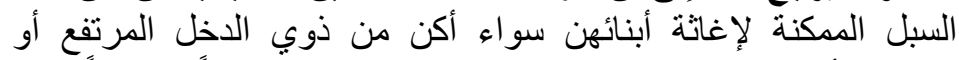

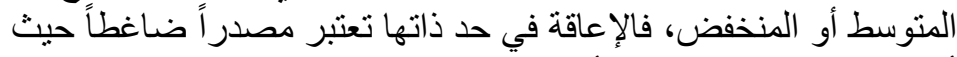

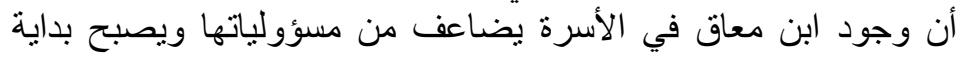

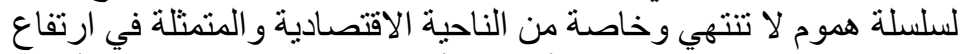

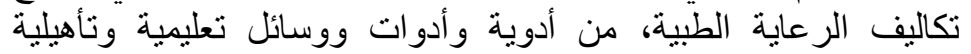

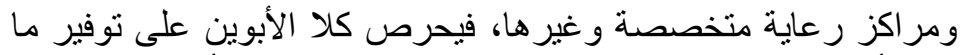

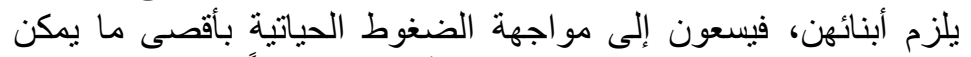

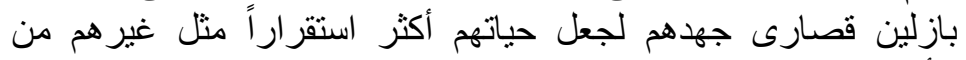
الأسوياء.

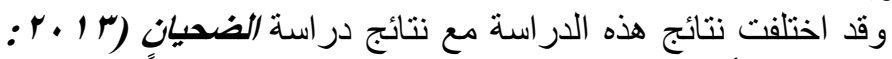

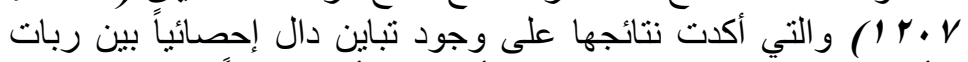

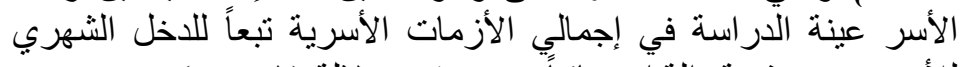

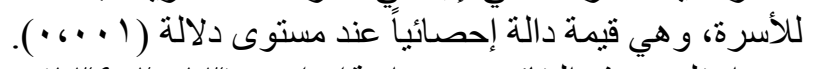

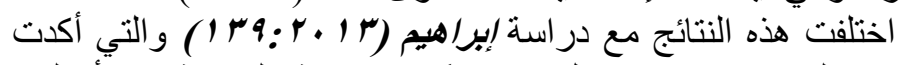

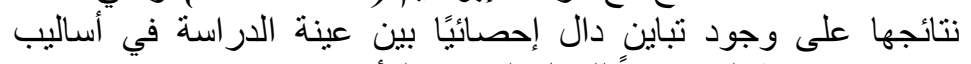

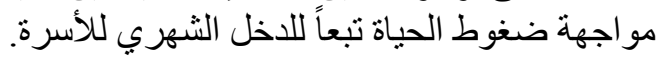

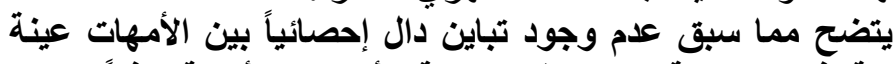

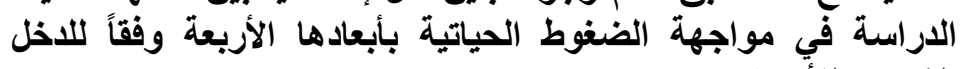
الثهري للأسرة. 


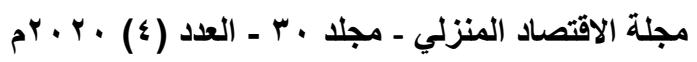

ثالثًا: المستوى التعليمي للزوج

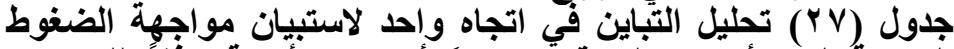

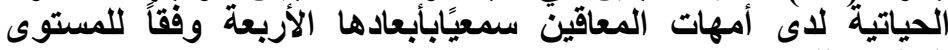
ن التعليمي للزوج لإني

\begin{tabular}{|c|c|c|c|c|c|c|}
\hline مستوى الالالة & قيمة ف & متوسط المربعات & الحرية & المربعات & مصدر التباين & \\
\hline 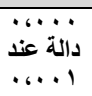 & $\varepsilon, r \wedge$. & $\begin{array}{l}\& 6 \% 0 V \\
17.9 V A\end{array}$ & $\begin{array}{c}q \\
r \leq r \\
r \leq q\end{array}$ & $\begin{array}{l}\leq \leqslant 7,1 \leq 1 \\
\leqslant 1 \% 0,0 \vee 0 \\
\varepsilon 0816 V 17\end{array}$ & داخل المجمو المجموعات & الاجتماعياتدة \\
\hline غير دالة به & I.YIA & $\begin{array}{l}1 \leq 6 \wedge 7 Y \\
1 Y 6 \% .7\end{array}$ & $\begin{array}{l}q \\
r \leq r \\
r \leq q\end{array}$ & $\begin{array}{l}1961 V \varepsilon \\
\text { r9776.9. } \\
r .00679 \varepsilon\end{array}$ & داخل المجنمو المجموعات & تفعيل الأت \\
\hline 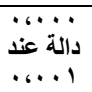 & 7.YYV & $\begin{array}{l}1916 r \cdot V \\
r .6 \leqslant 1 .\end{array}$ & $\begin{array}{l}q \\
r \leq r \\
r \leq q\end{array}$ & 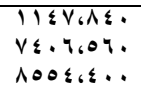 & داخل المجمو المجموعات & الإزفشيد \\
\hline غير دالة & 16799 & $\begin{array}{l}r .{ }^{\prime} 9 r^{\prime} \\
r r_{6} \Lambda . q\end{array}$ & $\begin{array}{l}q \\
r \leq r \\
r \leq 9\end{array}$ & $\begin{array}{l}\text { INO6OV. } \\
\text { OVAE،VYY } \\
\text { OQV. . FYY }\end{array}$ & داخل المجمو المجموعات & التقبل \\
\hline 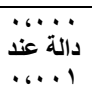 & $\varepsilon, 01 Y$ & $\begin{array}{l}\Lambda \leqslant \Psi ، V \leqslant V \\
1 \wedge \neg ، ৭ \wedge \Lambda\end{array}$ & $\begin{array}{c}q \\
r \leq r \\
r \leq q\end{array}$ & $\begin{array}{l}0.7 Y, \leqslant \Lambda Y \\
\leq 0 \leq Y \wedge, 17 Y \\
0.0 . .74 \leq \varepsilon\end{array}$ & داخل المجنمو المجموعات & الضغوط \\
\hline
\end{tabular}

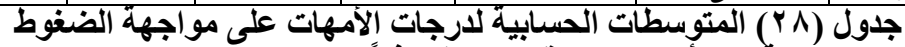

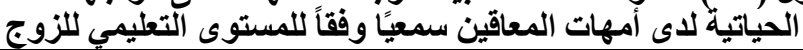

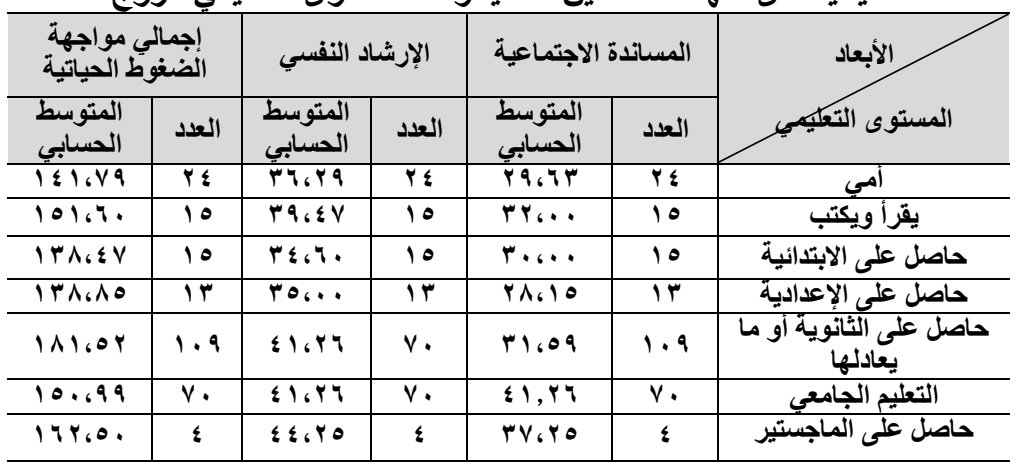


مجلة الاقتصاد المنزلي - مجلد · r - العدد (ع) • r • r م

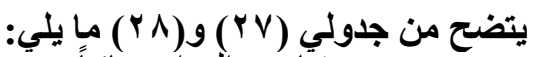

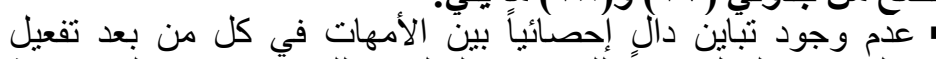

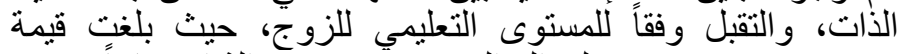

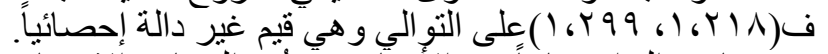

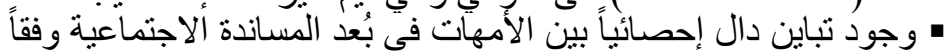

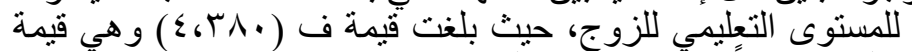

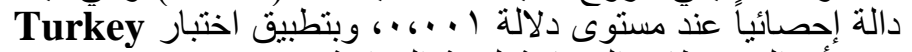

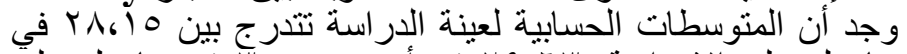

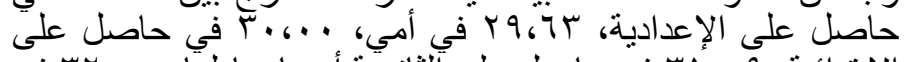

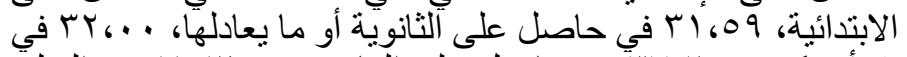

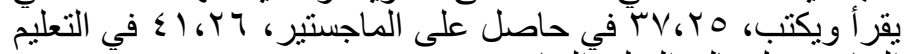

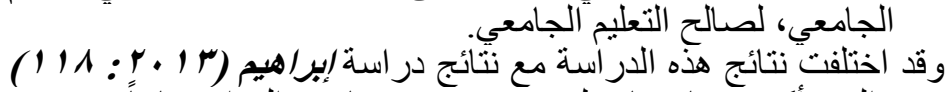

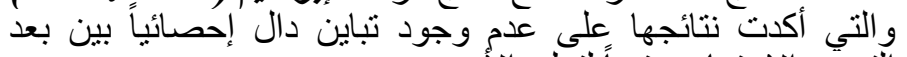

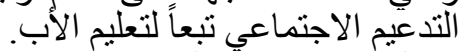

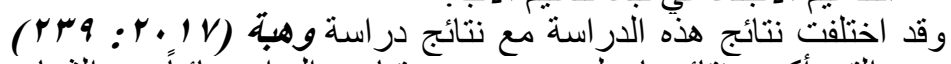

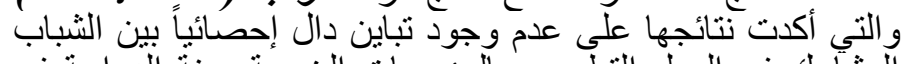

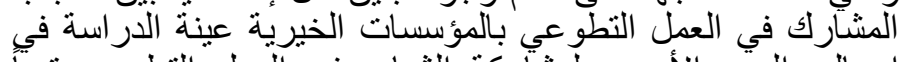

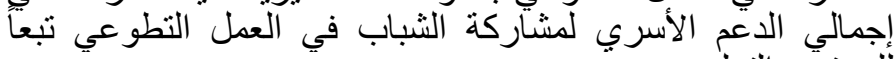

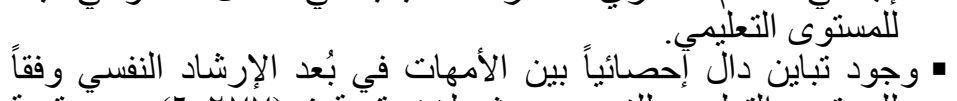

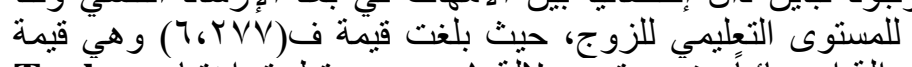

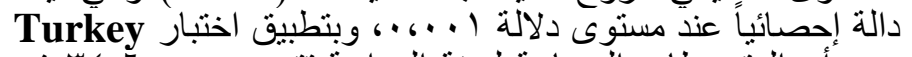

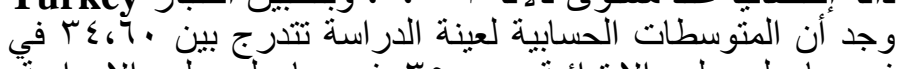

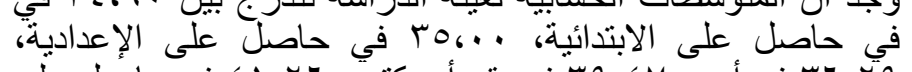

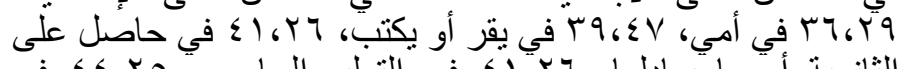

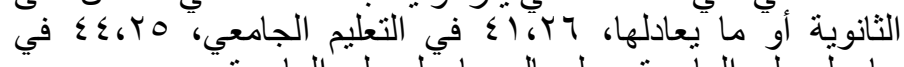

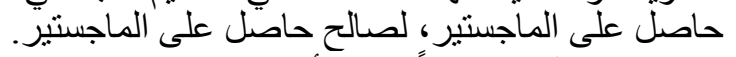

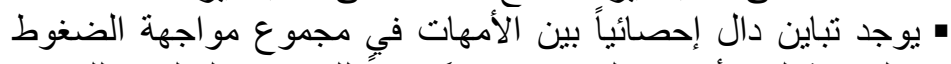

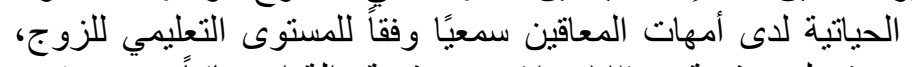

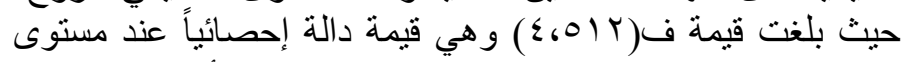

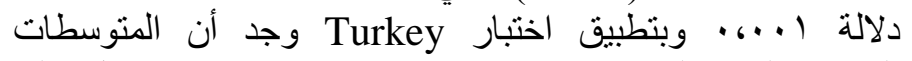

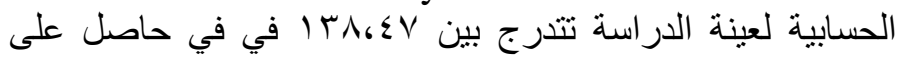


مجلة الاقتصاد المنزلي - مجلد · r - العدد (ع) • r • r م

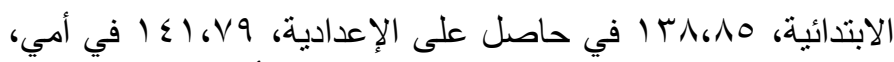

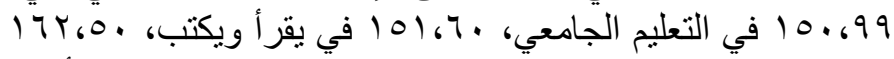

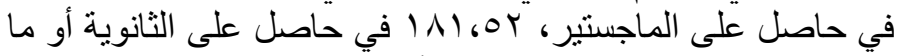

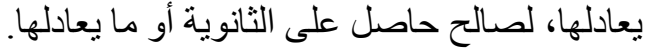

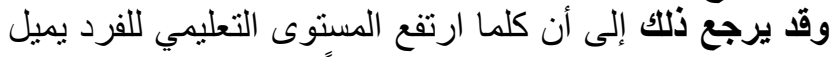

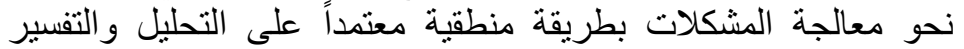

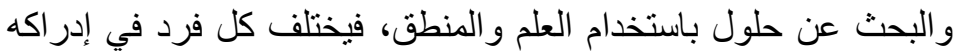

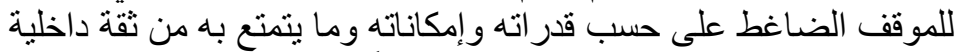

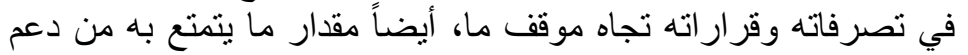

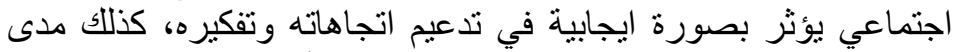

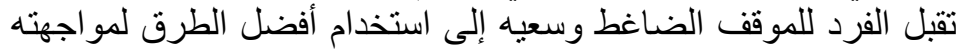

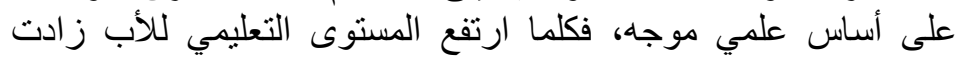

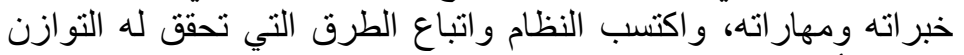

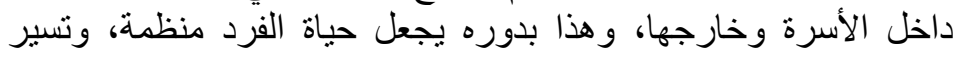

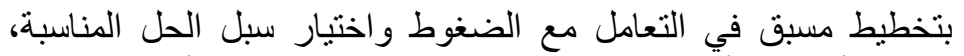
وتفهم الأسرة والأبناء و التعامل معهم بهدف الحصول على الحي أفضل مو اجهة ممكنة.

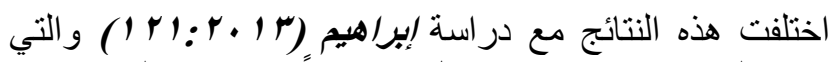

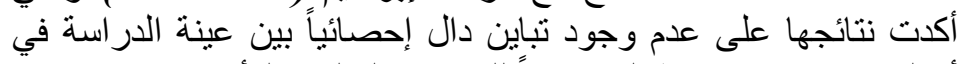

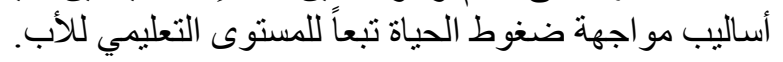

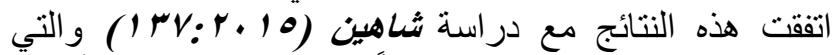

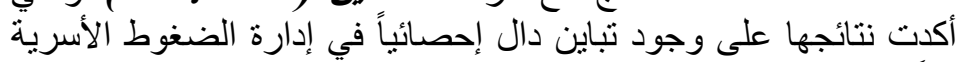

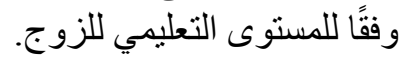

يتضح مما سبق وجود تباين دال إحصائياً بين الأمهات عينة

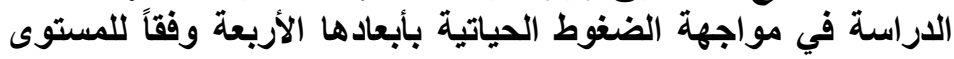
التعليمي للزوج. 
مجلة الاقتصاد المنزلي - مجلد · r - العدد (ع) • r • م م

رابعًا: المستوى التعليمي للزوجة

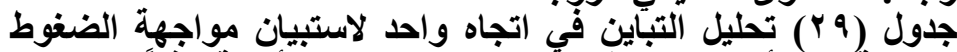

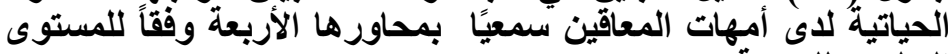

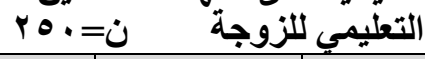

\begin{tabular}{|c|c|c|c|c|c|c|}
\hline مستوي & قيمة ف & المربعات & الدرجية & المزبعوت & مصدر التباين & \\
\hline دالَّة & $r \cdot v \cdot q$ & $\begin{array}{l}\text { THGQYYT } \\
\text { IVGYTO }\end{array}$ & 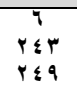 & 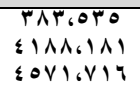 & دأخل الكجمموعات & الاجتماعيةة \\
\hline غير دالة & एवाYT & $\begin{array}{l}r 0, r \leqslant Y \\
11,9 \leqslant V\end{array}$ & $\begin{array}{l}r \\
r \leqslant r \\
r \leqslant q\end{array}$ & 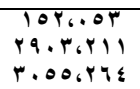 & دأخلِ الكجموعوعات & تفعيل الذات \\
\hline 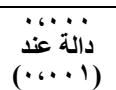 & 8,044 & $\begin{array}{l}1 \leqslant \%, 7.99 \\
r 1,70 \mathrm{~V}\end{array}$ & $\begin{array}{l}r \\
r \leq r \\
r \leq 9\end{array}$ & 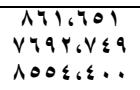 & دأخل الكجموعات المجات & الالنفَشسيد \\
\hline 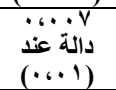 & TarYT & $\begin{array}{l}r 9,11 Y \\
\text { rroATr }\end{array}$ & $\begin{array}{l}r \\
r \leq r \\
r \leq 9\end{array}$ & 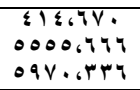 & دأخل الكجموموعات & التُقبل \\
\hline 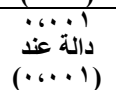 & $4, .10$ & $\begin{array}{l}V 09,194 \\
1199 ., V V\end{array}$ & $\begin{array}{l}r \\
r \leq 4 \\
r \leq 9\end{array}$ & $\begin{array}{l}\leqslant 00 \leqslant 19 \wedge . \\
\leqslant 09 \leqslant 0.79 \leqslant \\
0.0067 \leqslant \leqslant\end{array}$ & دأخل الكجمموعات & مجؤجموع \\
\hline
\end{tabular}

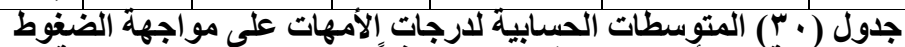

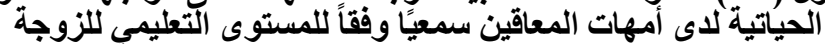

\begin{tabular}{|c|c|c|c|c|c|c|c|c|}
\hline \multicolumn{2}{|c|}{ الضغوط الحياتية مواجهة } & \multicolumn{2}{|c|}{ التقبل } & \multicolumn{2}{|c|}{ الإزشسيد } & \multicolumn{2}{|c|}{ الاجتماعية المسة } & \\
\hline المتوسط الحسبي & العدد & الحستوسط & العدد & المتّابط & العدد & الحتوسط الحسب & العدد & \\
\hline $1 \leq \varepsilon, \varepsilon$ & ro & $\varepsilon \cdot 6 \mathrm{VI}$ & ro & 79.77 & ro & $r /, r$. & ro & أمي \\
\hline $10 \%, 1 \leq$ & $\mathrm{V}$ & $\$ 76 \ldots$ & $\mathrm{V}$ & $\varepsilon \cdot 61 \leq$ & $\mathrm{V}$ & $r 9,0 V$ & $\mathrm{~V}$ & يقرأ ويكتب \\
\hline $1 \Gamma \leqslant 64$ & V & $r 7 ، \varepsilon r$ & V & ro, $0 V$ & $v$ & r. . I & 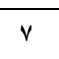 & \\
\hline $11 \% 9,09$ & 17 & rq,ro & 17 & $r 0,19$ & 17 & $r_{q} \leq \leq \leq$ & 17 & \\
\hline $1 \leq V_{6} \Lambda 1$ & $|r|$ & $\$ 1,70$ & $|r|$ & r^.৭q & $|Y|$ & $r . ، 9 r$ & $|r|$ & حأصل علَّ \\
\hline $10 r_{6}+r$ & $7 Y$ & $\$ 1617$ & $7 Y$ & \& 1, TE & $7 r$ & Pr. & $7 r$ & التعليم الجامعي \\
\hline $1 \leq 76 \ldots$ & r & $\leqslant 1, \ldots$ & $r$ & $r v_{6} .$. & $r$ & rr.o. & $r$ & الماجستير على \\
\hline
\end{tabular}

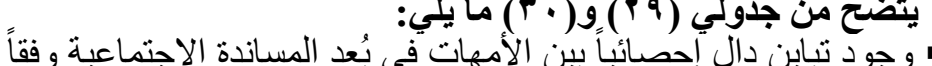

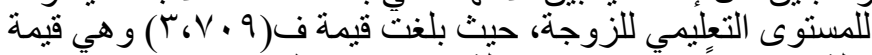

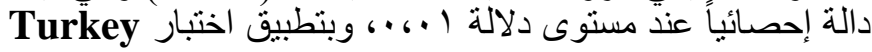




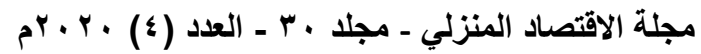

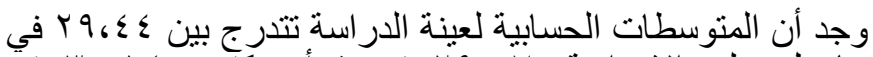

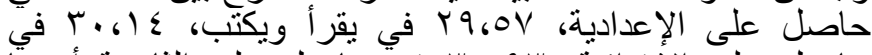

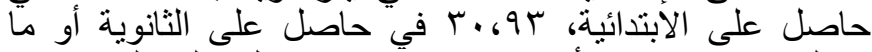

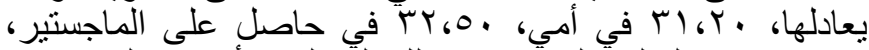

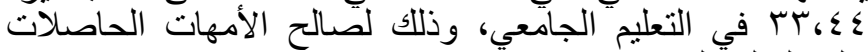

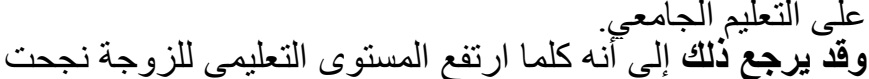

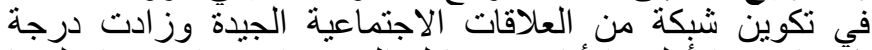

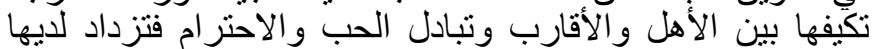

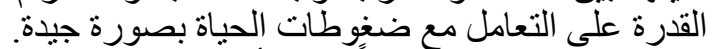

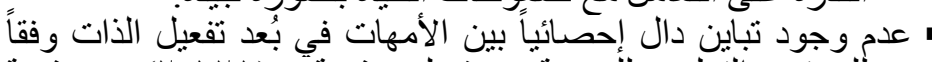

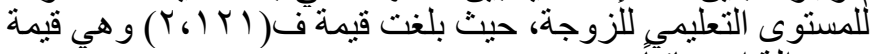
غير دالة إحصائيًا. • وجود تباين دال إحصائياً بين الأمهات في بُعد الإرشاد النفسي وفقاً

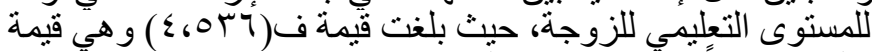

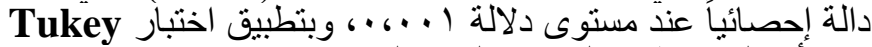

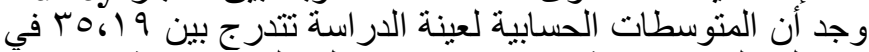

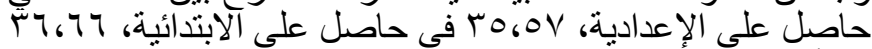

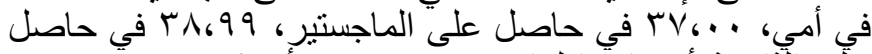

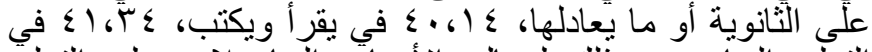

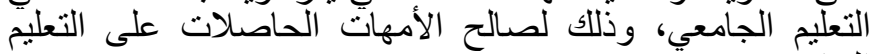
وقاتيرجيع ذلك إلى أنه كلما ارتفع المستوى التعليمي للأم يكون لهاتيا

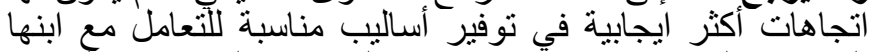

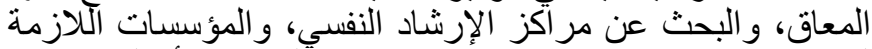

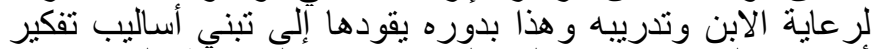

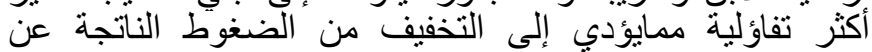
الإعاقة.

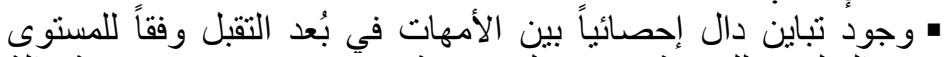

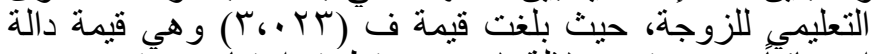

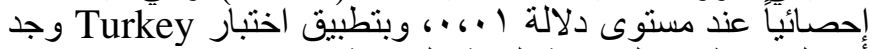

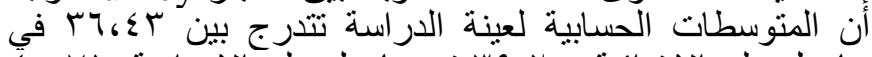

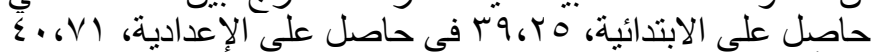

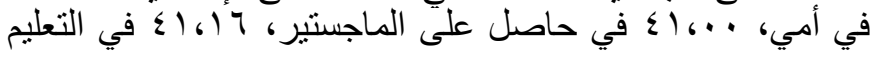




$$
\text { مجلة الاقتصاد المنزلي - مجلد · ب - العدد (؟) • ب • م م }
$$

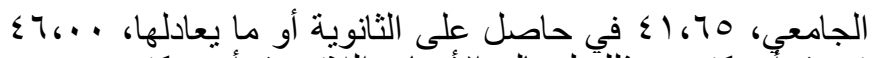

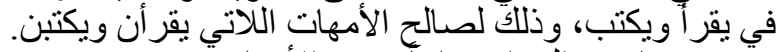

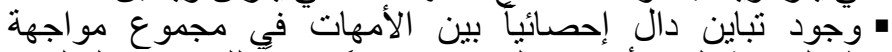

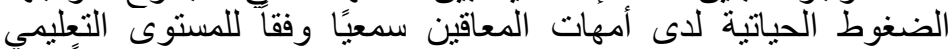

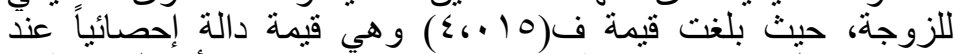

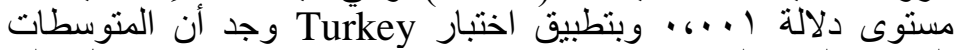

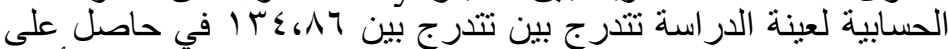

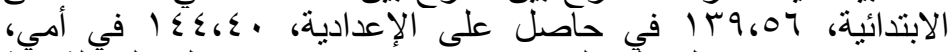

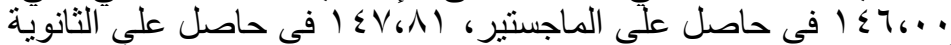

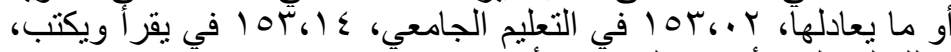

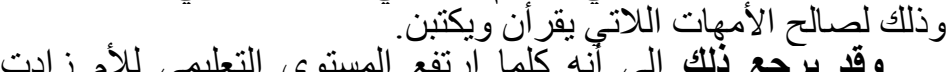

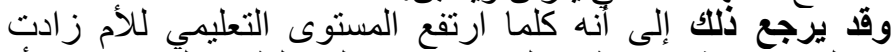

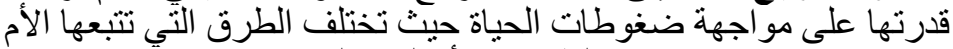

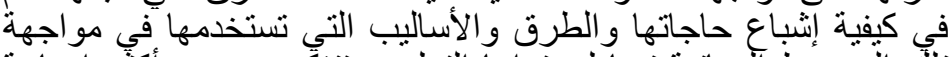

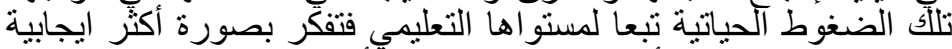

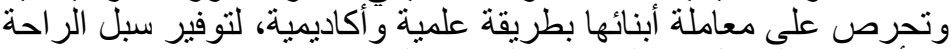
و الأمان في التعامل مع الضغوط النيان الحياتية الناتجة عن إعاقة ابنها.

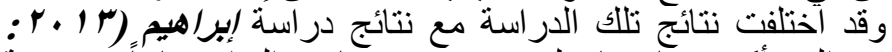

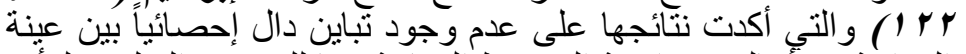

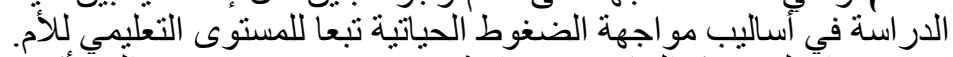

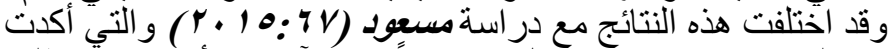

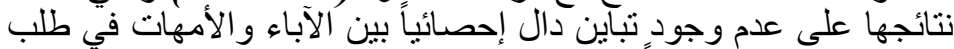

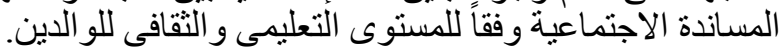

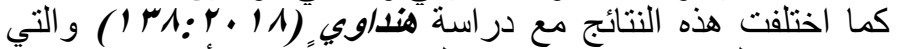

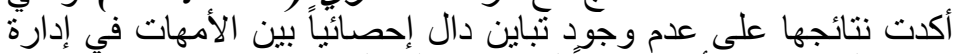

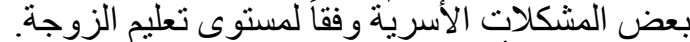

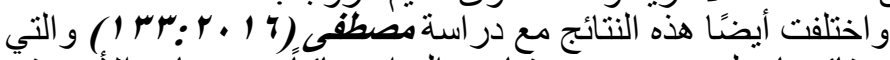

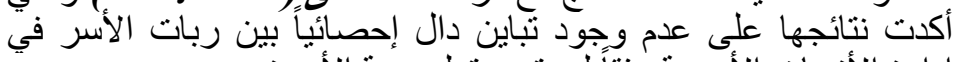

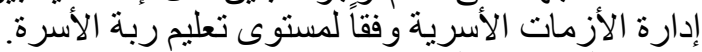

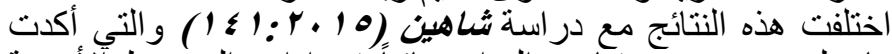

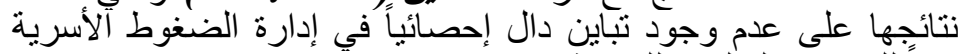
وفقاً للمستوى التعليمي للزوجة تباين. 
مجلة الاقتصاد المنزلي - مجلد · r - العدد (ع) • r • r م

يتضح مما سبق وجود تباين دال إحصائياً بين الأمهات عينة

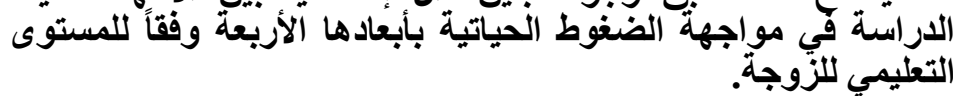

توصيات البحث من ما تم التوصل إليه من نتائج يوصي البحث الحالي بما أُّلّي: توصيات خاصة بوسائل الإعلام

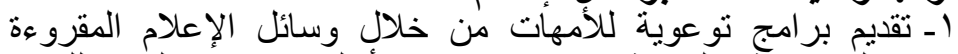

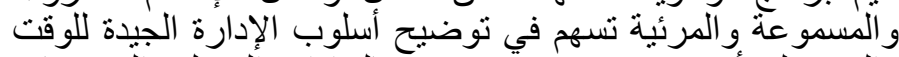

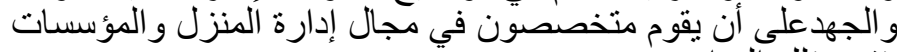

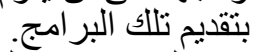

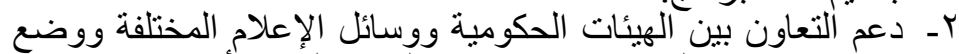

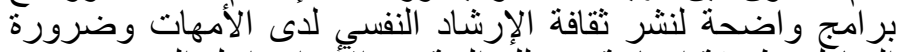

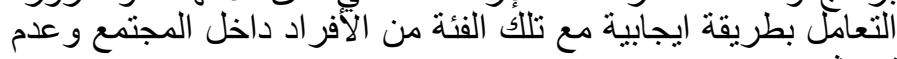
توهيشهُ. بـ نوعية الامههات من خلال البرامج الأسرية التي تقدمها وسائل الإعلام

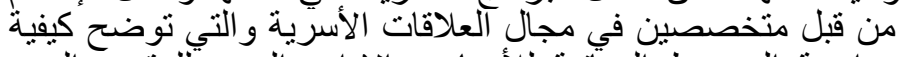

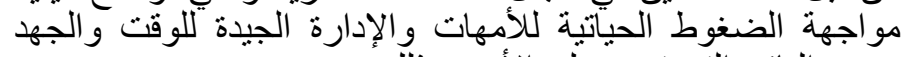

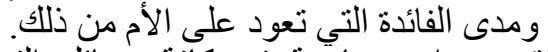

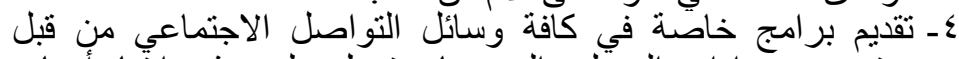

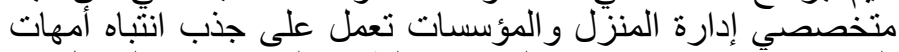

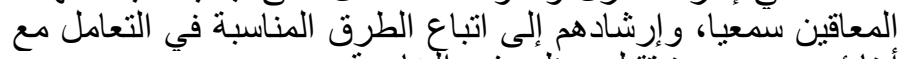

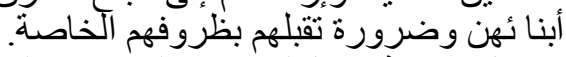

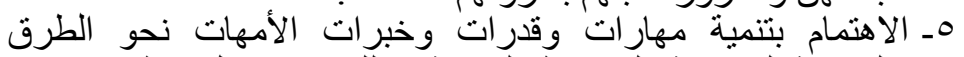

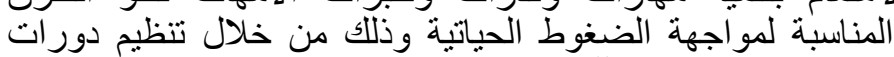

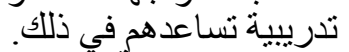

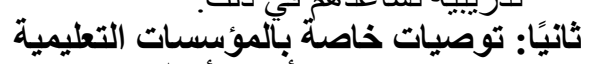

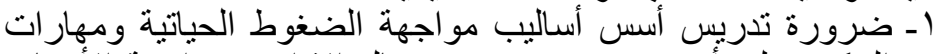

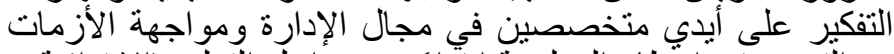

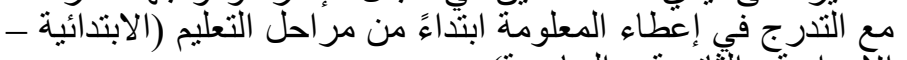

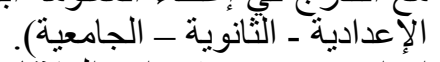

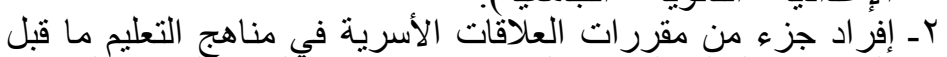

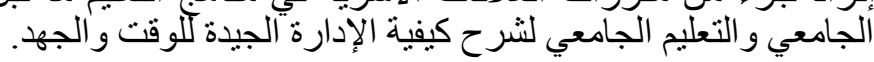




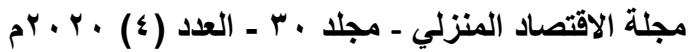

بـ عقد دورات تدريبية أسبو عية وندوات تثقيفية لأمهات المعاقين سمعيًا

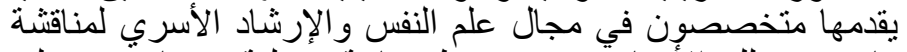

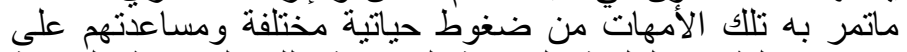

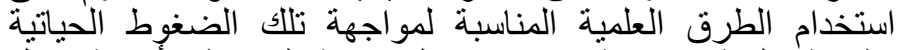

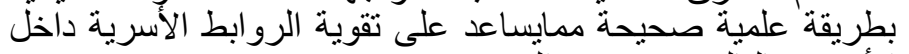
ألأسرة وبالتالّي دعم و وتقدم المجتمع.

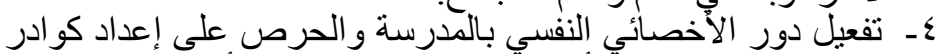

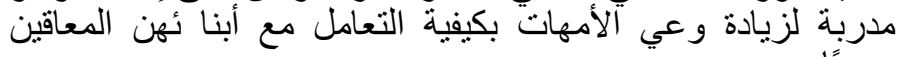

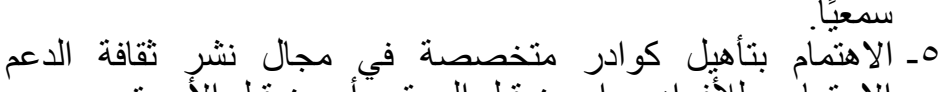

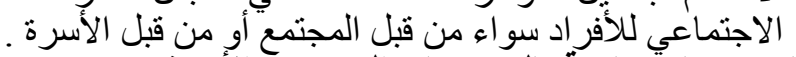

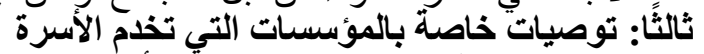

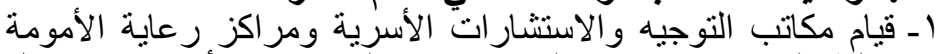

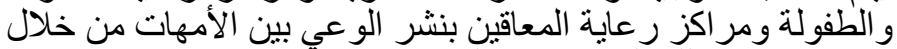

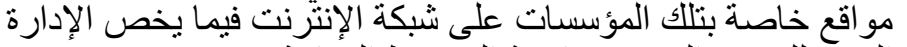

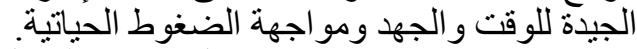

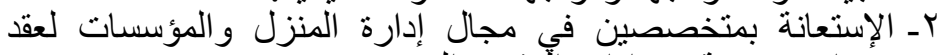

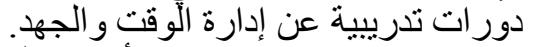

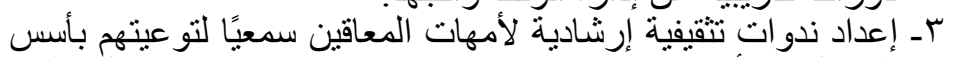

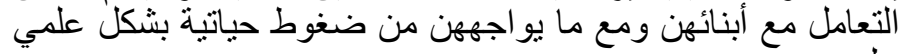

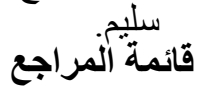

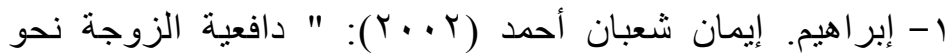

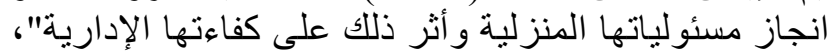

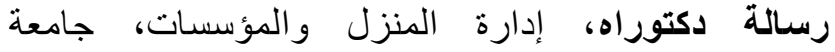
المنوفية، جمهورية مصر الدراهة العربية.

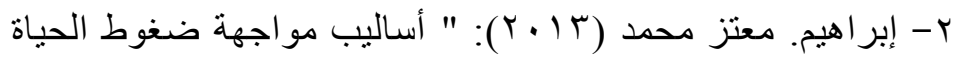

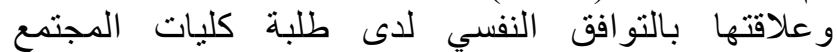

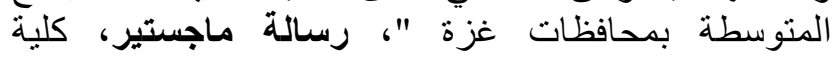
التربية، جامعة الأزهر ه غزة غزة، فلسطين.

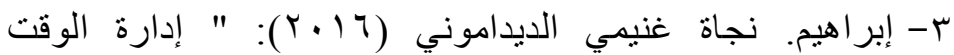

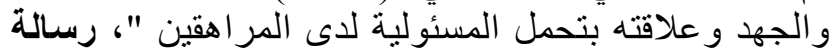




$$
\text { مجلة الاقتصاد المنزلي - مجلد · r - العدد (؛) • ب • م م }
$$

ماجستير، جامعة المنوفية، المنوفية، جمهورية مصر

$$
\text { العربية. }
$$

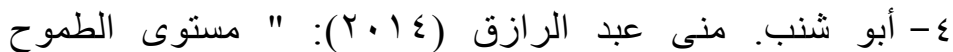

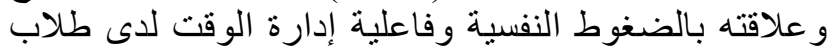

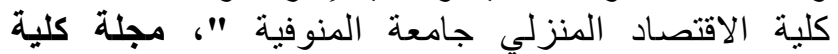
التربية، جامعة المنوفية، المنوفية، جمهورية مصر العية العربية.

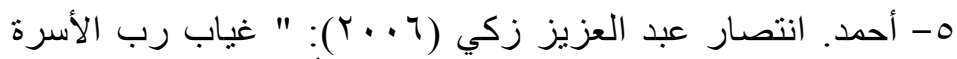

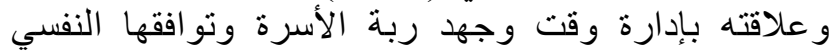

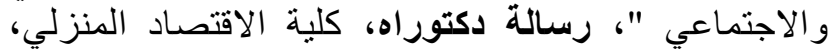

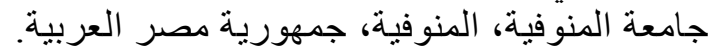

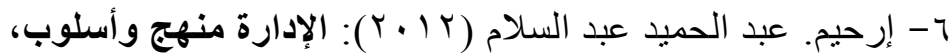

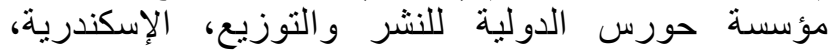
جمهورية مصر العربية.

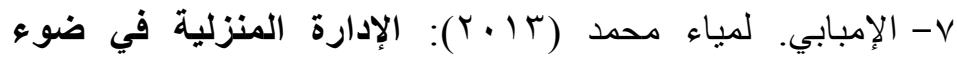

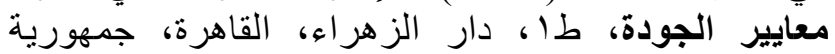
مصر العربية.

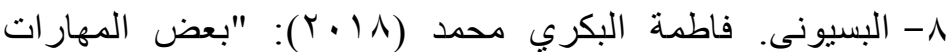

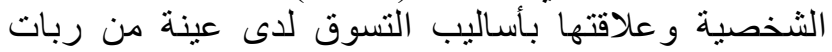

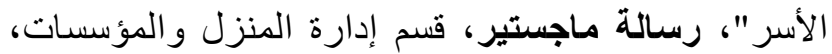

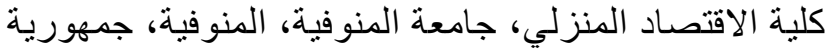
مصر العربية.

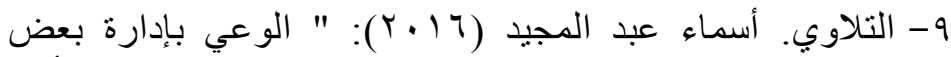

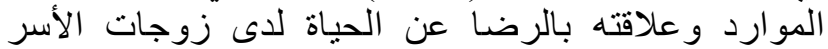

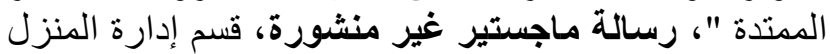

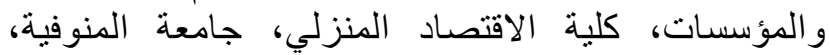

$$
\text { المنوفية، جمهورية مصنية كصر العربية. }
$$

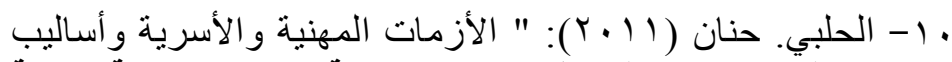

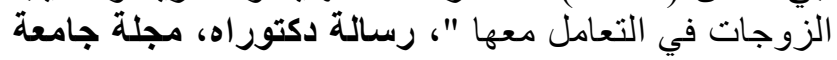




$$
\text { مجلة الاقتصاد المنزلي - مجلد · ب - العدد (؟) • ب • م م }
$$

دمشق، المجلد (YV) )، العدد الثالث و الرابع، كلية التربية،

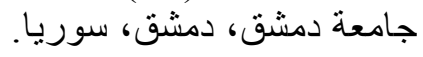

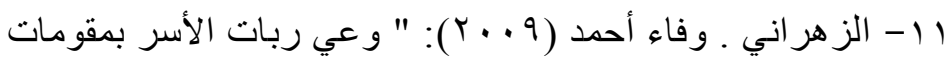

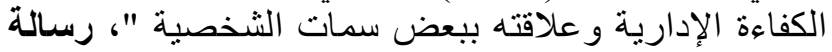

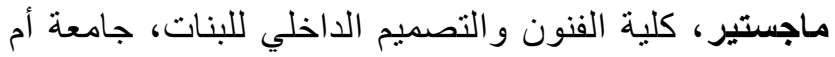
القرى، مكة المكرمة، المملكة العربية السعونة السعودية.

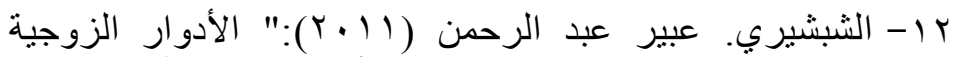

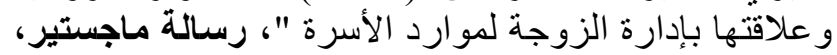

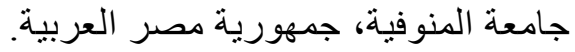

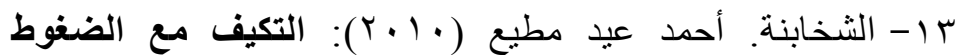

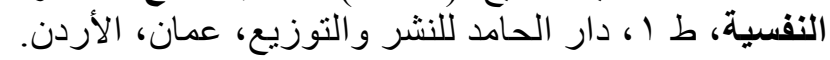

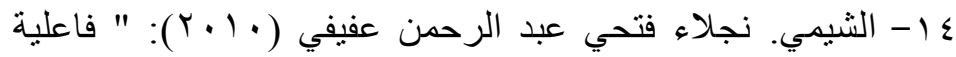

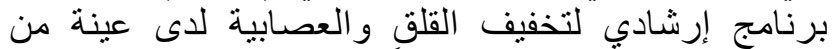

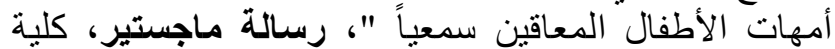

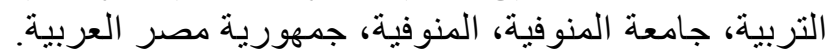

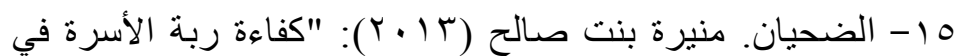

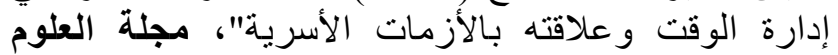

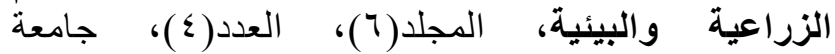
المنصورة، المنصورة، جمهورية مصر الينة، العربية.

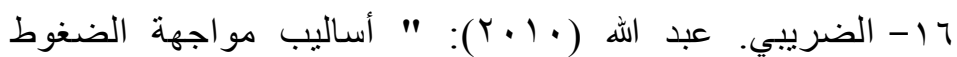

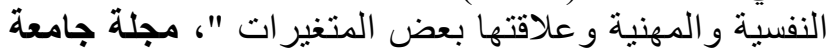

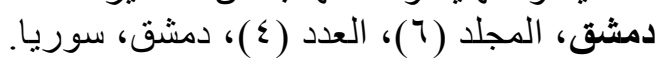

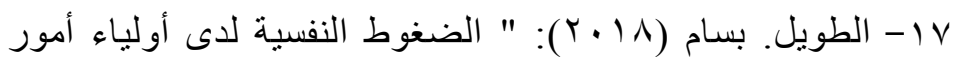

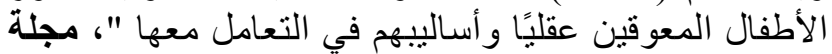

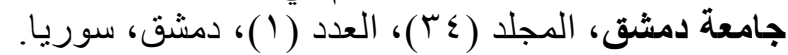

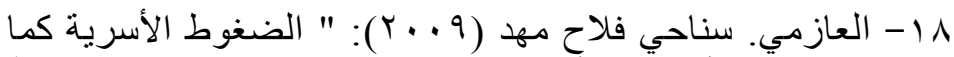

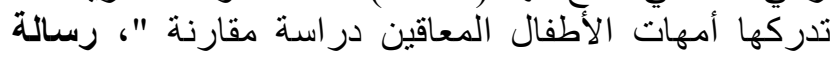




$$
\text { مجلة الاقتصاد المنزلي - مجلد · ب - العدد (؟) • ب • م م }
$$

دكتور اه، معهد الدراسات العليا للطفولة، جامعة عين شمس،

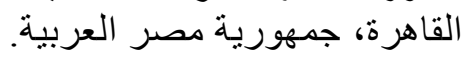

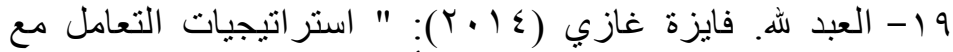

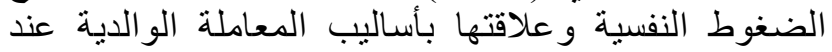

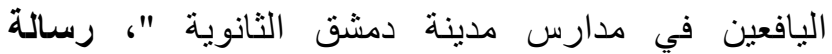

دكتور اهو، جأمعة دمشق، دمشق، سوريا.

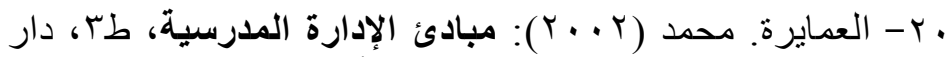

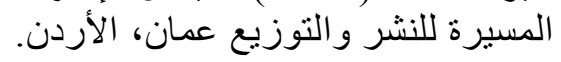

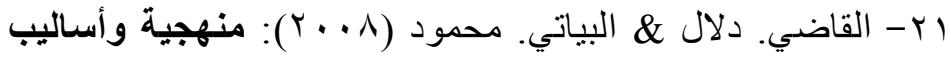

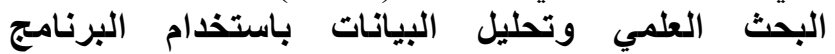

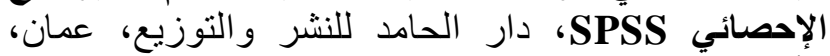

$$
\text { الأردن. }
$$

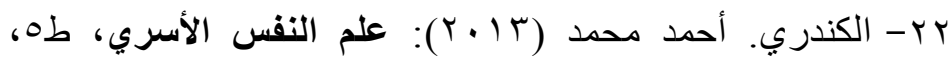
مكتبة الفلاح للنشر و التوزيع، الكويت.

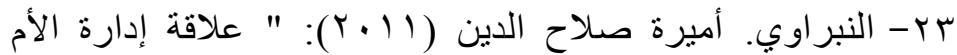

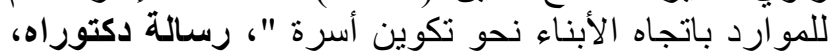

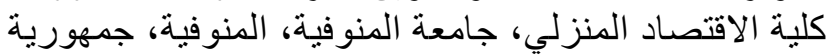
مصر العربية.

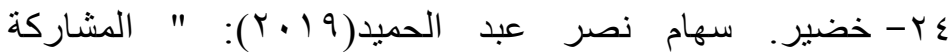

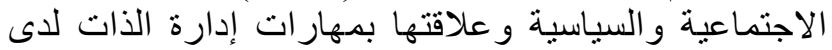

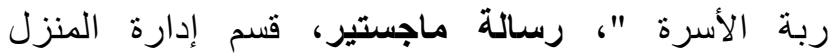

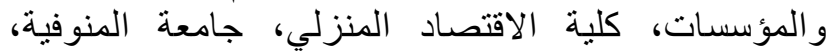

$$
\text { المنوفية، جمهورية مصر العية العربية. }
$$

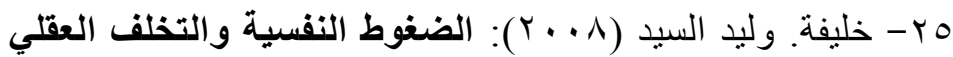

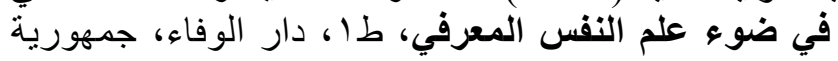
مصر العربية.

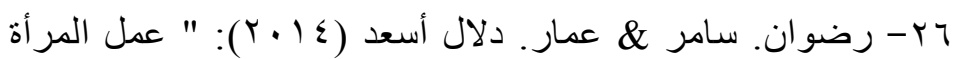

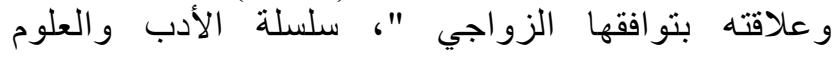




$$
\text { مجلة الاقتصاد المنزلي - مجلد · ب - العدد (؟) • ب • م م }
$$

الإنسانية، المجلد (جب)، العدد (ع)، جامعة تشرين للبحوث و الدر اسـات العلمية، اللاذقية، سوريا.

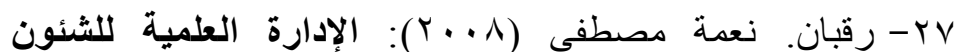

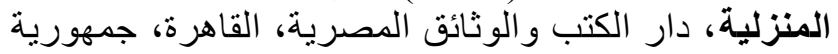

$$
\text { مصر العربية. }
$$

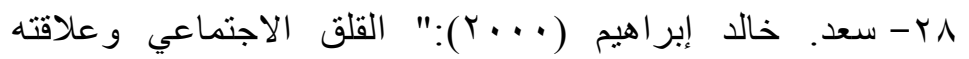

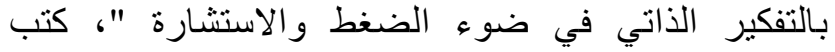

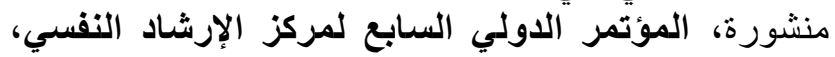

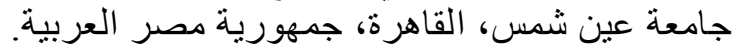

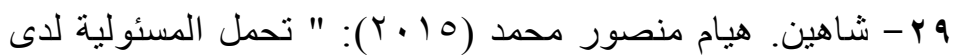

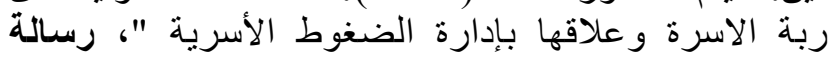

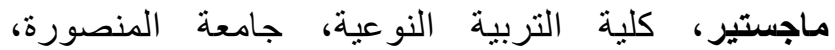

$$
\text { المنصورة، جمهورية مصر العربة التية. }
$$

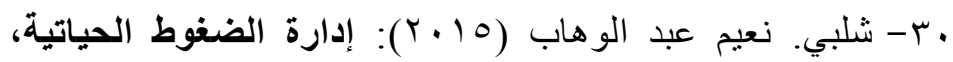

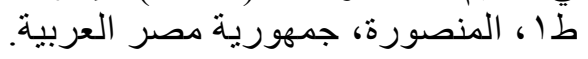

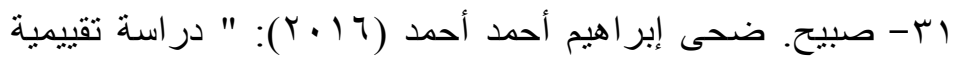

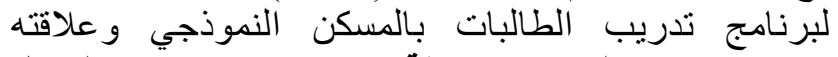

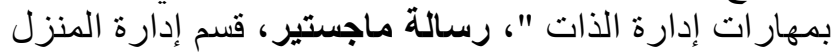

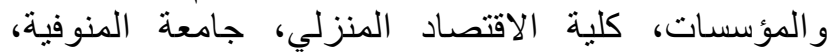

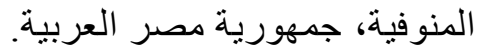

r

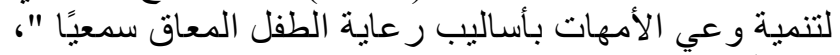

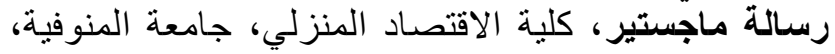

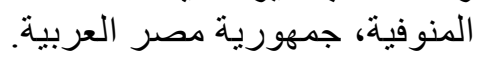

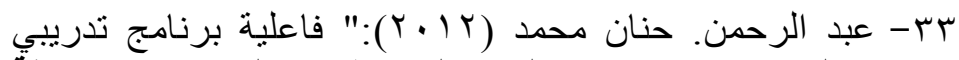

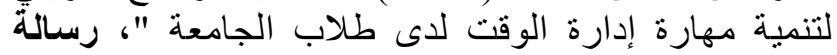

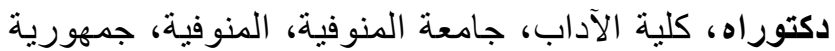

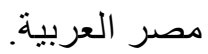




$$
\text { مجلة الاقتصاد المنزلي - مجلد · r - العدد (؛) • ب • م م }
$$

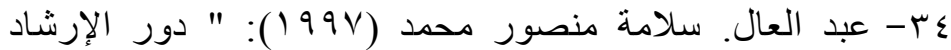

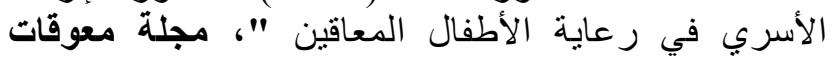

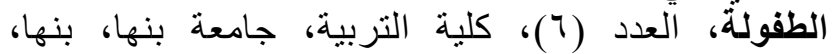

$$
\text { جمهورية مصر العربية. }
$$

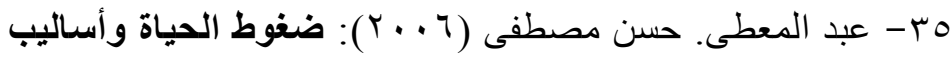
مواجهتها، طا، أهن زهر اء الشرق، القاهرة، جمهورية مصر

$$
\text { العربية. }
$$

צr- عجاجة. صفاء أحمد أحمد (V . . . إ):" النموذج السببي و العلاقة

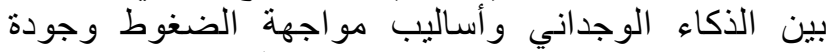

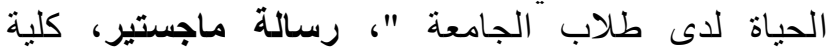

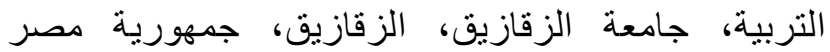
العربية.

V

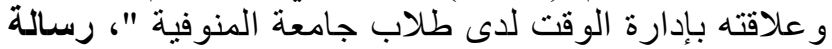

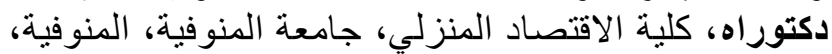

$$
\text { جمهورية مصر العربية. }
$$

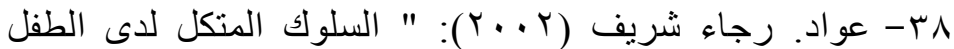

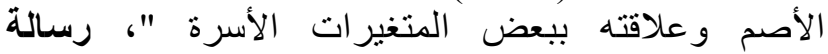

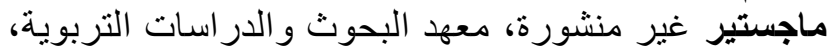
جامعة القاهرة، القاهرة، جمهورية معهية مصر العربية.

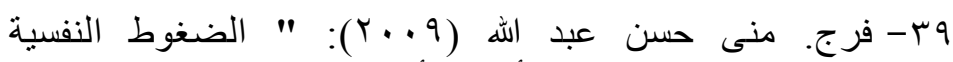
وعلاقتها باحتياجات أولياء أمور غير الهاء العاديين (المعاقين

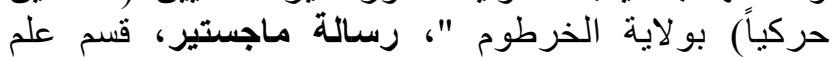
النفس، جامعة الخرطوم، لابة الخرطوم، الخرطوم، السودان.

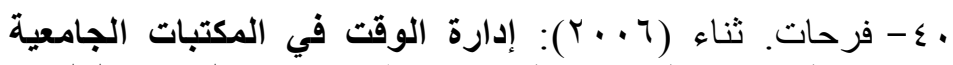

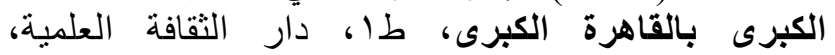
الإسكندرية، جمهورية مصر العربية. 


$$
\text { مجلة الاقتصاد المنزلي - مجلد · ب - العدد (؟) • ب • م م }
$$

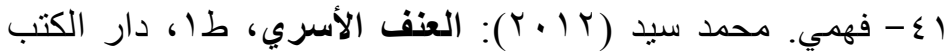

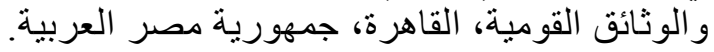

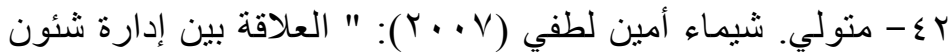

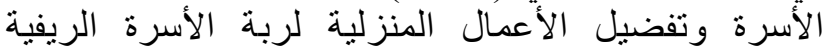

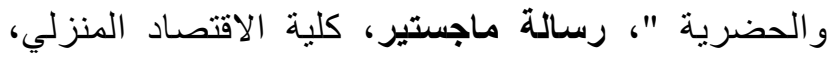

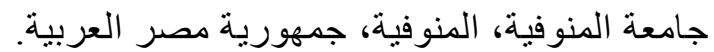

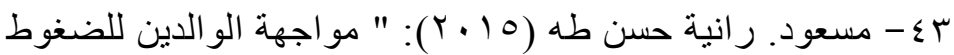

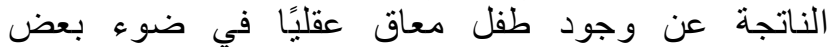

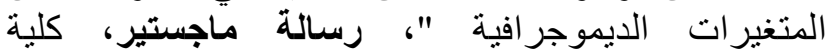

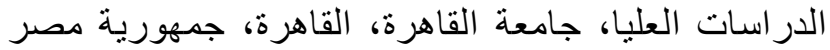
العربية.

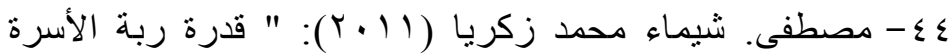

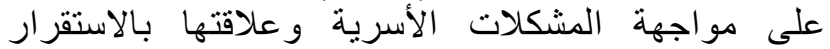

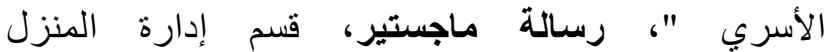

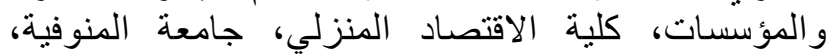

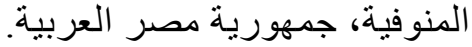

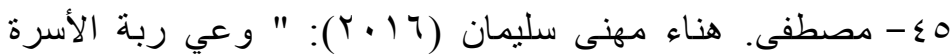

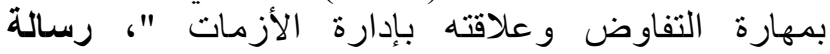

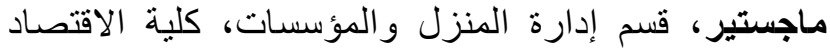

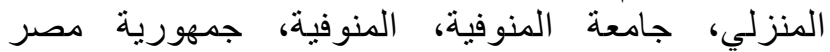
العربية.

T؟ - معوض. زينب \& عويس. ناصر (1 (Y): " دور الخدمة

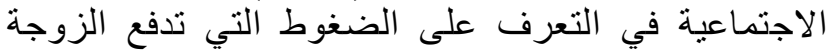

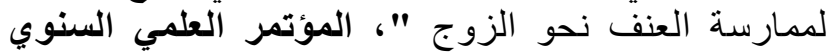

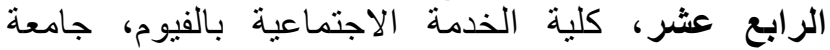

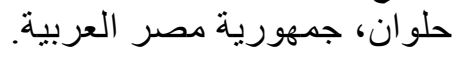




$$
\text { مجلة الاقتصاد المنزلي - مجلد · ب - العدد (؟) • ب • م م }
$$

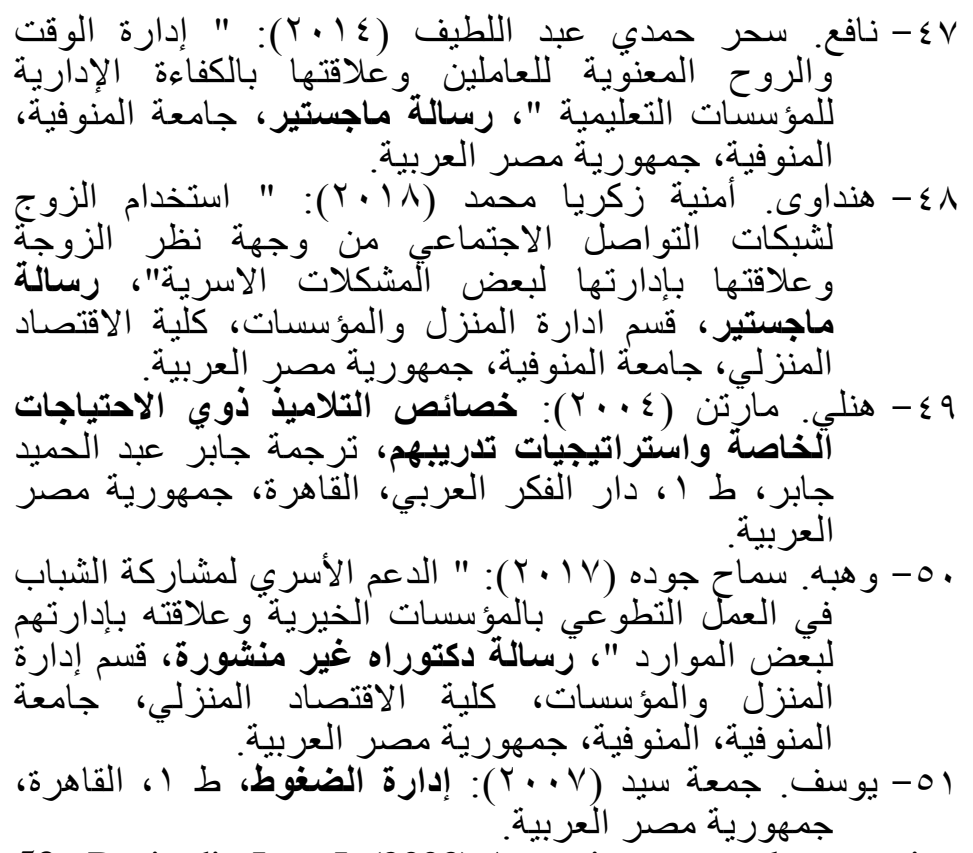

52- Desjardin,Jean L.(2003).Assessing parental perception of self - Efficacy and involvement in families of young children with hearing loss . Volta review . Vol.103 Issue 4, PP.390-398.

53- Luterman, David (2004): Counseling families of children with gearing loss and special needs volta Review. vol. 104. Issue 4, pp.213-220.

54- Mahmoud Boudarene (2005): Le stress entre bien etre et souffrance, berti edition, alger .

55- Stednitz \& Epkins(2006) : Girls and mothers socialanxietry, social skills, and loneliness : associations after accounting for depressive symptoms, journal of clinical child and adoleseent psychology, 35(1) 145-155 


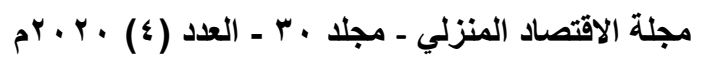

The $7^{\text {th }}$ international- $21^{\text {th }}$ Arabic conference for Home Economics

"Home Economics and sustainable development 2030"

Journal of Home Economics

December -15th, 2020

http://homeEcon.menofia.edu.eg ISSN 1110-2578

Time and effort management and its relationship to facing life pressures on mothers with hearing disabilities

\title{
Rabie Mahmoud Nofal,Mona Mohamed Zaki Sakr, Marwa Mokhtar Abo Atya
}

\begin{abstract}
The aims of the study were to identify the nature of the relationship between time and effort management in its two axes (time management - effort management), and facing life pressures in its four aspects (social support, self-activation, psychological counseling and acceptance) among mothers with hearing disabilities, and to study the differences between rural and urban , working and non-working mothers, in both managing time and effort in its two axes, and facing the four aspects of life pressures among mothers with hearing-disabilities, clarifying the discrepancy between mothers in the study sample in managing time and effort in its axes, and facing life pressures in its four aspects according to the number of children, family monthly income and the educational level of parents.

The current study has followed the descriptive and analytical approach, by setting two questionnaires; the first was on the management of time and effort upon deaf mothers, and the other was about facing life pressures. The two were applied to a sample of 250 of deaf mothers selected in a random and objective method consisting from rural and urban areas in Gharbia Governorate from different social and economic levels.
\end{abstract}




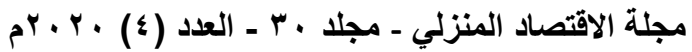

The results showed that there is a positive statistically significant correlation relationship at function level of $(0.01)$ between managing time and effort in its two axes and facing life pressures in its four aspects. There are statistically significant differences between working and non-working mothers in facing life pressures at a function level of (0.05) in favor of working mothers. On the other hand, There is no statistically function discrepancy between the study sample mothers in time and effort management in its two axes according to the number of children in the family, the husband's age, the wife's age, and the family monthly income, while there is a statistically function discrepancy in the educational level of the husband and wife in favor of higher education level. there is no statistically function discrepancy between the study sample is in facing life pressures in its four aspects, according to the number of children in the family, the monthly income of the family, and the parents' educational level .

The study presented a set of recommendations. The most important one was the providing awareness programs through all kinds of media to raise mothers' awareness about the proper methods to run their time and effort with the help of specialists in the field of home management and institutions. In addition to holding specialized courses, seminars and interviews in the field of hearing disabilities and how to face the resulting pressures provided by specialists in The field of home management and institutions for the benefit of all family members. The role of civil society organizations should be activated through the media to emphasize the importance of their role in encouraging them to follow good management of time and effort. Also we should put into consideration supporting psychological and family counseling programs through experts specialized in psychology and mental health to increase mothers' awareness of overcoming life pressures in a proper scientific way.

Key words: time management, stress management, coping, life stress, mothers with hearing dis 